\title{
Le Panveau : une ferme de La Tène à proximité de l'oppidum du Mesnil à Moulay (Mayenne)
}

Le Panveau: A La Tène Far near to the Mesnil Oppidum at Moulay (Mayenne)

Le Panveau: ein latènezeitliches Gehöft in der Nähe des oppidums von Mesnil bei Moulay (Mayenne)

Panveau: una granja de La Tène cerca del oppidum de Mesnil en el pueblo de Moulay (Mayenne)

Alain Valais, Maxime Mortreau, Jean-François Nauleau et Boris Robin

\section{OpenEdition}

\section{Journals}

Édition électronique

URL : https://journals.openedition.org/rao/2536

DOI : $10.4000 /$ rao. 2536

ISBN : 978-2-7535-4053-8

ISSN : 1775-3732

\section{Éditeur}

Presses universitaires de Rennes

Édition imprimée

Date de publication : 15 décembre 2014

Pagination : 151-197

ISBN : 978-2-7535-4051-4

ISSN : 0767-709X

\section{Référence électronique}

Alain Valais, Maxime Mortreau, Jean-François Nauleau et Boris Robin, « Le Panveau : une ferme de La Tène à proximité de l'oppidum du Mesnil à Moulay (Mayenne) », Revue archéologique de l'Ouest [En ligne], 31 | 2014, mis en ligne le 15 décembre 2016, consulté le 23 août 2022. URL : http:// journals.openedition.org/rao/2536; DOI : https://doi.org/10.4000/rao.2536 


\title{
Le Panveau : une ferme de La Tène à proximité de l'oppidum du Mesnil à Moulay (Mayenne)
}

\author{
Le Panveau: A La Tène Farm near to the Mesnil Oppidum at Moulay (Mayenne)
}

\author{
Alain Valais*, Maxime Mortreau**, Jean-François Nauleau*** et Boris Robin****
}

Résumé : La ferme du Panveau à Aron a été découverte au cours d'un diagnostic mené sur le contournement de la ville de Mayenne à un peu plus de deux kilomètres au nord du rempart de l'oppidum du Mesnil à Moulay mis en évidence dans le cadre de cette même opération. Cet habitat enclos occupé durant La Tène moyenne et La Tène finale montre une évolution dans les gabarits de fossés qui l'entourent. De nombreux bâtiments dont un exemplaire à tranchées de fondation de près de 80 mètres carrés y ont été fouillés.

\begin{abstract}
The Panveau farm in Aron was discovered during an archaeological evaluation prior to the construction of the Mayenne town bypass. It is located about $2 \mathrm{~km}$ north of the ramparts of the Mesnil Moulay oppidum which was also discovered during the same investigation. The size of the ditches enclosing this settlement dating from the middle and late La Tène period evolve during its occupation and several buildings including an $80 \mathrm{~m} 2$ construction with foundation trenches were brought to light.
\end{abstract}

Mots clés : La Tène moyenne et finale, habitat enclos, bâtiments, céramique, meules.

Keywords: Middle and Late La Tène, enclosed settlement, buildings, pottery, whetstones.

\section{Présentation}

\section{Circonstance de la découverte (fig. 1$)^{1}$}

Le site du Panveau a été découvert sur la commune d'Aron lors d'une des opérations de diagnostic archéologique réalisées sur le contournement de la ville de Mayenne (Valais et al., 2005). Cet aménagement de 11 kilomètres de longueur longe l'est de la vallée de la Mayenne, en franchissant la plupart de ses affluents, depuis l'Aron au sud jusqu'au ruisseau du Coulonges à l'extrême nord. À l'occasion des trois phases de sondages un très vaste oppidum et plusieurs enclos de l'âge du Fer ont été repérés. La fouille d'un des enclos, celui du Panveau à Aron, a dû être réalisée dès septembre 2006 bien avant que ne commencent les fouilles des autres sites découverts sur le tracé de la rocade.

\section{Un contexte archéologique riche (fig. 1)}

Les indices les plus anciens des environs de la ville de Mayenne remontent au Mésolithique ou au tout début du Néolithique. Ils ont été recueillis au cours du diagnostic du contournement sur le site de La Hucherie à Moulay (Forré, Valais, 2006). Les autres vestiges néolithiques se résument à une allée couverte, celle de la Petite Giraudière à Aron et au ramassage de quelques haches polies.

* Inrap Le Mans. (alain.valais@inrap.fr)

** Inrap Beaucouzé/UMR 6566 CReAAH Lara/Polen Nantes.

*** Inrap Carquefou.

**** Service archéologique d'Orléans.

1. J.-F. Nauleau a réalisé les plans de cet article et M. Mortreau les planches céramiques. 


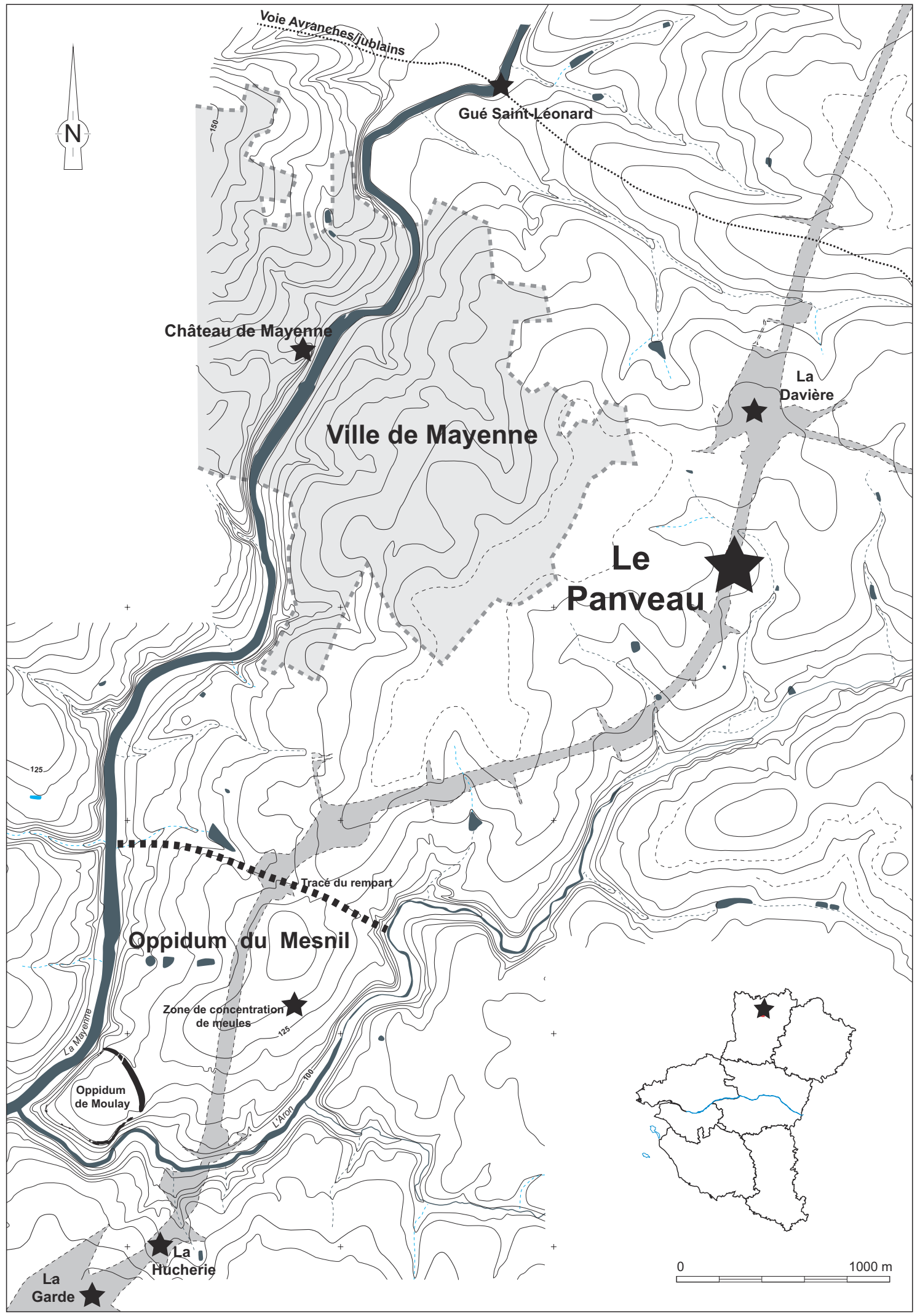

Figure 1 : Localisation générale du site du Panveau et contexte archéologique. Figure 1: Localisation of the Panveau site and its archaeological context. 
Quelques éléments de la fin de La Tène ancienne ou du début de La Tène moyenne sont mis en évidence sur le contournement de Moulay/Mayenne à La Davière à Aron. À cette occasion, les traces d'un bâtiment, un enclos circulaire et quelques fossés sont relevés (Valais, 2008, p. 207-208).

La période la mieux documentée reste néanmoins la fin de La Tène. Depuis le XIX siècle, un éperon barré d'une douzaine d'hectares alors attribué à l'époque de César a été repéré à la confluence de la Mayenne et de l'Aron, leurs vallées encaissées offrant au nord-ouest, au sud et au sud-est des falaises de plus de 20 mètres de hauteur. Au nord-est, la partie la plus vulnérable de l'ensemble est défendue par un rempart conservé sur près de 300 mètres de longueur, 20 mètres d'épaisseur et sur une hauteur de 6 à 8 mètres (photo 1).

Les fouilles menées de 1972 à 1975 aboutissent à la localisation au sud-est de l'entrée principale de cet oppidum doté également de deux poternes, une à l'extrémité nord du rempart (Naveau, 1973, p. 6), la seconde en baïonnette à la pointe ouest de l'enceinte (Naveau, 1974, p. 11). Les différents sondages réalisés à l'intérieur recueillent des indices d'activités domestiques caractérisées par des meules et du mobilier céramique (Boissel et al., 1972, p. 23-25 et 33). Un fragment de moule à bracelets godronnés, des scories et déchets de bronze attestent également d'activités artisanales (op. cit., p. 29). En 1974, à 800 mètres au nord-est, un lot de presque deux cents fragments de meules est recueilli (Naveau, 1974, p. 21-35). Pratiquement tous les éléments identifiés sont issus de petits moulins rotatifs du type de ceux recueillis dans l'oppidum. La quantité de fragments, le matériau utilisé d'origine locale et la présence d'ébauches de meules permettent d'identifier les rebuts d'un atelier de production. Des tessons et des éléments de torchis sur clayonnage issus des labours environnants montrent qu'un habitat de La Tène finale existe en outre à proximité (op. cit., p. 20).

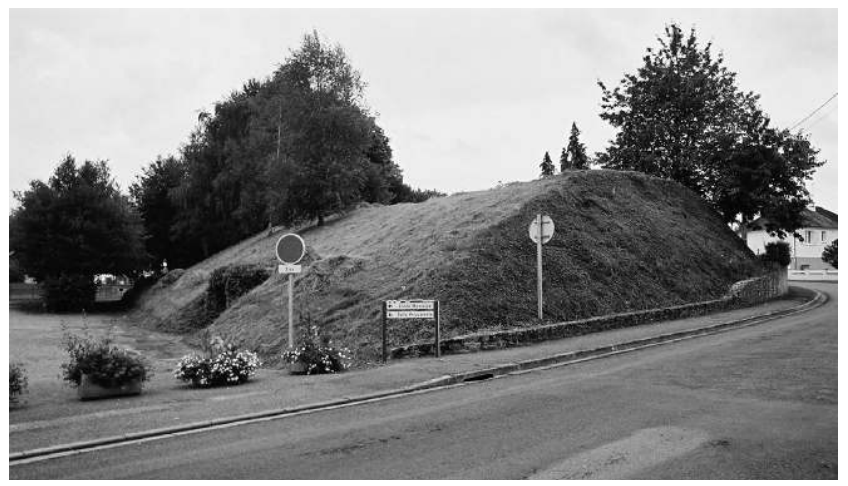

Photo 1 : Le rempart de l'oppidum de Moulay qui limite cette première enceinte à une douzaine d'hectares. Cliché A. Valais. Photo 1: The ramparts of the Moulay oppidum that delimit the first 12 hectare enclosure .
Toutes ces données vont être reconsidérées à la lumière des résultats du diagnostic de la rocade et de la découverte d'une seconde fortification, à plus d'un kilomètre au nord du premier rempart. Conservée dans le paysage sur près d'un kilomètre de longueur, elle devait initialement parcourir les $1,3 \mathrm{~km}$ qui séparent les deux rivières.

Ce nouvel ensemble fortifié que nous appellerons l'oppidum du Mesnil occupe ainsi près de 135 hectares au sein duquel ont été relevés de nombreux fossés de La Tène finale. Beaucoup ont reçu des rejets domestiques (vidanges de foyer, fragments de meules) et artisanaux (pesons de métier à tisser et creusets). Ce très vaste oppidum, l'un des dix plus vastes du pays, constitue alors la capitale des Aulerques Diablintes.

Les opérations de diagnostic ont également permis de repérer trois autres sites enclos de La Tène (fig. 1). Le premier, La Hucherie, un enclos carré de 19 mètres de côté, est implanté au milieu du versant sud de la vallée de l'Aron (Valais, 2008, p. 213).

Deux fermes de La Tène moyenne/finale complètent cet inventaire. La première, La Garde à Moulay, domine le versant sud de la vallée de l'Aron à quelques centaines de mètres à vol d'oiseau de l'oppidum de Moulay (Valais, 2008, p. 212) et la seconde, Le Panveau à Aron fait l'objet du présent article (fig. 1).

Les vestiges attribuables à la période gallo-romaine sont relativement rares si l'on excepte la présence au gué SaintLéonard d'un trésor mis en évidence en 1864 juste au nord de la ville de Mayenne (Lambert, 1865) : 26000 monnaies dont une majorité du $\mathrm{I}^{\mathrm{er}}$ siècle apr. J.-C. ont été recueillies autour de ce point de franchissement (Besombes, 2005). Un fragment de borne milliaire de Marc Aurèle y a également été découvert (Naveau et Boufflet, 1999, p. 99). Il indique une distance de $9 \mathrm{~km}$ jusqu'à Jublains, ce gué se situant en effet sur le tracé de la voie romaine Jublains/Avranches.

Le mobilier romain est rare dans l'emprise de l'oppidum de Moulay; il se résume à quelques tessons, une monnaie de Caligula et quelques fragments de tuiles. Il n'est cependant pas exclu que la nef de l'église de Moulay remonte à cette période comme semblent l'indiquer les maçonneries de sa nef et un arc en brique visible au sud (photo 2). D'autre part, si l'on en juge par la présence d'un vase coriosolite sous les remblais du petit rempart de l'oppidum (Boissel et al., 1972, p. 25 et Naveau, 1999), la construction de ce retranchement pourrait remonter à la seconde moitié du $\mathrm{I}^{\text {er }}$ siècle av. J.-C. Si l'on admet que l'église est en grande partie d'origine romaine, ne peut-on pas comparer Moulay à Entrammes où un sanctuaire a été établi exactement au milieu de l'oppidum du Port-Salut (Naveau, 1982)?

Les données attribuables à la période gallo-romaine issues des trois phases de diagnostic de la rocade se limitent à des trous de poteau et à quelques fossés relevés sur le site de La 


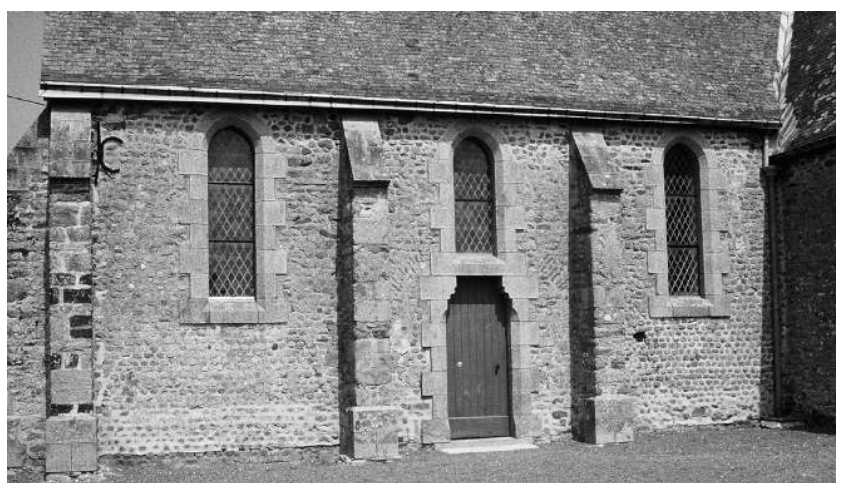

Photo 2 : Le mur sud de la nef de l'église de Moulay où l'on distingue du petit appareil et un arc en brique. L'hypothèse d'une réutilisation d'un bâtiment antique ne peut être écartée. Cliché A. Valais. Photo 2: The south wall of the nave of the church at Moulay where brickwork and a brick arch can be seen. It is probable that a Roman building was reused in its construction.

Davière à Aron (Valais, 2008, p. 214). Une fosse particulièrement riche en mobilier a par ailleurs été découverte à proximité de l'enclos de La Garde à Moulay (Valais, 2008, p.212).

L'oppidum du Mesnil semble en grande partie abandonné avant la Conquête. Il paraît dès lors se limiter aux seuls 12 hectares de l'oppidum de Moulay. Ce phénomène d'abandon se produit probablement à la faveur de Jublains qui devient alors chef-lieu de cité.

Le premier Moyen Âge est attesté par la découverte de quelques sarcophages aux abords de l'église de Moulay (Angot, 1910, t. 3, p. 143b) et quelques indices d'habitat (Naveau, 1976, p. 87-96). Des fossés du haut Moyen Âge ont par ailleurs été repérés au cours du diagnostic dans l'emprise de l'oppidum du Mesnil à proximité de la ferme du Préhaucher à Moulay et sur le site de La Davière à Aron. Mais les vestiges les plus significatifs sont dès lors concentrés au château de Mayenne, cette résidence construite vers 900 sans doute à l'initiative du comte du Maine. Elle vient remplacer une construction sur poteaux qui reste difficile à dater (Early, 2001). Le site qui domine la rive droite de la Mayenne abrite alors toutes les marques du pouvoir alors que le rempart de l'oppidum du Mesnil marque toujours le paysage : les limites des paroisses de Saint-Martin de Moulay et de Mayenne en reprenant très précisément le tracé.

\section{Localisation générale du site du Panveau ET CONTEXTE GÉOLOGIQUE}

Les vestiges du Panveau à Aron ont donc été découverts dans le cadre du diagnostic du contournement de la ville de Mayenne à 2,5 kilomètres au nord-est de l'oppidum du Mesnil à Moulay. Le site enclos est implanté sur le haut du versant nord de la vallée peu encaissée d'un modeste ru, un affluent de la rive gauche de l'Aron. Les vestiges occupent toute la largeur de l'emprise de la rocade, une bande orientée nord-sud de 140 mètres de longueur et de 48 mètres de largeur.

Les structures apparaissent à une quarantaine de centimètres sous le sol labouré. On atteint alors les limons de plateau dont l'épaisseur varie de 0,40 à 0,70 mètre. Lessivés ou oxydés, ils recouvrent des graves constituées essentiellement de quartz, de roches siliceuses et de galets. Elles reposent sur le socle granitique totalement réduit en arène, voire en argile. Localement enduites d'oxyde de manganèse, les graves assurent un bon drainage des eaux; elles conduisent au lessivage des limons qui ont ainsi perdu l'essentiel de leurs fines.

\section{Des fossés - Présentation géNérale (FIG. 2)}

D’une manière générale, les relations entre les fossés ont été difficiles à observer en raison d'un réseau de drains établi il y a une trentaine d'années. C'est en particulier le cas pour les connexions entre les fossés F.21, F.354, F.368 et F.154. Les contacts sont tout aussi difficiles à apprécier entre les fossés F.1 et 365, F.1 et 206. D'autre part, l'absence de contraste entre des remplissages le plus souvent lessivés en a rendu l'étude malaisée. Il apparaît toutefois qu'à plusieurs reprises des structures de fort gabarit ont oblitéré le tracé de fossés plus modestes. Ainsi, le fossé F.154 est repris par le fossé F.21 et le fossé F.365 par le fossé F.1.

Par ailleurs, au sud-est, un fossé de dimension modeste F.175 longe pendant plus d'une quarantaine de mètres le fossé F.31. En admettant que ce dernier ait été associé à un talus implanté assez logiquement au nord, il serait alors peu probable que le fossé F.175 ait pu être ouvert sous l'emprise de ce cordon de terre. On peut donc admettre que le fait F.175 existait déjà au moment du creusement de F.31.

Associées aux résultats de l'étude céramique, ces observations permettent de proposer un phasage général entre plusieurs phases d'enclos, la plus ancienne remontant à La Tène moyenne et les deux plus récentes à La Tène finale.

\section{Trois Phases D'enclos}

\section{Un premier enclos de La Tène moyenne (fig. 3)}

Des similitudes dans les gabarits de fossés permettent de rapprocher certains de leurs tronçons pourtant déconnectés. Avec des dimensions voisines (entre 0,40 et 0,70 mètre de largeur, et 0,10 et 0,36 mètre de profondeur) et une 


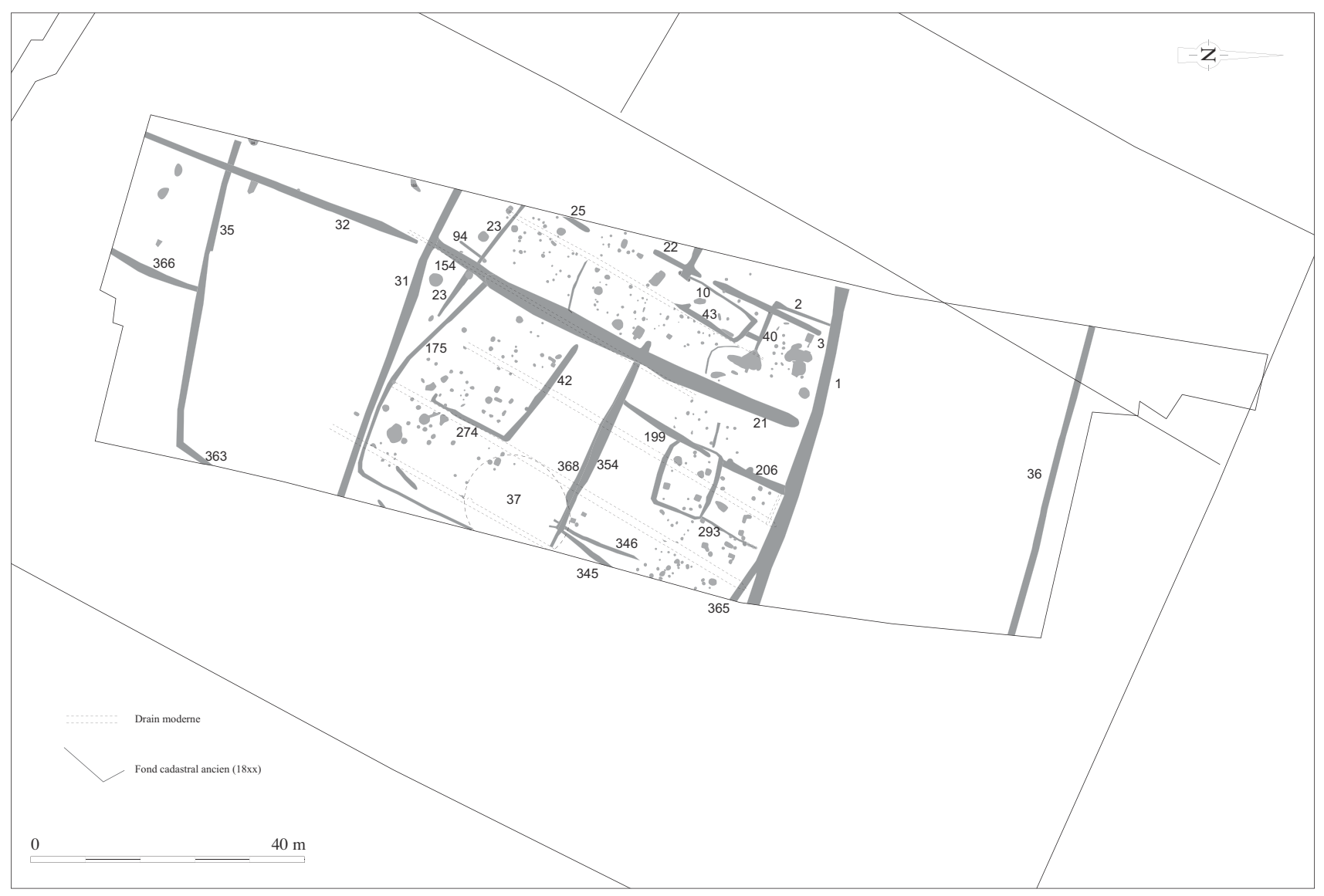

Figure 2 : Plan général de la fouille sur fond cadastral ancien (1828).

Figure 2: General plan of the excavation overlaying the cadastral map of 1828.

convergence d'orientation, il est ainsi possible d'associer les fossés F.23 et F.175. En revanche, nous saisissons mal leur relation au niveau de leur interruption en chicane qui laisse peu de place à une éventuelle entrée. Ces deux fossés pourraient néanmoins constituer le côté sud d'un enclos dont nous aurions également l'angle sud-est ainsi qu'une bonne partie de la limite orientale.

Le côté nord de cet ensemble paraît plus difficile à identifier. Plusieurs fossés en limitent nettement l'extension de ce côté. Pourtant, le fossé F.1 est bien trop large et profond pour constituer le pendant des fossés sud. De son côté, le fossé F.365 que F.1 recoupe, n’a livré que du mobilier de La Tène finale. Il est donc probable que la limite nord de l'enclos de cette première phase ait été totalement remaniée par des fossés bien plus larges.

Si les similitudes d'orientation peuvent constituer des informations qui permettent d'attribuer certaines limites relevées à l'intérieur de l'enceinte, c'est surtout l'origine $\mathrm{du}$ mobilier le plus ancien qui sert de fossile directeur, sa présence dans les remplissages permettant d'associer tel ou tel fossé à cette première phase. Ont livré du mobilier de
La Tène moyenne, les fossés F.3, F.42, F.368. Ces limites compartimentent l'enclos ou, comme le fossé F.368, en marquent exactement l'axe. Ce dernier associé au fossé F.42 pourrait même limiter une zone de passage.

Dès cette phase ancienne, il pourrait donc s'agir d'un enclos doté de fossés de faible gabarit. Un seul de ses angles aurait été découvert. À l'intérieur, l'espace serait divisé longitudinalement par les fossés F.368 et 42 et transversalement par le fossé F.3 probablement prolongé par le fossé F.22. L'entrée de cette première phase d'enclos pourrait se situer à l'est, juste en dehors de l'emprise au niveau du retour oriental du fossé F.175 quelque part entre les fossés F.368 et 42.

\section{Une seconde phase d'enclos (La Tène finale) (fig. 4)}

Les fossés de la phase ancienne semblent, nous l'avons vu, avoir été re-calibrés. Au sud, le fossé F.31 donne à l'enclos une emprise plus importante. Cette limite rectiligne qui semble remplacer le fossé F.175 mesure de 0,92 à 1,32 mètre de largeur pour des profondeurs qui varient de 


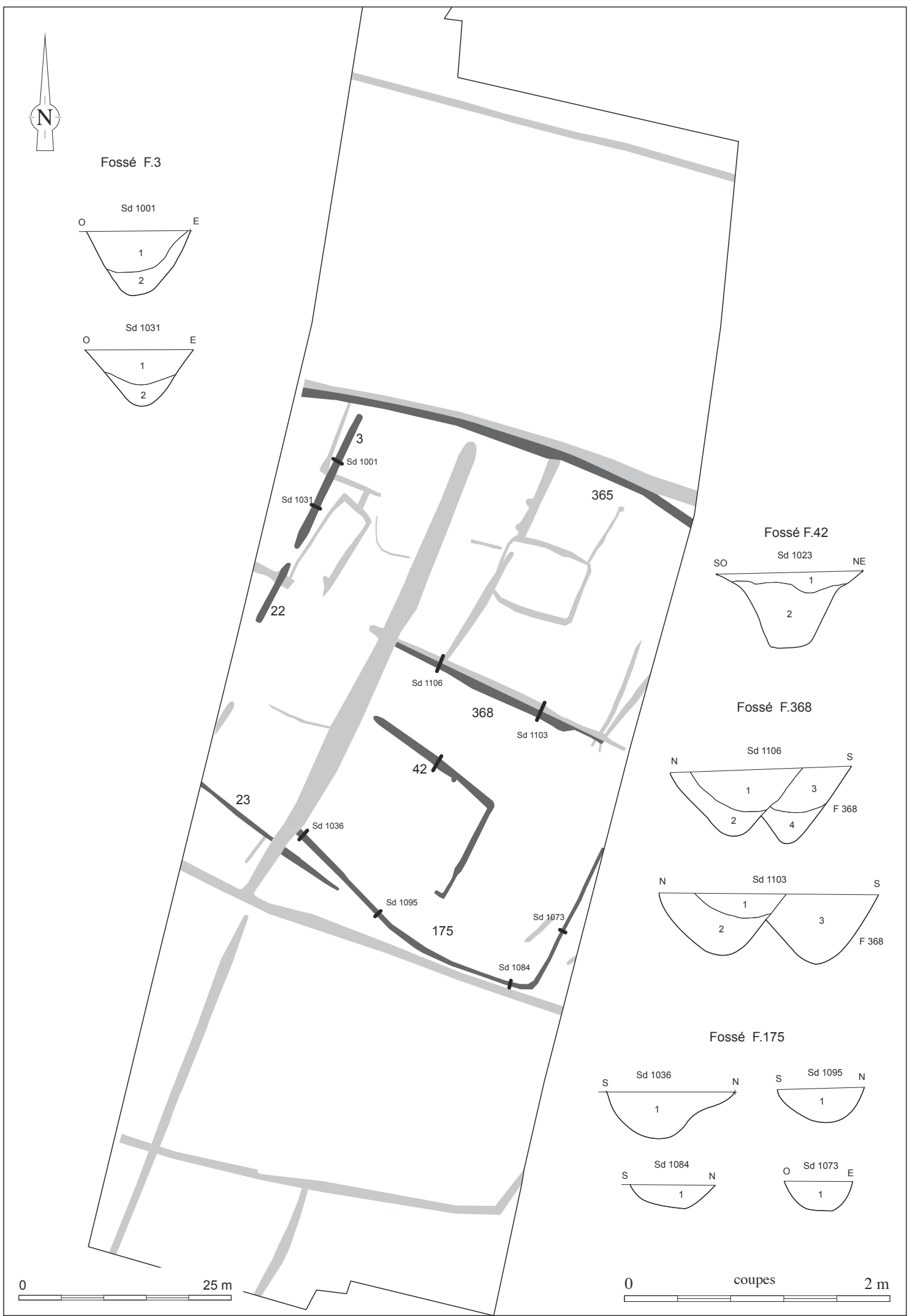

Figure 3 : Les fossés de la première phase et leurs profils (La Tène moyenne).

Figure 3: The ditches belonging to the first phase and their sections (Middle La Tène). 


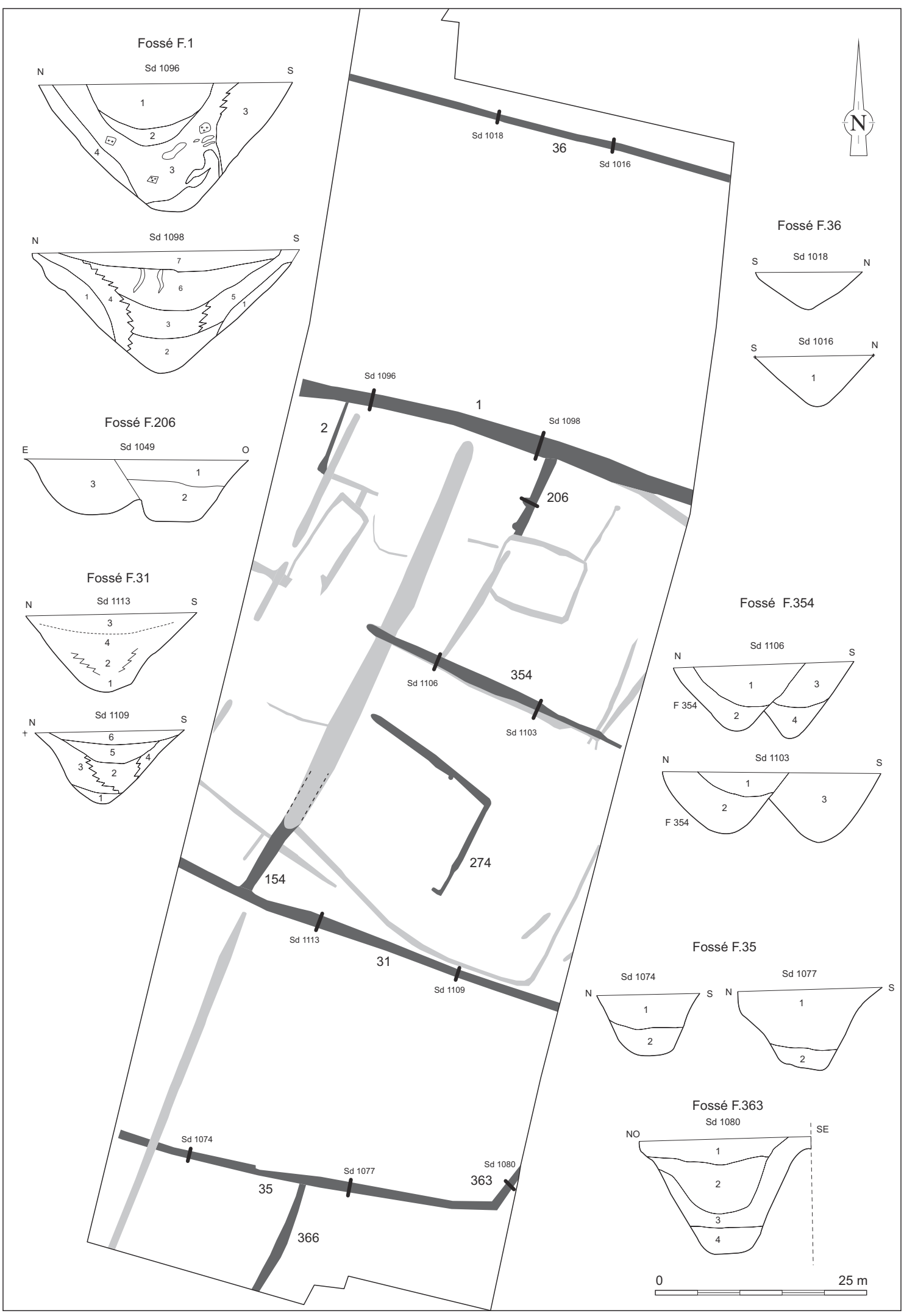

Figure 4 : Les fossés de la seconde phase et leurs profils (La Tène finale).

Figure 4: The ditches belonging to the second phase and their sections (Late La Tène). 
0,44 à 0,60 mètre. Parmi les huit sondages ouverts tout au long des 48 mètres reconnus d'un bord à l'autre de l'emprise décapée, deux seulement (1012 et 1085) ont livré un peu de mobilier de La Tène finale. On peut clairement connecter ce fossé F.31, avec le fossé perpendiculaire F.154. Présentant un gabarit comparable (au moins 1,10 mètre de largeur pour 0,30 mètre de profondeur), ce fossé nord/sud apparaît au contact du fossé $\mathrm{F} .31$ et disparaît après 9,50 mètres au contact du fossé F.21 beaucoup plus large et qui en reprend très exactement l'axe. Du côté nord, le phénomène semble identique avec le fossé F.1 extrêmement large qui vient remanier en grande partie le fossé F.365. Ce court tronçon pourrait en effet constituer le dernier témoin de cette seconde phase d'enclos. Cette limite n'a été reconnue en plan que sur moins de 3 mètres de longueur. En étudiant les coupes, il est possible, semble-t-il, de la reconnaittre sur une douzaine de mètres si l'on se fie à l'anomalie du profil du fossé F.1 relevée à l'ouest d'un sondage de diagnostic. Pour ce qu'on en sait, il mesure 0,57 mètre de largeur et 0,45 mètre de profondeur. Un peu de mobilier de La Tène finale en est issu. Les fossés F.36, son symétrique F.35 associé à son retour F.363, appartiennent probablement à cette période où l'espace est plus largement organisé. F.366 connecté à F.35 fait également partie de ce même horizon parcellaire. Toutes ces limites aux profils en $\mathrm{V}$ mesurent entre 0,80 mètre et 1,10 mètre de largeur et de 0,20 à 0,60 mètre de profondeur. Notons que seul le tronçon F.363 avec 0,90 mètre de profondeur et 1,30 mètre de largeur se singularise par rapport à l'ensemble de ces limites. Outre que son profil montre une phase de re-creusement, son gabarit supérieur pourrait être lié à sa position dans l'organisation générale de l'enclos. Il pourrait, avec ces dimensions supérieures, confirmer qu'il constitue la «façade » de l'enclos...

À l'intérieur, il est difficile d'associer de manière certaine, d'autres limites. Il semble que le fossé F.154 en fasse partie sans que l'on connaisse son développement vers le nord. Les fossés appartenant à cette phase n'ont livré que du mobilier de La Tène finale comme F.354 qui reprend le tracé du fossé F.368 attribué lui à La Tène moyenne. On peut éventuellement ajouter à cette phase F.206 qui s'inscrit bien dans ce nouveau complexe fossoyé.

\section{Une troisième phase d'enclos (La Tène finale) (fig. 5)}

Durant cette ultime phase, certaines limites comme F.21 et F.1 sont mises en place. Elles viennent alors en remplacer de plus anciennes (F.154 et F.365) en les élargissant. Ces nouvelles structures sont les plus imposantes du site avec des mesures qui varient d'1,74 à 2,20 mètres de largeur et 0,86 mètre à 1,04 mètre de profondeur pour le fossé F.1. F.21 de son côté est encore plus imposant avec des largeurs comprises entre 2 mètres et 2,70 mètres et 0,60 mètre et 1,10 mètre de profondeur. Ces deux fossés présentent des profils en V. Ailleurs comme au sud, les limites ne semblent pas avoir été reprises et c'est l'état 2 qui pourrait avoir été maintenu.

Létude des coupes permet de restituer un talus du côté sud de F.1, ce que confirme l'espace laissé libre entre l'interruption nord du fossé F.21 et le fossé F.1 qui lui est perpendiculaire. La présence d'un talus à l'ouest du fossé F.21 est possible comme l'indique une partie de ses coupes. À son extrémité sud, un passage pourrait en outre avoir existé au moment où ce fossé de partition F.154 est re-calibré. Ce nouveau fossé plus large s'interrompt en effet à 9,50 mètres du fossé F.31. Nous savons par ailleurs que cette limite de fort gabarit recoupe l'extrémité de F.354. Il est probable que durant cette phase, la plus imposante, en termes de gabarit de fossé, les limites de parcellaires F.35, 363, 366 et F.36 soient également actives. Toutefois, on ne sait pas si elles appartiennent déjà au parcellaire qui entoure le site ou si elles ont encore à voir directement avec un système d'enclos emboîtés plus vaste à la manière de ce qui a pu être étudié sur le site du Vieux-Moulin à Louvres (Val-d'Oise; Casadéi et al., 2009). Sur cette implantation, on observe une enceinte principale qui constitue le cœur du site. Elle est desservie par une entrée monumentale, le tout inséré au sein de parcelles accolées. Cette division au sein de l'enclos n'est pas sans évoquer l'exemple de La Voie Neuve à Bazochesles-Braye (Malrain et al., 2002, p. 140).

\section{L'OCCUPATION DES ENCLOS}

\section{Les trous de poteau, leur répartition et leur conservation}

Les trous de poteau sont nombreux sur le site et leur état de conservation est plutôt bon (fig. 6). En effet, sur les 262 unités répertoriées, la moitié mesure entre 11 et $20 \mathrm{~cm}$ de profondeur, $36 \%$ mesurent plus de $21 \mathrm{~cm}$ et seulement $14 \%$ sont en-deçà de $10 \mathrm{~cm}$. Leur répartition est régulière. Ils sont regroupés en îlot contre les fossés nord et sud de l'enclos. Dans cette partie orientale du décapage, la zone médiane n'en présente en revanche qu'un faible nombre. À l'ouest du site, leur répartition semble beaucoup plus aléatoire. Des zones, où il n'en existe peu ou pas du tout, sont présentes de part et d'autre des fossés F.368/354, mais également entre les fossés F.31, 115 et 23. Il en est de même au-delà des fossés F.3 et 22 (vers l'ouest) et également à l'est du tronçon oriental du fossé F.175.

Le fait d'avoir pu nettoyer finement l'ensemble du décapage nous permet de localiser des zones où les poteaux sont 


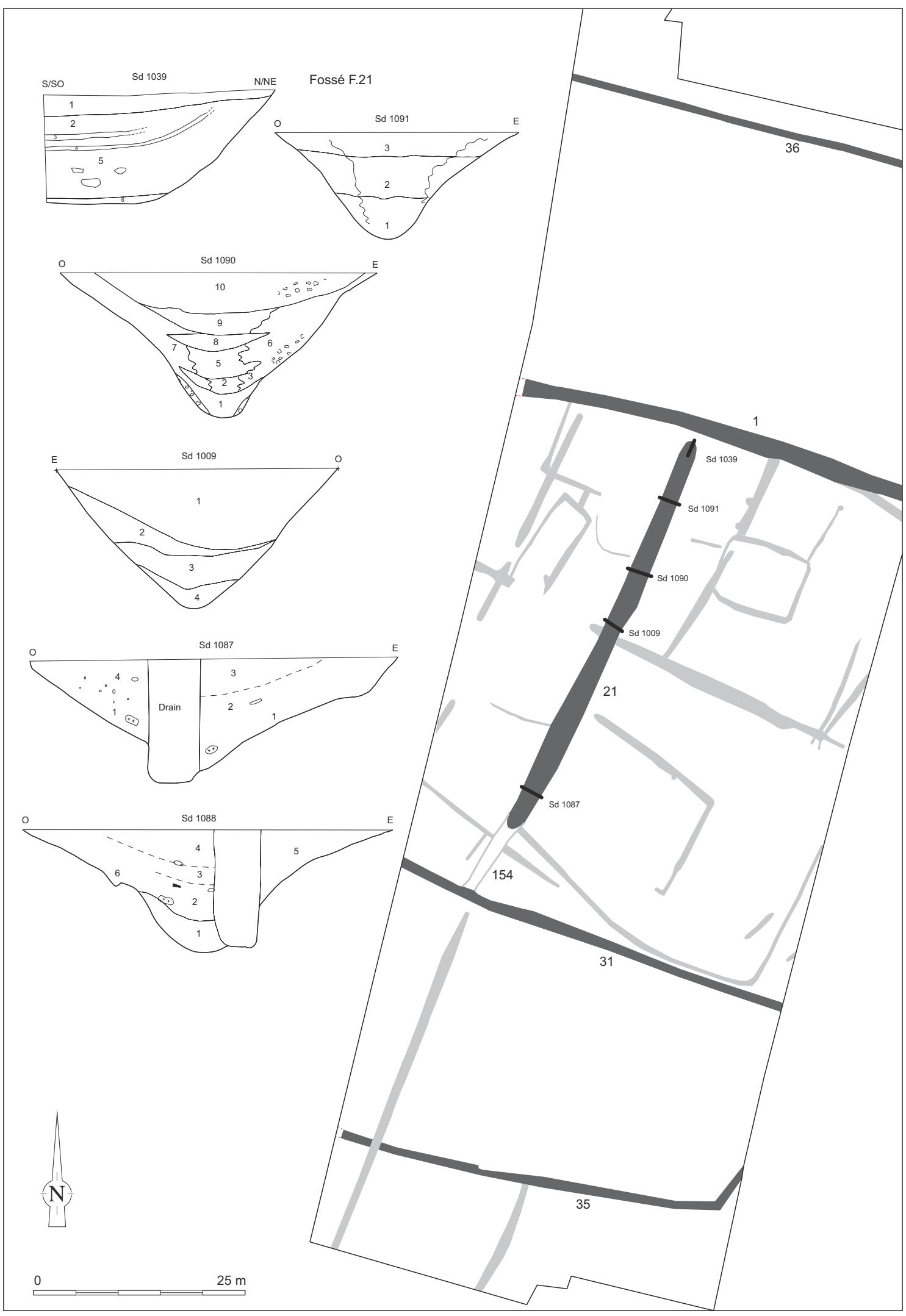

Figure 5 : Les fossés de la troisième phase et leurs profils (La Tène finale).

Figure 5: The ditches belonging to the third phase and their sections (Late La Tène). 


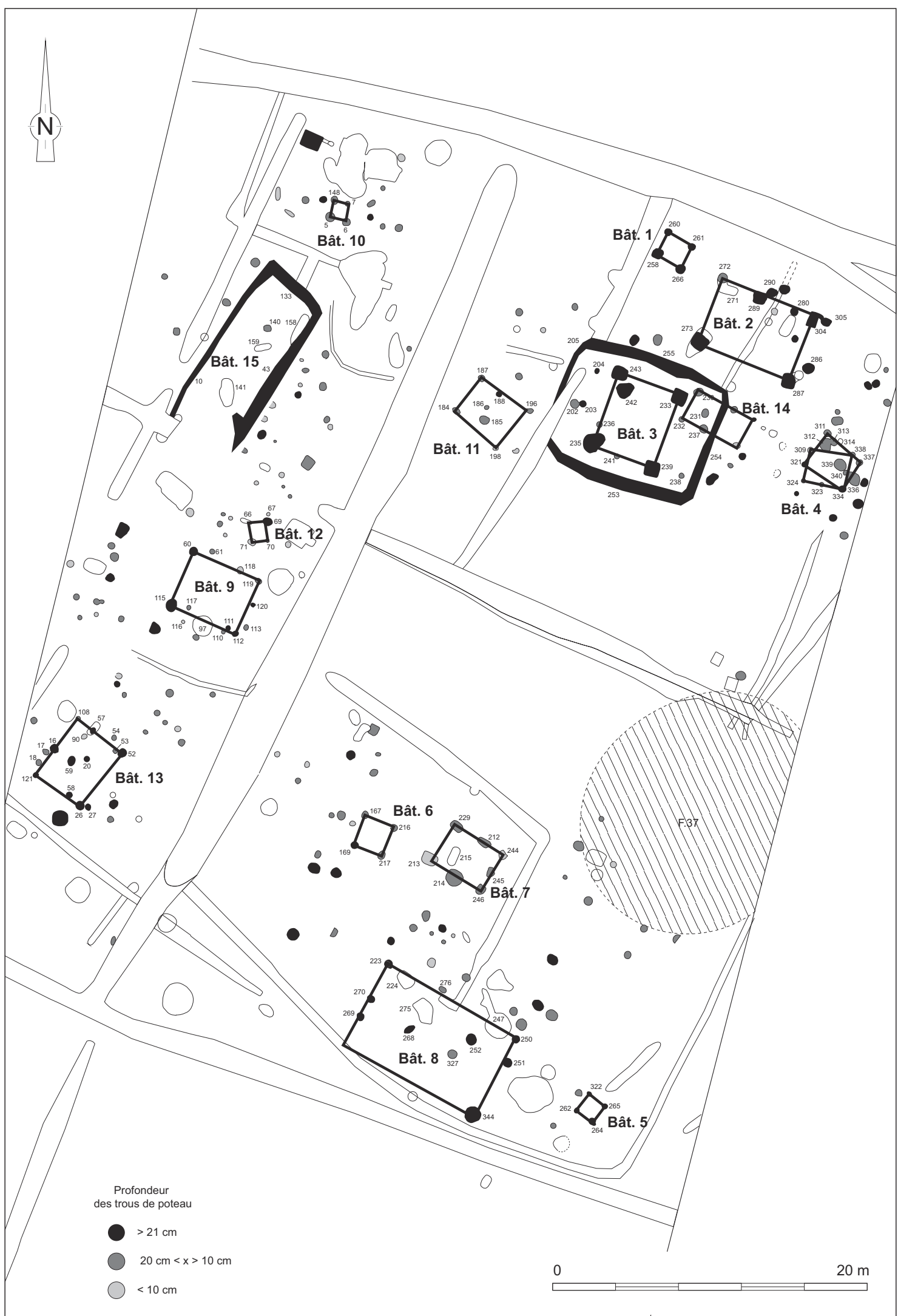

Figure 6 : Plan général avec représentation des hypothèses de bâtiments et des trous de poteau par classe de profondeur. Figure 6: Site map showing the hypothetical buildings and the post holes classed by depth. 
rares voire absents (photo 3). Des zones «non remaniées", notamment par les trous de poteau, ont été relevées au nordouest du décapage, autour de l'extrémité nord du fossé F.21, de part et d'autre des fossés F.354/368 mais aussi à l'est du fossé F.175 au-delà de son tronçon nord-sud. Ces secteurs dépourvus de structures déterminent autant de zones périphériques (est du fossé F.175, et de part et d'autre de l'extrémité du fossé F.21) ou des zones de passage comme entre les fossés F.23 et 31 au sud ou dans le grand axe du site de part et d'autre du fossé F.354/368.

\section{Les bâtiments}

\section{Les grands bâtiments}

Les bâtiments sur poteaux

\section{- Le bâtiment 2 (fig. 7)}

Constitué de quatre avant-trous de poteau aux angles (F.287, 273, 272, 304), cet espace rectangulaire mesure environ 4,50 mètres sur près de 7 mètres de longueur. Les avanttrous de poteau ont des formes quadrangulaires au moins

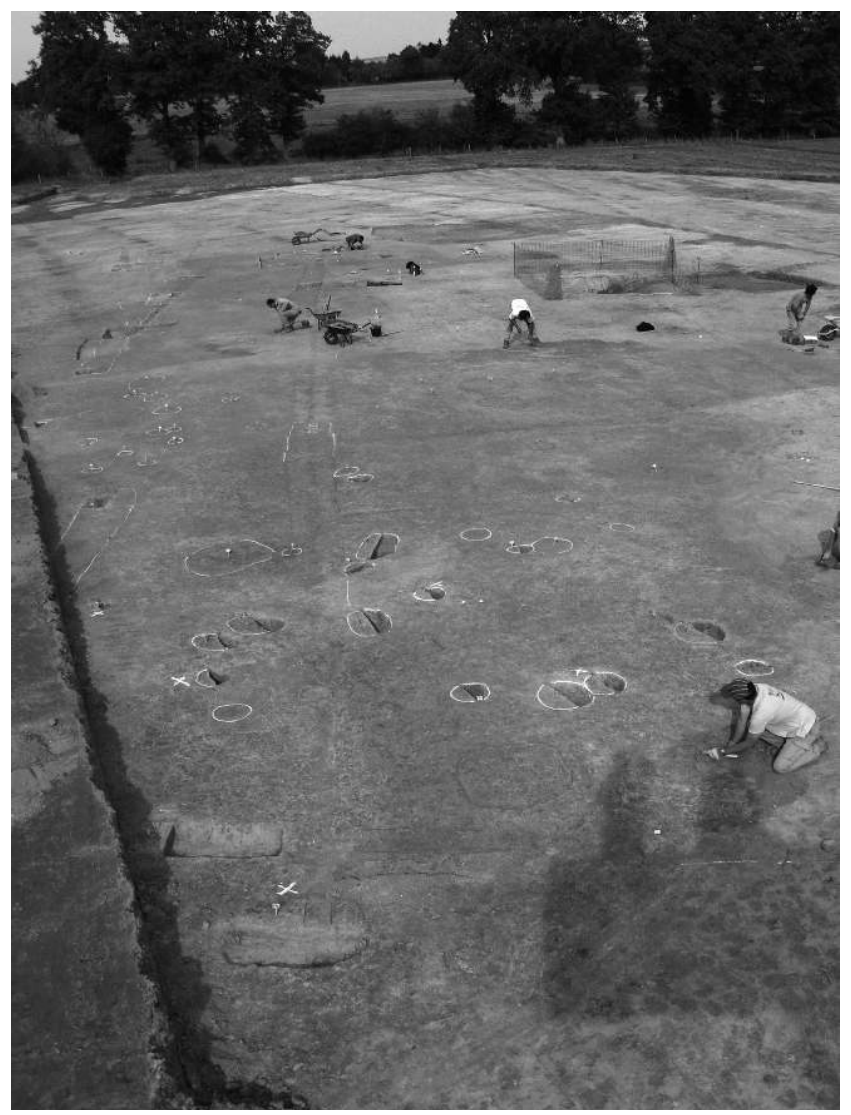

Photo 3 : Vue générale de la fouille du Panveau depuis le sud-ouest. Le décapage est en cours de nettoyage manuel. Cliché A. Valais. Photo3: General view of the Panveau excavation from the south-west. The surface is in the process of being cleaned. pour deux d'entre eux (F.287 et F.304). Le poteau F.273 pourrait également présenter cette forme. F.287 montre ainsi une forme carrée d'un mètre de côté, longueur également mesurée par F.304 qui ne fait cependant que 0,60 mètre de largeur. F.273 pourrait avoir mesuré à l'origine plus d'1,30 mètre de longueur pour 1,10 mètre de largeur. F.272 de son côté a une forme plutôt circulaire de 0,60 mètre de diamètre. Les profondeurs de F.287, 272 et 304 sont voisines et comprises entre 0,20 (F.272) et 0,24 mètre (F.287). Seul F.273 dépasse 0,60 mètre de profondeur. Cet ensemble d'emprise régulière couvre ainsi une surface qui dépasse 31 mètres carrés.

Il s'agit d'un plan de bâtiment extrêmement cohérent tout comme son orientation avec celle de la plupart des autres constructions du site. La présence d'un tesson qui semble dater du haut Moyen Âge, le seul du site, pose toutefois un problème d'attribution chronologique.

\section{- Le bâtiment 8 (fig. 8)}

Le bâtiment 8 appartient à la partie sud de l'enclos. Il est en contact avec le fossé F.115. Son emprise est limitée par six avant-trous de poteau (F.269, 270, 223, 1058 ?, 250 et 344). À cet appariement qui dessine un rectangle de 10 mètres sur 6, peuvent être associées deux autres structures (F.327 et F.268) qui forment un alignement parallèle à celui formé par les faits F.250 et F.223. Nous ne connaissons que trois des angles de cet ensemble (F.344, F.250 et F.223), le quatrième n’a pas été vu. En s'appuyant sur la cohérence de cet appariement, ce poteau manquant aurait dû être relevé au niveau du fossé F.175. On ne sait si ce dernier l'a détruit, ou si la structure n'a pu être vue dans le remplissage de cette limite excavée. S'il est difficile de trancher entre ces deux possibilités, il nous semble plus logique en raison de la chronologie des fossés (voir paragraphe précédent) de considérer que c'est bien la structure qui est venue recouper le fossé, cette dernière n'aurait pas été vue dans un remplissage de fossé lessivé. Notons que ce vaste ensemble n’a pas été reconnu sur le terrain mais seulement sur plan, à l'issue de la fouille. Deux poteaux sont implantés sur l'axe de construction, chacun en retrait et à égale distance des deux pignons. Cet alignement interne divise l'espace en deux nefs et en trois travées égales. Deux autres poteaux distants d'un mètre marquent également le centre du côté occidental de l'ensemble. En dehors de la structure F.344 qui montre un diamètre bien supérieur, toutes les autres traces mesurent entre 0,50 (F.250 et 270) et 0,60 mètre de diamètre. Les profondeurs des structures vont de 0,20 mètre (F.327) à 0,40 mètre (F.223). Quelques traces observées en coupe permettent de restituer des diamètres de poteau compris entre 0,25 et 0,28 mètre.

Malgré l'absence d'un supports cornier à ce bâtiment, il est possible d'en proposer une élévation. La position des deux supports de l'alignement intérieur permet de resti- 


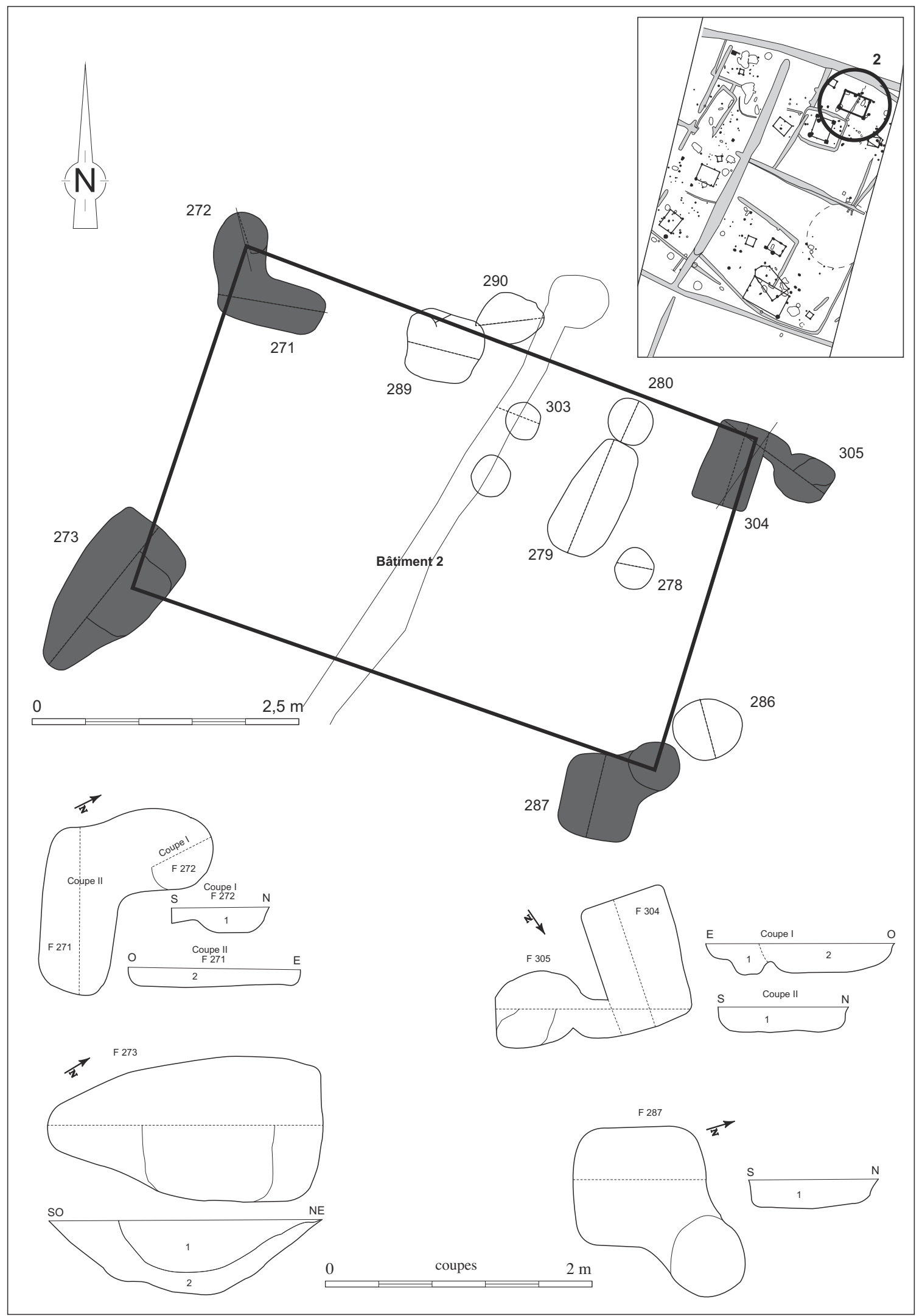

Figure 7 : Plan du bâtiment $\mathrm{n}^{\circ} 2$ avec les profils des structures qui le constituent.

Figure 7 : Plan of building $n^{\circ} 2$ with the sections of its structures. 


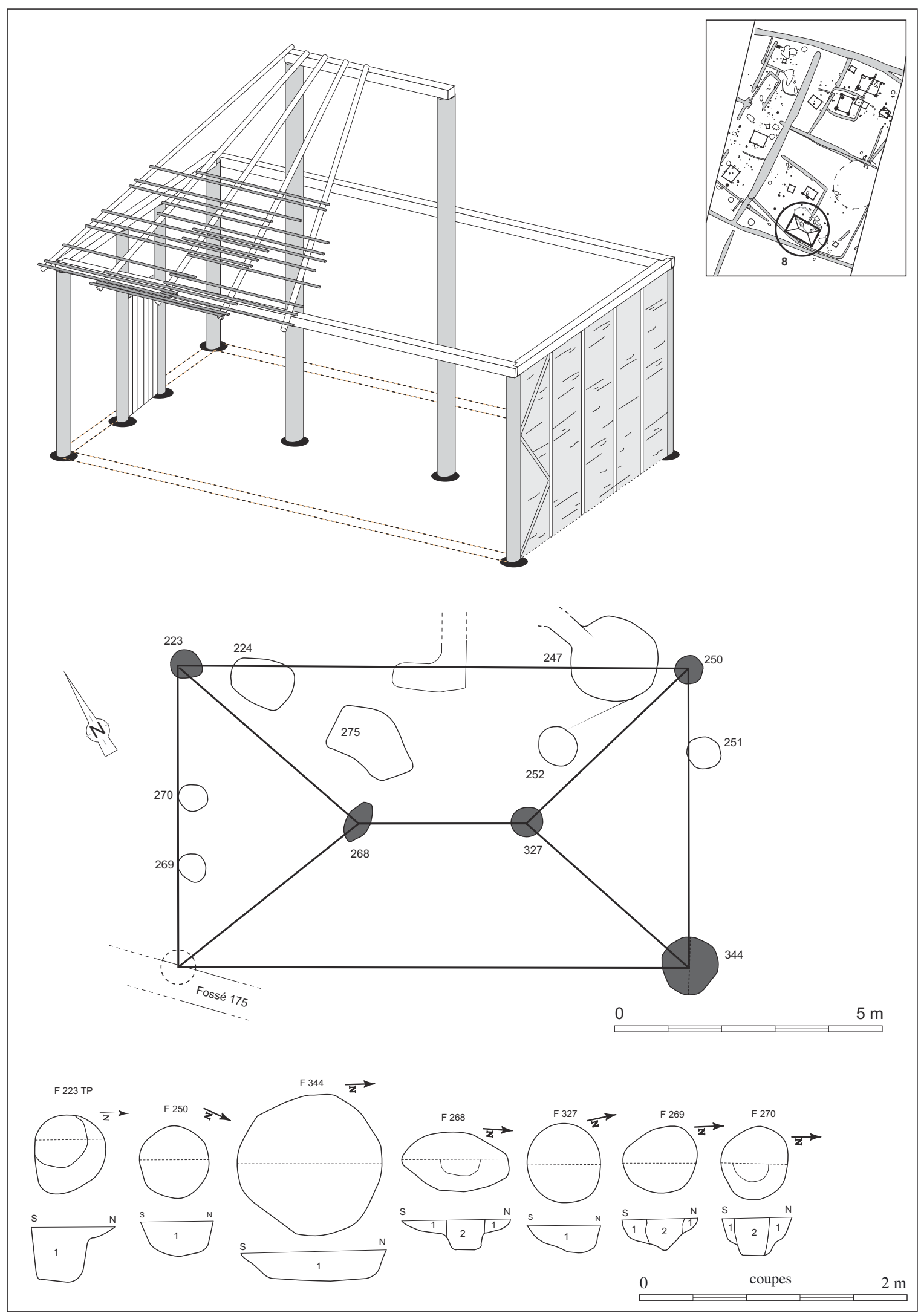

Figure 8 : Plan du bâtiment $\mathrm{n}^{\circ} 8$ avec les profils des structures qui le composent et proposition de restitution de cet ensemble. Figure 8: Plan of building $n^{\circ} 8$ with the sections of its structures and a proposed restitution. 
tuer une toiture à quatre pans qui repose sur une sablière haute continue. Les deux structures implantées au centre du pignon occidental permettent semble-t-il de localiser l'entrée du bâtiment. Cet accès pourrait ainsi mesurer un mètre de largeur. Avec 64 mètres carrés de surface, cet ensemble pourrait constituer les vestiges d'une habitation.

Les bâtiments sur poteaux porteurs et parois

- Le bâtiment 3 (fig. 9)

Préalable : comme dans le cas du bâtiment 8 , l'ensemble n'a été perçu que partiellement au moment de la fouille. Probablement en raison de la profusion de fossés et de structures dans le secteur, seul un bâtiment à quatre poteaux (F.243, 233, 239, et 235) avait été initialement reconnu. L'enceinte excavée dans laquelle il était cantonné avait été interprétée comme un simple enclos.

Le bâtiment 3 appartient au quart nord-est du site. Il est constitué de quatre avant-trous qui décrivent un quadrilatère de 5,20 à 5,30 mètres d'est en ouest et de 5,80 mètres de nord au sud. Les quatre avant-trous présentent en plan des formes quadrangulaires ou même carrées. Elles mesurent entre 0,94 mètre à 1,04 mètre de côté. Le fait F.235, le plus irrégulier mesure 1,56 sur 1,20 mètre. Ce gabarit singulier est la conséquence d'un re-creusement, dont l'existence a été confirmée en coupe. Les profils de ces structures sont semblables avec des fonds plats et des parois le plus souvent verticales. Leurs profondeurs varient de 0,36 mètre (F.233) à 0,60 mètre (F.235). Il ne fait aucun doute qu'il s'agit bien ici d'avant-trous de poteau d'un type déjà rencontré dans la région notamment, quelques exemples dans l'oppidum de Mesnil à Moulay (Valais, 2004, fig. 26) ou sur le Clos des Primevères à Entrammes (Guillier, 2010, p. 74). Les négatifs de poteaux qui ont été relevés dans les structures F.239, F.233 et F.243 permettent de restituer des montants de plus de 0,40 mètre de diamètre (F.239, 233, 243). Ce complexe est implanté exactement au centre d'un enclos quadrangulaire qui limite une zone barlongue d'environ 7 mètres sur 9,50 mètres. Il s'agit d'une structure excavée confondue à la fouille avec les fossés d'un petit enclos aux angles abattus. Cet ensemble se compose de quatre côtés (F.253, 205, 255 et 254). D'un côté à l'autre, les coupes réalisées montrent des variations de dimensions. Le côté occidental (F.205) est le plus modeste avec des largeurs comprises entre 0,34 mètres ( $S d$ 1046) et environ 0,40 mètre ( $S d$ 1047) et de 0,18 (Sd 1046) à 0,26 mètre (Sd 1047) de profondeur. De la même façon, il semble que trois des angles (sud-ouest, nord-est et sud-est) présentent des dimensions légèrement inférieures au reste de la structure. À l'opposé, le côté sud est le plus large avec des mesures de 0,72 mètre ( $S d$ 1080) et 0,84 mètre ( $S d$ 1051) de largeur. Les côtés nord et est ont en revanche des dimensions assez voisines, leurs largeurs oscillant entre 0,52 mètre et 0,56 mètre. En coupe, la structure présente souvent des profils dont au moins un bord tend à la verticale comme le montrent les sondages 1056, 1055, 1054 et 1053 . Ailleurs, comme au niveau des côtés ouest et sud, les profils sont plutôt en V. Si ces derniers ne permettent pas de les différencier de simples fossés, ceux aux bords droits, permettent de proposer une autre interprétation. Il pourrait en effet s'agir de tranchées d'ancrage de murs. La position de chacun des poteaux au sein de cette structure excavée constitue également un argument intéressant, chacun des supports étant implanté à égale distance de l'angle de la tranchée qui lui est le plus proche. Cette remarque permet dès lors de relier les deux faits. En les associant à un seul bâtiment dont l'emprise au sol avoisinerait 80 mètres carrés, il est possible de proposer deux hypothèses de restitution. Admettons que chacun des poteaux relevés, du fait également de leur fort diamètre, supporte par le biais d'entraits et de sablières les charges d'une charpente. Ainsi, les extrémités inférieures des rampants reposent sur des murs dont subsistent les tranchées. Les chevrons, en plus d'être solidement reliés entre eux au niveau du faitage devaient également être fixés à la sablière pour en retenir le poids (charpente et matériaux de couverture; fig. 10). Les quelques éléments céramiques recueillis permettent d'attribuer cet ensemble à La Tène finale.

Avec une telle hypothèse, l'emprise rectangulaire soulignée par les tranchées, conjuguée à l'implantation des poteaux, impliquent également une toiture à quatre pans. Le positionnement des poteaux plus près des grands côtés conduit également à restituer une courte faîtière d'orientation nord-sud. Nous disposons de peu d'éléments sur le mode de construction de ces parois. L'absence d'angles vifs permet d'exclure l'hypothèse d'une sablière basse continue. En revanche, on ne peut écarter qu'il en ait existé seulement sur les grands côtés. Une autre proposition peut être faite sous la forme de poteaux verticaux associés à des tronçons de parois de clayonnage. Une troisième option peut également être avancée, celle qui utiliserait la terre comme matériau de base. Avec quatre poteaux solidarisés par des entraits, les murs n'ont en effet pas l'obligation de porter la totalité de la charge de la charpente. Ainsi, une simple paroi de clayonnage et de torchis pourrait suffire à soutenir la base des chevrons. La largeur de la tranchée pourrait même admettre des parois en pisé... Malheureusement et faute d'avoir repéré l'emprise de ce bâtiment dès la fouille, la tranchée a été testée comme la plupart des fossés du site à l'aide de coupes transversales. Seules des coupes longitudinales auraient éventuellement permis la mise en évidence de traces d'ancrage de piquets ou de poteaux.

Un type de construction présentant une structure porteuse interne constituée de quatre poteaux associée ou non à un complexe de tranchées de fondation a été reconnu et resti- 


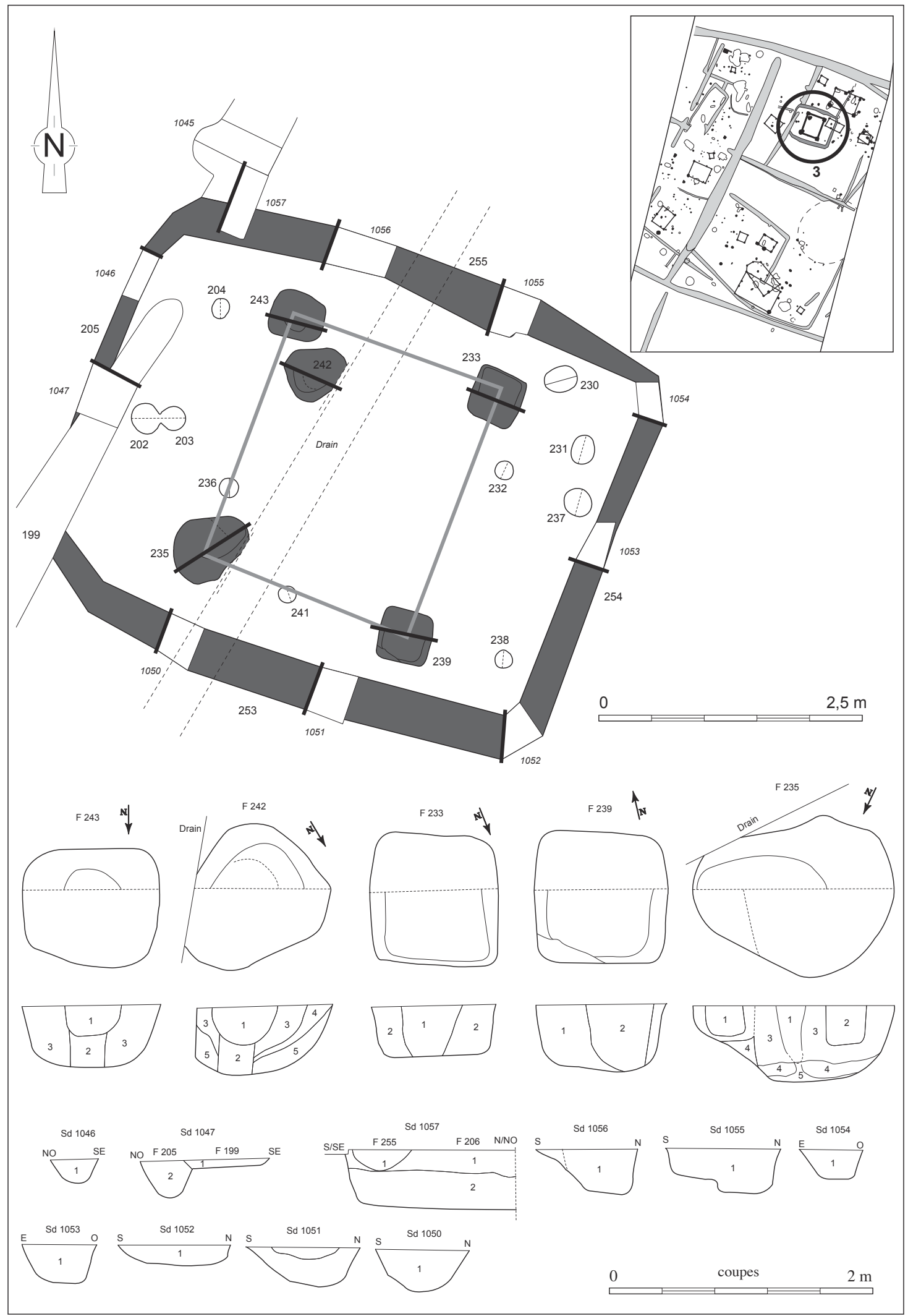

Figure 9 : Plan du bâtiment $n^{\circ} 3$ et profils des structures qui le composent.

Figure 9: Plan of building $n^{\circ} 3$ and the sections of its structures. 


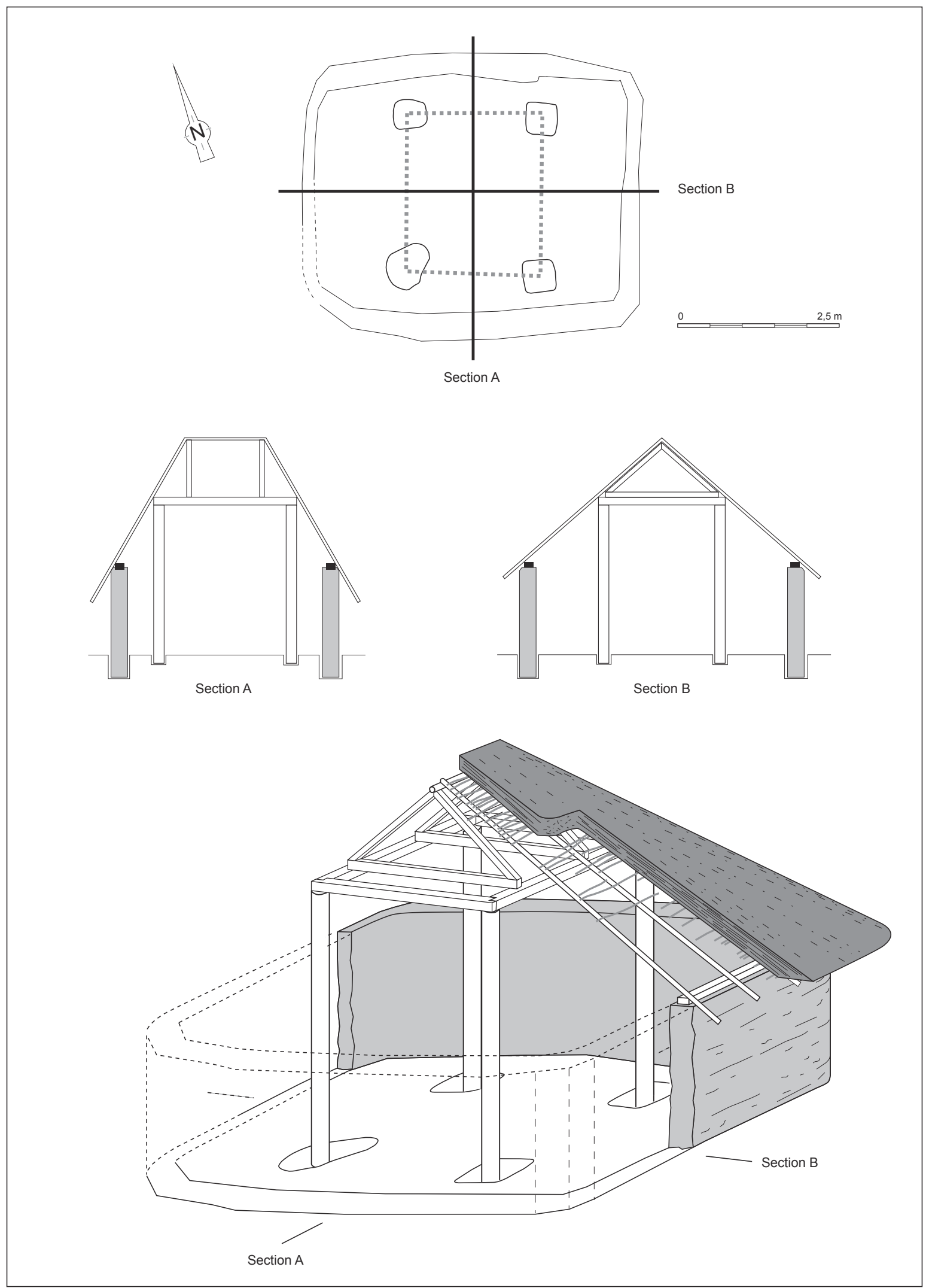

Figure 10 : Proposition de restitution du bâtiment $\mathrm{n}^{\circ} 3$.

Figure 10: proposed restitution of building $n^{\circ} 3$. 
tué sur plusieurs autres sites de la région, notamment aux Genâts (Nillesse, 2003, p. 279) ou à La Chapelière (Maguer, 2005, p. 35). Mais sur ces exemples à quatre structures de fort diamètre, sont associés seulement les deux poteaux d'un porche avancé qui permet, de restituer la position de parois disparues. Plus proche sans doute, l'exemple du Panveau peut être comparé à certains des bâtiments des Natteries à Cholet où les bases des parois non porteuses de ce type de construction étaient encore visibles comme dans le cas de l'ensemble E 49 de 75 mètres carrés de surface (Maguer, 2005). On peut certainement ajouter également celui de la Boirie à Chemillé (Guerin, 1999 et Maguer, op. cit., p. 332-333) ou encore celui de la Chauvelière Neuve à Cholet (Maguer, op. cit., p. 334-335) où l'on retrouve une structure porteuse constituée de quatre poteaux forts centrés au sein d'un complexe de tranchées de fondations continues. Les sites ayant livré des bâtiments de ce type de l'âge du Fer ne sont pas seulement présents dans le Maineet-Loire ou en Vendée. Il en existe également en Bretagne sur le site d'Inguiniel avec l'ensemble 311 (Tanguy, 2000). Pour cet exemple cependant, le plan présente deux supports de faîtage, particularité qui donne une stabilité évidente à l'ensemble. D'une manière générale, les restitutions proposées plus haut nous paraissent difficiles à réaliser en raison de l'importance des poussées exercées sur l'ossature de cette toiture. Pour en limiter l'effet, il faut absolument en augmenter la hauteur. En l'absence de supports de faîtage, il paraîtrait même plus aisé d'utiliser un mode de couverture constitué de deux parties distinctes. La première consisterait à couvrir l'espace limité par les quatre poteaux et ensuite, à partir de cet espace central, de couvrir le reste du bâtiment à l'aide de pans de toiture en appentis à la manière d'une des hypothèses émises aux Natteries (Maguer, op. cit., p. 339). Cette proposition présente l'avantage d'être beaucoup plus stable tout en étant moins consommatrice en bois. Le plan du Panveau pourrait même constituer une solution mixte entre ces deux propositions. Il est possible de restituer deux pignons couverts d'appentis, chaque poteau étant écarté des tranchées est et ouest et, d'autre part, des chevrons qui descendent jusqu'aux murs en s'appuyant sur les côtés sud et nord du module porteur à quatre poteaux.

Une autre hypothèse de bâtiment à ossature mixte (fig. 6, bâtiment 15)

Un ensemble constitué de trois structures qui évoquent autant de courts tronçons de fossés (F.43, 133 et 10) décrivent en plan un rectangle de 13,75 mètres de longueur et de 5 mètres de largeur hors tout. Ces creusements rectilignes mesurent de 0,44 à 0,68 mètre de largeur pour F.10 et 0,90 mètre pour F.133. Les dimensions sont plus aléatoires pour F.43 recoupé qu'il est par un drain. Leurs profondeurs oscillent entre 0,08 mètre (F.10) et 0,38 mètre (F.133). Au sud, F.10 et F.43 sont interrompus sans qu'aucun retour n'apparaisse à proximité. Au moins un trou de poteau F.140 semble associé à cet ensemble. Ce creusement d'un diamètre de 0,42 mètre et d'une profondeur de 0,20 mètre présente des éléments de calage. Implanté juste sur le grand axe de ce complexe, il constitue peut-être un support de faittage. Le creusement F.141 ne semble pas pouvoir y être associé car son plan et profil évoquent beaucoup plus une fosse qu'un trou de poteau. Avec cet avant trou de poteau F.140, les structures F.133, 10 et 43 pourraient constituer ainsi des tranchées de fondations. Les murs de ce bâtiment peuvent être constitués de parois de clayonnages ou de murs en pisé. Dans ce cas, il faut privilégier l'apport de supports de faitage dont le poteau F.140 pourrait témoigner. Son implantation pourrait même indiquer que le bâtiment disposait d'une toiture à quatre pans.

Avec une surface interne d'au moins 11 mètres sur environ 4 mètres, cet ensemble qui n'a pas été interprété comme tel sur le terrain mais seulement à l'analyse du plan, occuperait au moins 40 mètres carrés. Du mobilier de La Tène moyenne est issu des structures F.43 et F.10. Cette hypothèse de bâtiment n'est pas sans rappeler l'exemplaire de La Tène ancienne, beaucoup plus vaste, découvert à La Queute/Le Fond Baraquin à Pont Rémy (Buchez, 2005, p. 206 et 207). Il s'agit d'un bâtiment de 120 mètres carrés où sont associées des parois porteuses à deux supports de faitage. Le tout est couvert d'une toiture à quatre pans.

\section{Les bâtiments sur poteaux de 10 mètres carrés à 20 mètres carrés (fig. 6)}

Cinq bâtiments de 10 à 20 mètres carrés ont été repérés. Quatre d'entre eux s'inscrivent bien dans les orientations générales de l'enclos ( $\mathrm{n}^{\text {os }} 7,9,13$ et 14$)$, le cinquième ( $\left.\mathrm{n}^{\circ} 11\right)$ étant quelque peu désaxé. Ce dernier bâtiment est de ce fait le moins bien établi d'autant qu'il est le seul à présenter un plan trapézoïdal. Les quatre autres plans en revanche sont rectangulaires. En dehors du bâtiment 14 avec sa largeur égale à la moitié de sa longueur, le rapport des longueurs et des largeurs des quatre autres sont comprises entre 1,12 et 1,22 mètre, ce qui donne des ensembles relativement trapus.

Ces plans sont constitués de quatre poteaux corniers $\left(\mathrm{n}^{\text {os }} 9\right.$ et 11 ), l'exemple ${ }^{\circ} 13$ en compte lui au moins cinq. Les exemples $\mathrm{n}^{\text {os }} 7$ et 14 pourraient même en conserver sept. Un support supplémentaire existe au milieu de trois des quatre côtés du n ${ }^{\circ} 7$. L'exemple $\mathrm{n}^{\circ} 14$ montre également un support de faitage en plus à chacun de ses murs gouttereaux.

Les avant-trous y sont relativement bien conservés car presque tous mesurent entre 0,10 et 0,34 mètre de profondeur. Seuls trois unités sur les vingt-trois concernées n'atteignent pas les 0,09 mètre. Ces avant-trous ont des dimensions qui oscillent entre 0,4 et 1,02 mètre de dia- 
mètre ou de longueur pour ceux qui sont quadrangulaires. Aucune trace de calage n'a été relevée dans ces cinq plans de bâtiment.

Ces hypothèses de bâtiment de 10 à 20 mètres carrés sont dispersées un peu partout sur le site à la manière de ce qui est constaté pour les greniers (voir chapitre suivant). Leur faible surface permet probablement d'écarter une fonction résidentielle et d'y privilégier un usage agricole qu'il est toutefois impossible d'identifier précisément.

\section{Petites constructions à quatre poteaux (fig. 6)}

Six ensembles de moins de 10 mètres carrés qui peuvent correspondre à autant de greniers ont été repérés. Si l'interprétation de trois d'entre eux $\left(\mathrm{n}^{\mathrm{os}} 1,5\right.$ et 6$)$ ne posent guère de question, la fonction des autres en revanche ( $\mathrm{n}^{\text {os }} 10,12$ et 4 ) est beaucoup plus incertaine.

Ces ensembles se composent généralement de quatre avant-trous de poteau, excepté les deux hypothèses du bâtiment 4 qui pourraient en compter cinq. Les trois ensembles, les plus sûrs $\left(\mathrm{n}^{\text {os }} 1,5\right.$, et 6$)$ reposent chacun sur quatre poteaux dont les avant-trous mesurent entre 0,30 mètre et 0,70 mètre. Ils sont plutôt bien conservés avec des profondeurs comprises entre 0,18 mètre et 0,40 mètre. Seuls deux n'atteignent pas ces valeurs en ne dépassant pas 0,10 (F.167) et 0,12 mètre (F.217). D’une manière générale, les creusements sont de taille assez proche au sein de chaque bâtiment, et leurs surfaces (hors tout) sont comprises entre 3 mètres carrés (bâtiment 5) et 6 mètres carrés (bâtiment 6 ). Le bâtiment 1 occupe 5 mètres carrés. Des calages apparaissent dans un avant-trou des bâtiments 1 et 5 , tandis que des traces de négatifs ont été relevées uniquement en coupe dans deux structures de ce dernier. Elles montrent ainsi les traces de poteaux respectivement de 0,48 mètre et 0,28 mètre de largeur.

Les trois autres propositions de bâtiments dont deux (n $\mathrm{n}^{\text {os }} 4$ et 10) présentent également des orientations cohérentes sont néanmoins beaucoup plus incertaines avec des vestiges aux dimensions et aux profondeurs beaucoup plus irrégulières. C'est particulièrement le cas pour l'exemple $\mathrm{n}^{\circ} 12$ qui, en plus, présente une orientation singulière.

Les deux hypothèses proposées pour le bâtiment 4 sont également assez discutables en raison de la profusion de structures dans cette zone. Les profondeurs des avant-trous y sont également irrégulières.

En dehors de l'assemblage $\mathrm{n}^{\circ} 12$, les hypothèses de bâtiments à quatre poteaux s'insèrent plutôt bien au sein du site du Panveau en raison de la convergence de leurs orientations. Cependant seuls trois correspondent assurément aux restes de constructions. D'emprises modestes, ils s'apparentent plutôt à des greniers qui seraient implantés pour deux d'entre eux ( $\mathrm{n}^{\text {os }} 1$ et 5$)$ à proximité des fossés d'enclos, le bâtiment 5 étant même juste dans un de ses angles. Cette disposition a déjà été remarquée sur d'autres sites notamment à La Bleure à Cholet (Sandoz, 1999, p. 5 et Maguer et Lusson, 2009, p. 449) ou à La Chapelière à La Chaize-leVicomte "La Chapelière " (Maguer, 2005, p. 34). Notons encore que ces constructions de faible emprise sont dispersées un peu partout sur l'emprise de l'enclos et qu'elles sont, en dehors de l'exemplaire $\mathrm{n}^{\circ} 10$, toujours implantées non loin d'une construction plus grande. Les greniers 1, 5 et 6 semblent en effet associés aux bâtiments les plus vastes qui sont interprétés comme autant d'habitation. Chacune de ces dispositions pourrait constituer une unité d'habitat dont la ferme du Clos-Henry à Château-Gontier montre un remarquable exemple (Valais et al., 2008, p. 147 et 149).

\section{Les fosses}

\section{Les fosses circulaires (fig. 11)}

Une douzaine de creusements de forme circulaire a été relevée sur le décapage (F.95, 97, 107, 123 ?, 168, 172, 178, 247, 281). Ces fosses ne peuvent être confondues avec des avant-trous de poteau en raison de leur diamètre important qui dépasse 1,20 mètre (F.281). Certaines comme F.168 peuvent atteindre 2 mètres. Leur localisation est irrégulière, mais on constate qu'elles appartiennent principalement au sud-ouest de la fouille avec la moitié des exemplaires. Dans la moitié nord en revanche, elles sont plus rares, voire même isolées. Il n'en existe qu'une seule dans les quarts nord-ouest (F.178) et sud-est (F.247). Ces creusements circulaires sont mal conservés pour certains (F.281, 172 et 107), avec des profondeurs comprises entre 0,10 et 0,14 mètre. La plupart se situe toutefois au-delà de 0,30 mètre (F.247, 178, 123), les autres mesurent 0,40 mètre (F.123), 0,70 mètre (F.123). Le maximum est atteint avec 0,90 mètre (F.95). Les remplissages apportent peu d'information si ce n'est quelques fragments de charbons de bois dans tous les creusements. En dehors de la fosse F.247 particulièrement riche en mobilier, aucune ne semble avoir servi de dépotoir. Ces fosses ont pu servir à l'extraction de limons. Des structures comme F.95 et F.97, pourraient peut-être constituer des silos dont le goulot aurait été totalement détruit. Les quelques structures ayant livré du mobilier sont attribuées à La Tène finale.

\section{Les fosses rectangulaires (fig. 11)}

Quatre fosses rectangulaires (F.77, 98, 161 et 209) ont été repérées. Toutes appartiennent à la partie nord occidentale du décapage. En dehors de F.161, qui paraît bien exigu, ces creusements, aux plans et aux profils réguliers, couvrent des surfaces qui varient de 2,20 mètres carrés (F.98) à 4,6 mètres carrés (F.205). Les poteaux n'y sont pas clairement attestés et le mobilier manque le plus souvent. Seul F.209 a livré du 


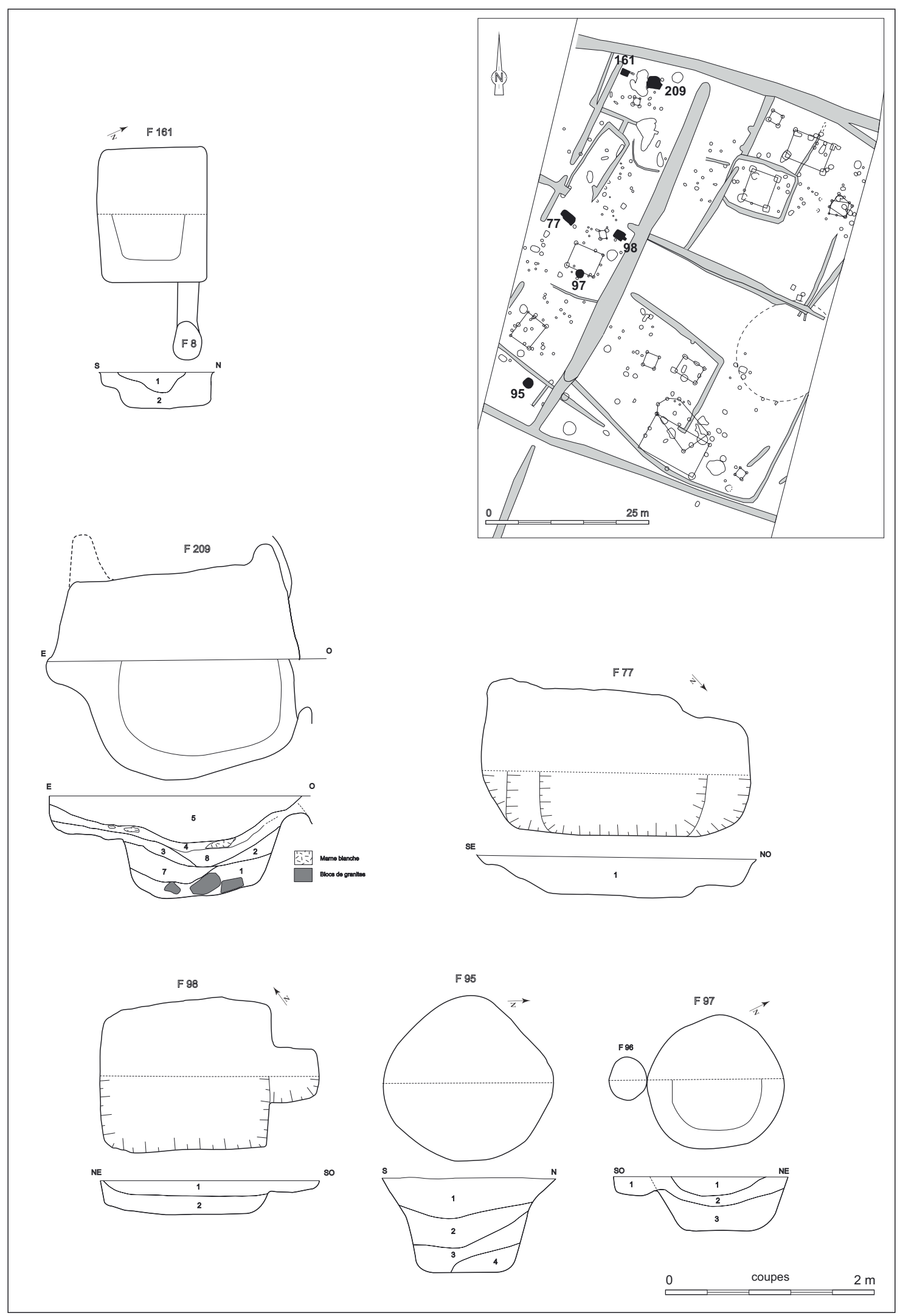

Figure 11 : Plan et profil des fosses rectangulaires et circulaires avec leur localisation sur le site.

Figure 11: Plan and section of the rectangular and circular pits and their localisation on the site. 
mobilier de La Tène moyenne ou finale. Avec des fonds plats et des bords proches de la verticale, ces structures excavées se distinguent assez nettement des fosses d'extraction de matériaux aux plans et aux profils beaucoup plus aléatoires. Des fosses rectangulaires ont, par exemple, été découvertes sur le site des Natteries à Cholet. On retrouve les mêmes surfaces, la fosse F.26 par exemple, qui est dotée de piquets à chaque angle (Maguer, 2000, p. 103). On propose d'y voir de petits ateliers semi-enterrés dont la présence est par ailleurs attestée dès l'âge du Fer (Audouze et Büchsenchutz, 1989, p. 73). Mais comme pour le haut Moyen Âge, ce type d'affectation reste toutefois difficile à percevoir en l'absence de mobilier spécifique.

\section{Les fosses aux contours irréguliers}

Des fosses (F.210, 38, 39, 292) aux emprises irrégulières montrent des gabarits imposants. F.210 atteint par exemple 4,10 mètres de longueur. Leurs profondeurs oscillent entre 0,34 mètre (F.38) et 0,50 mètre (F.292). Elles appartiennent à la périphérie du site. Leurs formes et profils irréguliers les différencient assez nettement des autres creusements plus soignés que nous avons présentés plus haut. Si certaines, notamment F.210, ont pu servir dans un second temps de fosse-dépotoir, la fonction initiale de ces creusements se situe d'abord dans l'extraction de matériaux de construction nécessaires à l'élaboration du torchis.

Cette hypothèse pourrait être proposée pour la fosse F.292. Située à proximité immédiate du bâtiment 8 , elle pourrait lui être directement associée. Ce type d'aménagement apparaît souvent aux abords des bâtiments, notamment des habitations qui demandent beaucoup de matériaux (Maguer et Lusson, 2009, p. 436).

\section{Un niveau de voirie (fig. 2)}

Une large cuvette (F.37) a été relevée à l'est de l'emprise décapée. Même si l'on ne connaît pas exactement son extension, nous savons qu'à son niveau d'apparition, elle mesure 16 mètres du nord au sud et au moins 12 mètres d'est en ouest. Deux sondages réalisés à l'intérieur de cette dépression montrent une profondeur maximale de 0,30 mètre. La coupe nord/sud relevée après nettoyage indique également une réduction de cette cuvette à une douzaine de mètres du nord au sud pour 8 à 9 mètres de largeur. Son profil est assez bien marqué au nord avec un bord relativement abrupt. Son profil au sud ne semble pas aussi clair. Il paraît moins abrupt. Il est difficile de connaître l'origine de cette vaste anomalie topographique qui est établie sur le haut d'un versant qui suit le méandre d'un ru. On ne sait si elle trouve son origine dans l'amorce d'un talweg sud-ouest/sud-est, vallée sèche qui abouti- rait au ruisseau en contrebas. Le haut de cette anomalie, aujourd'hui totalement masqué, aurait été en partie réaménagé par les Gaulois. Les informations archéologiques issues du remplissage de cette dépression sont plus claires car le niveau inférieur qui en tapisse le fond constitue un bel exemple de sol aménagé. Il se compose d'un horizon extrêmement régulier constitué de petits galets compactés. Sur la surface de cet aménagement, de nombreux tessons de céramique ont été relevés toujours à plat et parfois fracturés en place. Ce niveau de cailloutis régulier n’a pas été relevé sur la totalité de la cuvette mais seulement dans les secteurs les plus profonds de sa partie nord orientale. Ce niveau de sol et l'ensemble de la cuvette ont ensuite été respectivement recouverts et colmatés par une phase de remblais assez riches en mobilier, issus des activités domestiques environnantes. On dénombre de la céramique et des fragments de meules presque uniquement de La Tène finale. Un seul fragment de céramique pourrait remonter à La Tène moyenne.

Cet ensemble est en contact avec plusieurs fossés (F.346), les relations entre ces structures n'ont pu être établies, en raison des types de remplissage observés dans chacun des creusements. Il est possible, que les fossés au nord aient servi de trop plein capable de drainer le fond de cette cuvette en cas de forte pluie. Dans un premier temps, cette anomalie avait d'ailleurs été confondue avec une mare. Cette hypothèse a ensuite été revue en raison de la perméabilité du substrat environnant et de la présence de ce niveau de sol établi au fond de la structure. Les drains à proximité ont servi, au mieux, de trop plein, utile au drainage de la cuvette lors de fortes précipitations, cette proposition ne tenant bien sûr que s'il s'agit d'une dépression et non d'une vallée sèche.

Si nous n'avons aucune certitude quant à l'origine de cette anomalie, il est certain en revanche qu' elle occupe une zone située dans le grand axe du site, par où nous avons tendance à localiser une zone de cour ou de passage. Le niveau de sol relevé au fond de la " cuvette " pourrait ainsi constituer un horizon de circulation établi dans un chemin creux qui viendrait de l'est du site et où pourrait aussi se situer une entrée à La Tène finale. Il est donc probable que cette anomalie topographique soit en réalité l'un des axes principaux du site. Celui-ci aurait été aménagé dans un talweg que les aléas du temps et de l'évolution du paysage (travaux agricoles et installation d'une haie parallèle à l'axe du talweg) auraient depuis longtemps oblitéré. 


\section{LE MOBILIER}

\section{La céramique par M. Mortreau}

La fouille menée sur le site du Panveau à Aron (Mayenne) a livré un important mobilier céramique (1026 tessons au total pour 81 individus). Trois périodes chronologiques principales correspondant aux trois phases majeures d'occupation du site ont été distinguées.

La durée d'occupation du site du Panveau peut être estimée à environ trois siècles, entre La Tène moyenne et La Tène finale. Nous présenterons simultanément la céramique des deux horizons gaulois reconnus, en signalant dans le texte la datation respective des types ou des décors.

Les vestiges attribuables à La Tène moyenne concernent les faits 3, 10 (?), 13 (?), 15, 40 (?), 43, 133 (?), 203, 209 (?), 253 (?), 257 (?), 287 (?), 309, 354, et 358 (?). Les points d'interrogation soulignent la difficulté à attribuer à telle ou telle phase des lots de céramiques peu abondants pour chaque fait.

Les autres structures qui ont livré du mobilier gaulois appartiennent à La Tène finale, sans doute La Tène D1 .

Avancer une chronologie fiable est rendu difficile par le fait que plusieurs structures fossoyées (fossés notamment) ont connu une durée de vie très longue avec des re-creusements successifs. Le mobilier résiduel de la première phase est souvent piégé lors de cette phase de remobilisation.

Les quelques recollages existant entre les structures F.31 et F.38 et entre F.257 et F.255 permettent de conclure à l'existence d'une seule et même phase de comblement des structures fossoyées et d'assurer ainsi la contemporanéité des lots découverts dans ces structures.

\section{Quelques données chiffrées}

Avec 1022 tessons comptabilisant un total de 80 individus (dont 74 bords et 6 formes archéologiquement complètes) pour 10000 mètres carrés, il s'agit d'un lot important de mobilier céramique pour cette période dans le département de la Mayenne. En comparaison, on peut citer les fermes du Clos-Henry, de la Selle Craonnaise près de Château-Gontier, de La Glannerie à Athée, l'occupation gauloise de la Carie II, le fossé de la Carrière d'Écorcé à Entrammes et le site de l'oppidum du Mesnil sur la déviation Moulay-Mayenne. Le mobilier d'importation (ici en l'occurrence les amphores) se signale par son extrême rareté : seuls deux individus ont été identifiés. L'un présente une pâte sableuse beige (lot 21) et l'autre une pâte rose à spicules volcaniques (lot 255). Les caractéristiques techniques permettent d'attribuer l'origine de ces fabrications à des ateliers campaniens.

La céramique a été découverte dans le remplissage de structures fossoyées (fosses, fossés). L'état de conservation de la vaisselle céramique est en général assez médiocre. Les vases présentent souvent des surfaces très abîmées laissant apparaître les inclusions grossières présentes dans la pâte. L'érosion semble avoir touché surtout les pièces les plus anciennes qui présentent un aspect roulé, une surface desquamée, la petite taille des fragments qui ne permettent souvent pas de restitution de forme. Très fragmenté, le matériel n'offre que peu de formes archéologiquement complètes $(6$ au total). Le taux de fragmentation des vases approche 12/1 en moyenne.

A contrario, on signalera ainsi l'exemple de la structure 247. Cette structure fossoyée de grandes dimensions a livré les vestiges de l'incendie d'un bâtiment proche. Plusieurs vases montrant une ré-oxydation partielle des surfaces ont ainsi été mis au jour. Dans ce cas précis, le taux de fragmentation diverge considérablement (25/1). Quant au fossé 21 à l'abondant mobilier, il se caractérise par un ratio inférieur à la moyenne $(8,5 / 1)$ et par la présence de pièces de grande taille, signe d'un rejet primaire.

\section{Méthodologie}

En fonction du temps imparti et de l'importance du lot, nous avons privilégié l'établissement d'un corpus documentaire. L'accent a donc été mis sur le dessin systématique de tous les rebords figurables afin d'asseoir la typologie. À ce corpus, nous avons aussi ajouté quelques fonds quand ils présentaient des particularités remarquables. Les comptages par NMI ont été effectués à partir des rebords sans pondération avec les fonds. La mise en lots a cependant distingué les bords, les fonds et les éléments de panse. Le comptage n'a pu prendre en compte les groupes techniques, seule une quantification globale par tessons a été réalisée.

\section{La céramique : aspects technologiques}

La grande majorité de la céramique commune est fabriquée à partir d'argiles locales. La production est caractérisée par une pâte chargée en inclusions de quartz donnant un aspect rugueux à la pâte. Une seconde production est caractérisée par une pâte plus fine contenant du mica, des petits grains de quartz et du bioclaste blanc. La céramique paraît homogène tant au niveau de la cuisson que des techniques de montage. D'après les colorations de surface, la cuisson apparait majoritairement comme étant du type B (Picon, 1973) ou B' (mode sandwich). Des ré-oxydations partielles affectent la surface des vases ayant été au contact du feu ou d'un incendie violent.

Le tournage au tour ou tour lent semble majoritaire : $91,15 \%$ des pièces céramiques (amphores exceptées) sont tournées ou régularisées. Cette incertitude du chiffrage tient 


\begin{tabular}{|c|c|c|c|c|c|c|c|}
\hline FAIT & SOND & US & NT & NMI & DATATION & Lots LTM & Lots LTF \\
\hline 0 & & décapage & 7 & 2 & LTM & $1,2,3$ (fond) & \\
\hline 1 & & & 19 & 1 & LTF & & 5 \\
\hline 2 & & & 5 & 1 & LTF & & 11 \\
\hline 3 & & & 32 & 3 & LTM & $\begin{array}{c}12,15 \text { (fond) } \\
17\end{array}$ & \\
\hline 4 & & & 1 & & & & \\
\hline 9 & & & 1 & & & & \\
\hline 10 & & & 37 & 3 & LTM & $21,23,26$ & \\
\hline 13 & & & 49 & & LTM? & 28 (fond) & \\
\hline 14 & & & 4 & & & & \\
\hline 15 & & & 40 & 2 & LTM & 30,33 & \\
\hline 21 & 1009 & 3 et 4 & 4 & 2 & LTF & & 36,37 \\
\hline 21 & 1039 & 1 & 9 & 1 & LTF & & 39 \\
\hline 21 & 1039 & 5 & 21 & 5 & LTF & & $\begin{array}{c}40,41,42,43 \\
44\end{array}$ \\
\hline 21 & 1087 & & 18 & 2 & LTF & & 49,51 \\
\hline 21 & 1088 & & 4 & & LTF & & \\
\hline 21 & 1089 & & 38 & 3 & LTF & & $56,58,59$ \\
\hline 21 & 1090 & & 20 & 2 & LTF & & 62,63 \\
\hline 21 & 1091 & & 3 & 1 & LTF & & 68 \\
\hline 21 & & décapage & 19 & 2 & LTF et LTM? & 71,73 & \\
\hline 24 & & & 1 & & & & \\
\hline 31 & & & 16 & 2 & LTF et LTM? & 76 & 77 \\
\hline 38 & & & 27 & 3 & LTF & & $78,80,85$ \\
\hline 39 & & & 4 & & GR et LTF & & \\
\hline 40 & 1021 & & 7 & 1 & LTM? & 93 & \\
\hline 42 & 1023 & & 9 & 1 & LTF & & 97 \\
\hline 43 & & & 11 & 1 & LTM & 98 & \\
\hline 54 & & & 1 & & & & \\
\hline 61 & & & 1 & & & & \\
\hline 77 & & & 5 & & & & \\
\hline 95 & & 1 & 2 & & & & \\
\hline 97 & & & 5 & 1 & LTF & & 107 \\
\hline 98 & & & 4 & & & & \\
\hline 104 & & & 2 & & & & \\
\hline 107 & & & 1 & & & & \\
\hline 115 & & & 1 & & & & \\
\hline 122 & & 1 & 1 & & LTF & & 113 (fond) \\
\hline 133 & & & 17 & 1 & LTM? & 114,118 (fond) & \\
\hline 144 & & & 8 & & & & \\
\hline 153 & & & 1 & & MODERNE & & \\
\hline 156 & & & 1 & 1 & LTF & & 122 \\
\hline 161 & & & 1 & & & & \\
\hline 162 & & & 14 & & & & \\
\hline 178 & & & 7 & & & & \\
\hline 190 & 1042 & & 1 & & & & \\
\hline 195 & & & 3 & & & & \\
\hline 199 & & & 2 & & GR & & \\
\hline 203 & & & 1 & 1 & LTM & 132 & \\
\hline 205 & 1046 & & 2 & & & & \\
\hline 206 & 1045 & & 49 & 2 & LTF & & 135,136 \\
\hline 209 & & 1 à 7 & 40 & 3 & LTM? & $137,138,139$ & \\
\hline
\end{tabular}




\begin{tabular}{|c|c|c|c|c|c|c|c|}
\hline FAIT & SOND & US & NT & NMI & DATATION & Lots LTM & Lots LTF \\
\hline 216 & & & 2 & & & & \\
\hline 218 & & & 1 & & & & \\
\hline 233 & & & 2 & & & & \\
\hline 237 & & & 1 & & & & \\
\hline 238 & & & 1 & & & & \\
\hline 239 & & & 4 & & & & \\
\hline 240 & & & 2 & & & & \\
\hline 247 & & 1 & 100 & 3 & LTF & & $147,148,149$ \\
\hline 251 & & & 9 & & & & \\
\hline 253 & & & 2 & 1 & LTM? & 155 & \\
\hline 254 & & & 15 & & & & \\
\hline 255 & 1056 & & 12 & 2 & LTF & & 162 \\
\hline 257 & & & 39 & 1 & LTM? & $161 / 164,163$ & \\
\hline 258 & & & 1 & 1 & LTM? & 165 & \\
\hline 266 & & & 2 & 1 & LTM? & 166 & \\
\hline 273 & & & 4 & & HMA et LTF & & 170 \\
\hline 274 & & & 36 & 2 & LTF & & 173,175 \\
\hline 275 & & & 2 & & & & \\
\hline 277 & & & 3 & & & & \\
\hline 279 & & & 1 & & & & \\
\hline 281 & & & 11 & 1 & LTF & & 182 \\
\hline 282 & & & 1 & & & & \\
\hline 284 & & & 2 & & & & \\
\hline 287 & & & 1 & 1 & LTM? & 186 & \\
\hline 288 & & & 1 & & & & \\
\hline 289 & & & 1 & & & & \\
\hline 292 & & & 24 & 1 & LTF & & 198 \\
\hline 293 & 1062 & & 2 & 1 & LTF & & 199 \\
\hline 309 & & & 37 & 2 & LTM & 200,201 & \\
\hline 312 & & & 4 & 1 & LTM ? & 202 & \\
\hline 327 & & & 2 & & & & \\
\hline 331 & & & 1 & & & & \\
\hline 335 & & & 24 & 2 & LTF & & 207,209 \\
\hline 339 & & & 5 & 2 & LTF & & 210,211 \\
\hline 345 & & & 4 & 1 & LTF & & \\
\hline 346 & & & 4 & 2 & LTF & & 215,217 \\
\hline $354 / 366$ & & & 10 & 3 & LTF & & $218,219,220$ \\
\hline 354 & 1086 & & 2 & & LTM & 221 (fond) & \\
\hline 356 & & & 6 & & & & \\
\hline 358 & & & 6 & 1 & LTM? & 224 & \\
\hline 359 & & & 1 & & & & \\
\hline 361 & & & 1 & & & & \\
\hline 367 & & & 61 & 5 & LTF et LTM? & 229 & $\begin{array}{c}227,228,231, \\
232\end{array}$ \\
\hline TOTAL & & & 1026 & 81 & & & \\
\hline
\end{tabular}

Tableau 1 : Répartition chronologique du mobilier par faits.

Table 1: Chronological distribution of artefacts.

à ce que le lissage complet ou partiel des céramiques, qui masque ainsi les traces de tournage, limite la portée des observations. Ces chiffres militent pour une datation de la fin de La Tène pour les vases concernés. Le modelage, marginal, ne touche que $8,85 \%$ des vases. Il concerne des pots (lots 17, 62) et des formes basses de type écuelle (lot 33). 
Cette mise en forme concerne surtout les vases appartenant aux premières phases d'occupation du site.

\section{Le répertoire typologique}

Nous nous sommes appuyés sur les résultats des études précédentes menées dans la région proche afin de permettre une meilleure approche comparative des mobiliers mayennais (Naveau, 1975-1983; Bouvet, 1997; Cherel, 1999; Vauterin, 1999; Coffineau, 2006; Mortreau, 2007 et à paraître). L'examen des lots céramiques (formes et décors) a permis de séparer en deux lots distincts le mobilier céramique. Un premier lot est constitué de céramique relevant plutôt de La Tène moyenne, un second est attribuable à La Tène finale lato sensu.

\section{Les formes basses ouvertes de La Tène moyenne (fig. 12 et 13)}

On distingue tout d'abord les écuelles. Peu nombreuses, elles montrent une paroi oblique (lot 23) et peuvent aussi offrir un bord rentrant (lot 33). Ces formes modelées sont régulièrement attestées dans la région en contexte de La Tène moyenne. Les jattes, assez abondantes, comprennent des nombreuses formes carénées. La jatte à carène sinueuse (lot 71) correspond au type Gaudine 12 (Cherel, 1999). Un parallèle local peut aussi être trouvé sur le site d'Entrammes, La Carie II, dans l'horizon laténien 1 moyen (Coffineau, 2006, Pl. 25, vase 113). Les jattes à carène basse et profil en " $S$ " sont de loin les mieux représentées dans les ensembles étudiés (lots 73, 30, 3 et 221). Elles présentent un col court et un bord en bourrelet creusée d'une cannelure labiale interne. Le profil de ces jattes associé à la présence d'un fond annulaire caractérise la période de La Tène moyenne. Une autre jatte (lot 1) montre un bord oblique terminé par une lèvre épaissie externe. Le haut de la panse se pare d'un décor de bandes obliques lissées. Enfin, on trouve une dernière jatte à carène haute à col concave épaissi interne s'achevant par un bord en bourrelet. La liaison col/panse est marquée par une cannelure et le bas de la panse est orné d'un décor de bandes en croisillons lissées (lot 137). Enfin, une dernière jatte se singularise par un bord droit, fini par un bourrelet saillant externe et une panse hémisphérique semble constituer un prototype du fameux « bol mayennais » (lot 26).

\section{Les formes hautes de La Tène moyenne (fig. 12 à 14)}

Le premier type rencontré est un pot à col tronconique à bord droit épaissi externe. Un premier modèle, façonné à la main, offre une large cannelure labiale interne (fig. 12, lot 201). Le second pot est caractérisé par une large moulure à la liaison col/panse (fig. 13, lot 229). Le second type est un pot à bord droit, col tronconique et panse carénée biconique (lot 17). Ce vase, modelé, avec un décor peigné soulignant le dessus de la carène, présente un bord cassé et retaillé. Il peut s'agir d'un vase plus ancien qui a connu une seconde vie. La datation proposée (La Tène moyenne) peut être vieillie au regard de ces observations (La Tène ancienne?). Le troisième type est un pot à col concave et bord en bourrelet à cannelure interne labiale et moulure à la liaison col/panse. Les éléments décoratifs ainsi que la présence d'une enduction de graphite sur le col militent pour une datation de La Tène moyenne (lot 98). Le quatrième type est constitué d'un pot globulaire ou piriforme à col court droit et bord en bourrelet avec cannelure interne labiale et moulure sur la panse (lot 138). Attesté seulement par sa partie supérieure, ce vase unique de grande taille peut être rapproché d'une forme connue en Bretagne sur la ferme du Boisanne, à Plouër-surRance, Côtes-d'Armor (Menez, 1996, Pl. 10, pot 100A.3) et aussi à Athée, La Glannerie (Meuret, 2001). Une datation de La Tène moyenne est envisageable. Le cinquième type rassemble un nombre de vases caractérisés par un col oblique.

Le premier pot ovoïde présente un bord déjeté en bourrelet saillant. L'intérieur de la lèvre est marqué par trois fines cannelures (lots 161/164). Un deuxième pot ovoïde montre un bord déjeté en bourrelet avec une cannelure labiale interne et une panse décorée de chevrons lissés (lot 114). Régionalement, cette forme est connue à Vivoin (type Gaudine 21A) et à Oisseau-le-Petit, dans la Sarthe. Un troisième pot se signale par un bord en bourrelet saillant externe (lot 163). Un quatrième pot ovoïde à bord en bourrelet à cannelure interne labiale et cannelure sur la panse offre un remarquable décor fait d'une série de baguettes parallèles sur la panse (fig. 14, lot 155). Un cinquième pot ovoïde (ou gobelet?) présente un haut col oblique, un bord déjeté avec cannelure sur la panse (lot 12). Une forme comparable de taille plus imposante existe sur le site de La Gaudine, à Vivoin dans la Sarthe où elle est considérée comme exceptionnelle (Maguer et al., 2003, fig. $9 \mathrm{n}^{\circ}$ 13). Un dernier pot offre un bord oblique à cannelure interne labiale. La panse biconique s'orne d'un décor de " $S$ » estampés en deux registres superposés. Le contexte de découverte permet d'attribuer ce vase à La Tène moyenne (lot 200). Il est connu en Sarthe en contexte similaire mais sans décor (type Oisseau 10).

Plusieurs pots ne sont attestés que sous la forme d'un col concave et une cannelure labiale interne (lots 132, 76, 186, $166,202,165$ et 139). La grande fragmentation de ces vases ne permet pas de les rattacher à un type précis.

Enfin, on trouve les vases à réserve caractérisés par un grand diamètre à l'ouverture. Un premier vase n'est conservé que par un bord concave en bourrelet saillant interne (lot 93). Le profil d'un second vase, très fragmentaire, a pu toutefois être restitué : il s'agit d'un grand pot ovoïde à col 


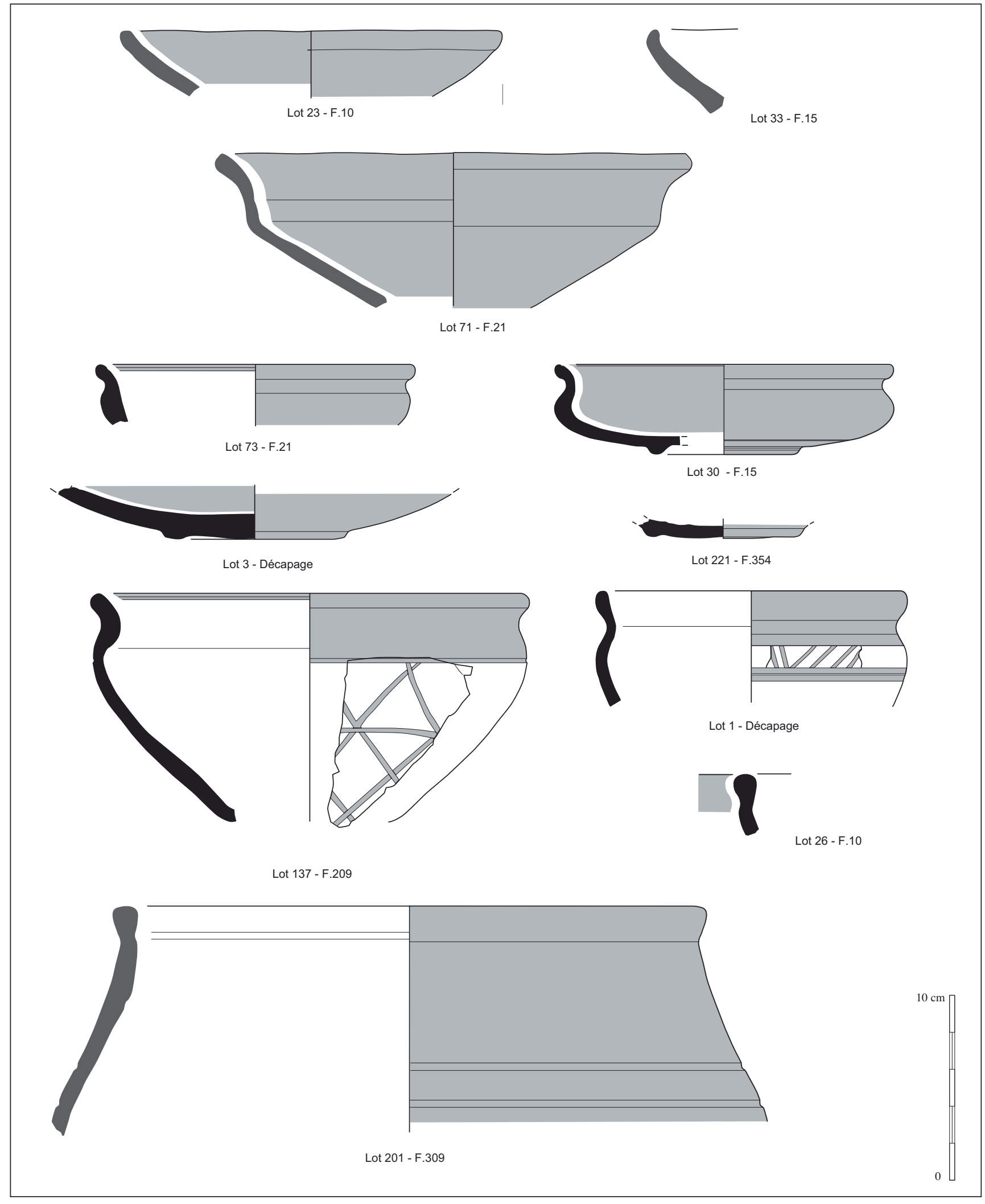

Figure 12 : Le mobilier céramique de La Tène moyenne : les écuelles, les coupes, jattes carénées et pots. Figure 12 : Pottery dating from the middle of the La Tène period: bowls, dishes, carenated bowls and pots. 


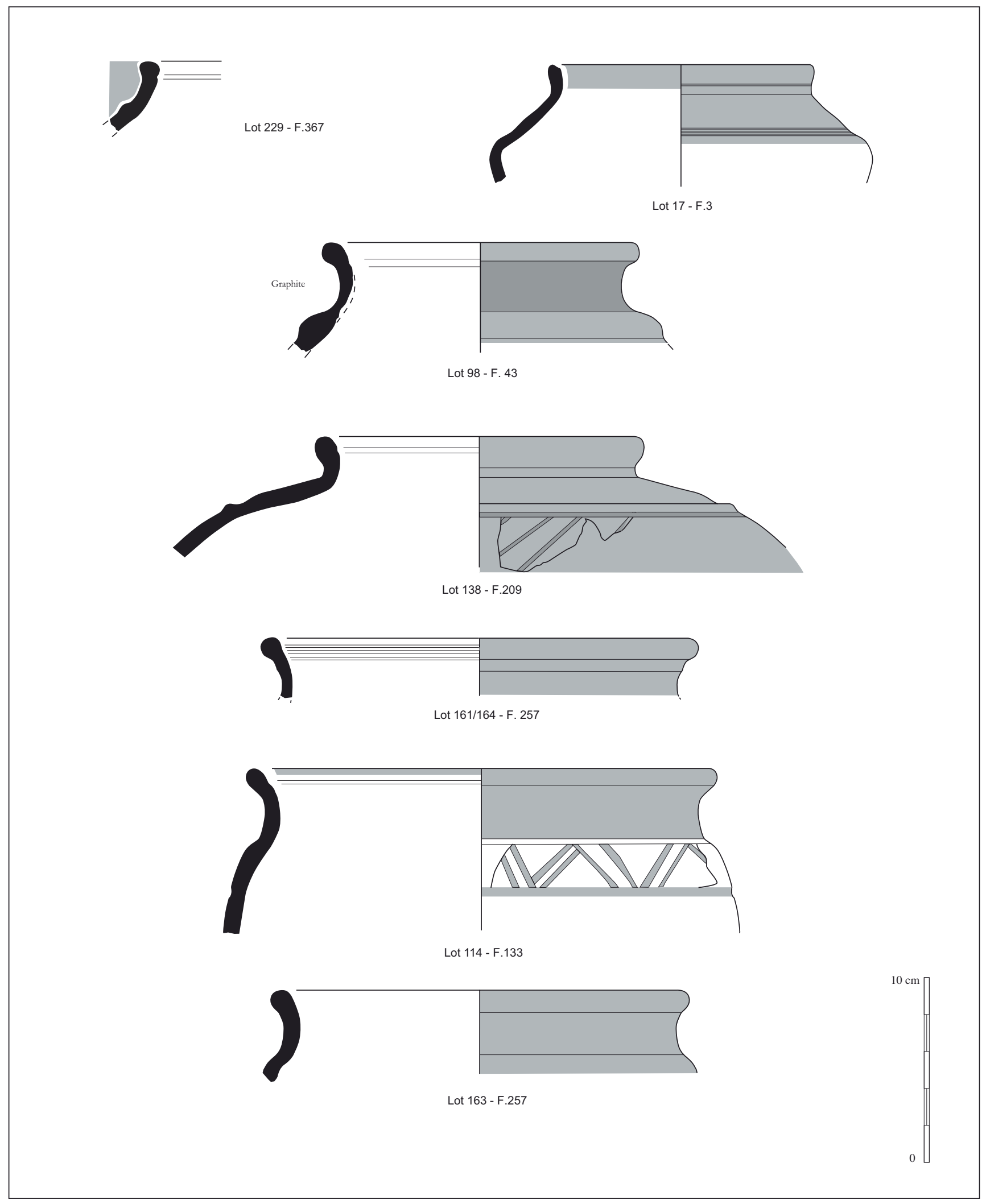

Figure 13 : Le mobilier céramique de La Tène moyenne : les pots. Figure 13: Pottery from the middle of the La Tène period: pots. 


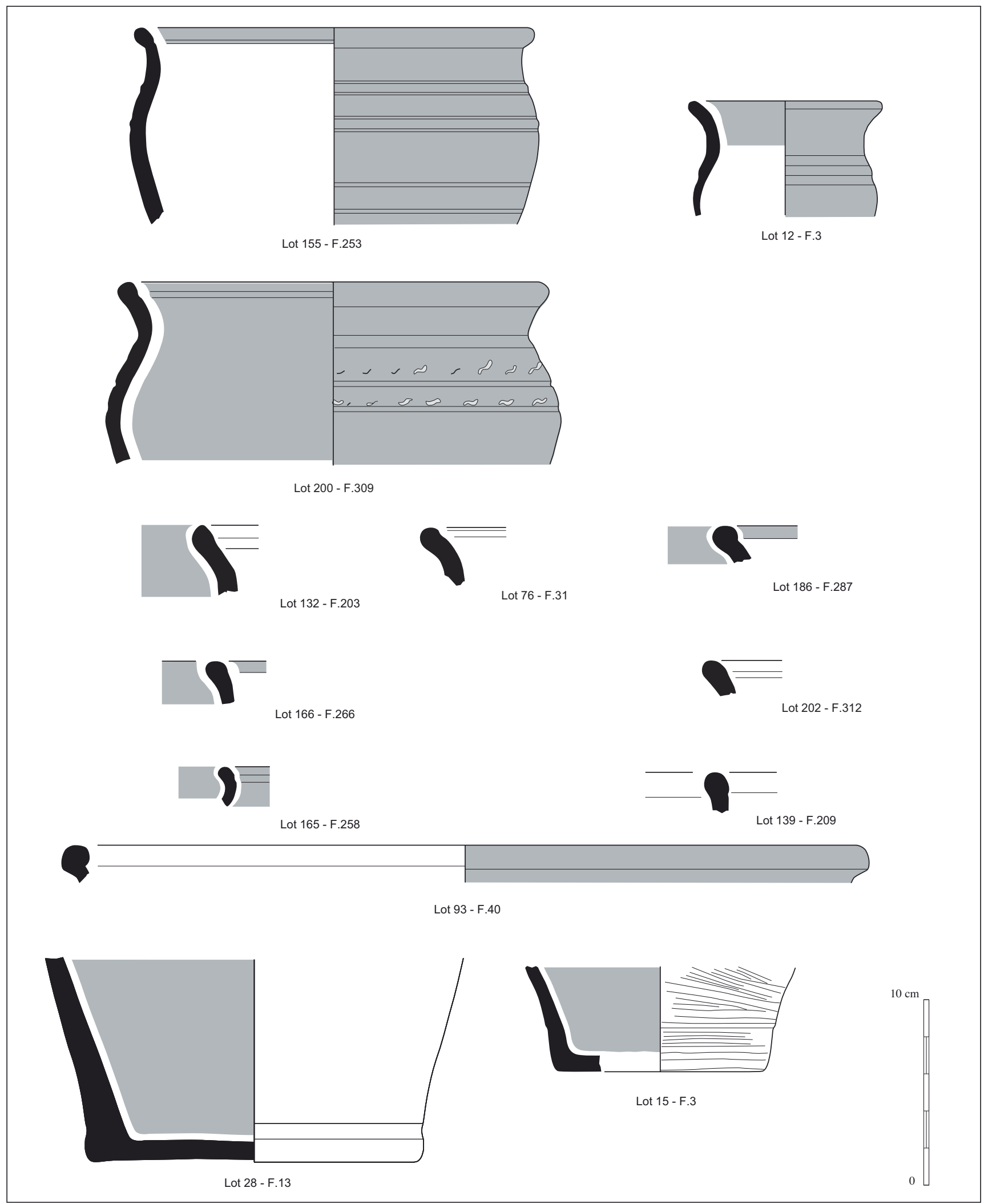

Figure 14 : Le mobilier céramique de La Tène moyenne : les pots. Figure 14: Pottery from the middle of the La Tène period: pots. 
droit, bord déjeté avec cannelure labiale interne et fond plat et offrant un ressaut à la liaison col/panse (fig. 15, lot 21). De même, un certain nombre de bords fragmentés de grand diamètre peut être mis en relation avec des vases occupant une telle fonction (lots 139, 166 et 186) ainsi qu'un fond présentant un grand diamètre (lot 28). Ce type se rencontre localement en Mayenne à Jublains, Taillis des Boissières dans une fosse de tisserand datée de La Tène Moyenne (Mortreau, à paraître). Régionalement, cette forme est connue dans la Sarthe sous l'appellation Gaudine 21a ou Oisseau 15.

\section{Les formes basses ouvertes de La Tène finale (fig. 15 à 17)}

On trouve tout d'abord les jattes tronconiques à bord rentrant et bourrelet saillant externe. Ce type bien représenté à Aron (fig. 15, lots 217, 43 et fig. 16, lots 42, 218 et 5) qui présente une cannelure sous la lèvre formant une moulure à la liaison avec la panse peignée correspond à la description du fameux « bol mayennais ». Il est attribué généralement à La Tène finale. Une variante est attestée par un exemplaire (lot 224) dont un parallèle a été observé sur le site d'Entrammes, La Carie II (Coffineau, 2006, Pl. 26, vase 17).

Les jattes tronconiques à bord rentrant anguleux (lot 44) présentent quelques traits similaires au type précédent. On observe la présence non systématique d'une cannelure interne labiale ainsi qu'un peignage de la surface externe. La céramique issue des sondages de diagnostic de la future déviation de Moulay-Mayenne, au pied de l'oppidum du Mesnil, (Valais, 2004, fig. 29; sondage 704, $\mathrm{n}^{\text {os }} 13$ à 16) présente les mêmes détails morphologiques au niveau de la lèvre. Ce trait constitue un indice sérieux pour une production locale. Une forme proche existe en Sarthe à Vivoin sous le type Bildoux 3b (Vauterin, 1999) et à Oisseau-le-Petit (Mortreau, 2007) mais avec un bord plus droit.

Les jattes carénées peuvent être divisées en plusieurs sous groupes. Tout d'abord les jattes à carène haute et à profil en " $S$ » : elles peuvent être à col concave, bord en bourrelet, cannelure labiale interne et liaison col/panse marquée par une moulure figurée par le lot 135 (fig. 17), à col droit et liaison col/panse marquée par une moulure (lot 97) - forme connue dans la Sarthe, à Yvré-l'Évêque, en contexte de La Tène D1 (Mortreau, 1999) - et à col concave et liaison $\mathrm{col} /$ panse marquée par une moulure (lot 77). Cette dernière forme est répertoriée sous le type Bildoux 1b, à Vivoin et est également présente au Camp de Saint-Symphorien à Paule, Côtes-d'Armor, dans le deuxième ensemble attribué à la charnière $\mathrm{II}^{\mathrm{e}} / \mathrm{I}^{\mathrm{er}}$ av. J.-C. (Menez, 2001, Pl. 2, n ${ }^{\circ}$ 5). Les jattes ou bols à carène douce comportent souvent des décors. Le premier type s'orne d'un décor de cannelures parallèles (lot 136) et le second d'un décor de baguettes (lot 40). Une évolution est discernable pour ce dernier type. À La Tène
$\mathrm{D} 2$, on remarque que la carène est plus marquée (Bouvet, Mortreau, 1998).

\section{Les formes hautes de La Tène finale (fig. 18 à 21)}

Une première série regroupe des pots ovoïdes à petit col concave bord oblique ou en bourrelet épaissi interne à cannelure labiale interne ainsi que sur le haut de la panse (fig. 18, lots 175, 49, 149, 219, 56 et fig. 19, lots 198, 68 et 85$)$. Ces pots généralement datés de La Tène finale trouvent de nombreux parallèles dans la littérature archéologique locale comme au Clos-Henry, à Château-Gontier (Valais et al., 2008, fig. 12, $\mathrm{n}^{\circ} 1$ ).

Une seconde série rassemble les pots ovoïdes à col oblique et bord en bourrelet incisé d'une fine cannelure dont la liaison col/panse s'orne parfois d'une baguette (lots 162, 147 et fig. 20, lot 148). La fouille menée en 1972 sur l'oppidum de Moulay a permis de recueillir un vase semblable dans un contexte de La Tène finale (Boissel, Diehl, Naveau, 1972, p. 23, JKLM-2).

Une troisième série réunit les pots ovoïdes dont la particularité est de présenter un col concave. Il peut s'orner d'une fine cannelure labiale interne (lot 39), son profil peut être épais en S (lot 107) avec une cannelure sur la panse (lot 62). Un vase au profil proche a été mis au jour sur le site de La Gaudine à Vivoin (Maguer et al., 2003, fig. 9, n 2). Il peut aussi avoir une lèvre arrondie (lot 210), un bord déjeté et une moulure à la liaison col/panse (lot 80 ) avec une panse aux stries de peignage marquées. Un pot semblable à ce dernier a été découvert à Oisseau-le-Petit (Mortreau, 2007, fig. 28, CE 221). Un type de pot ovoïde à col droit, bord en bourrelet, cannelure interne labiale et baguette à la liaison col/ panse (lots 209, 215) est connu localement à Entrammes, La Carie II (Coffineau, 2006, Pl. 21, vase 104). Très fragmentaires, attestés seulement par des fragments de bords, on trouve des pots à col concave et cannelure labiale interne (fig. 21, lots 228, 37) ou à col concave sans décoration (lot 231). Un pot de petite dimension à col concave, avec un ressaut à la liaison col/panse, et décoré d'une baguette à la base de la panse se signale par l'emploi d'une argile riche en inclusions de type bioclastes différente de celle rencontrée sur le reste du site (lot 232). Deux autres fragments de bords épaissi interne (lot 63) ou oblique (lot 122) appartiennent à des formes de pots indéterminés.

Une quatrième série n'est documentée que par un exemplaire unique de pot ovoïde à bord oblique épaissi interne (lot 220). Un fragment de bord droit épais à lèvre arrondie pourrait s'y rattacher éventuellement (lot 170).

Une cinquième série rassemble des vases inclassables du fait de leur état de conservation. Dans cette catégorie rentre un col droit et bord en bourrelet saillant (lot 59). L'allure générale d'un fragment de col droit et bord épaissi, interne 


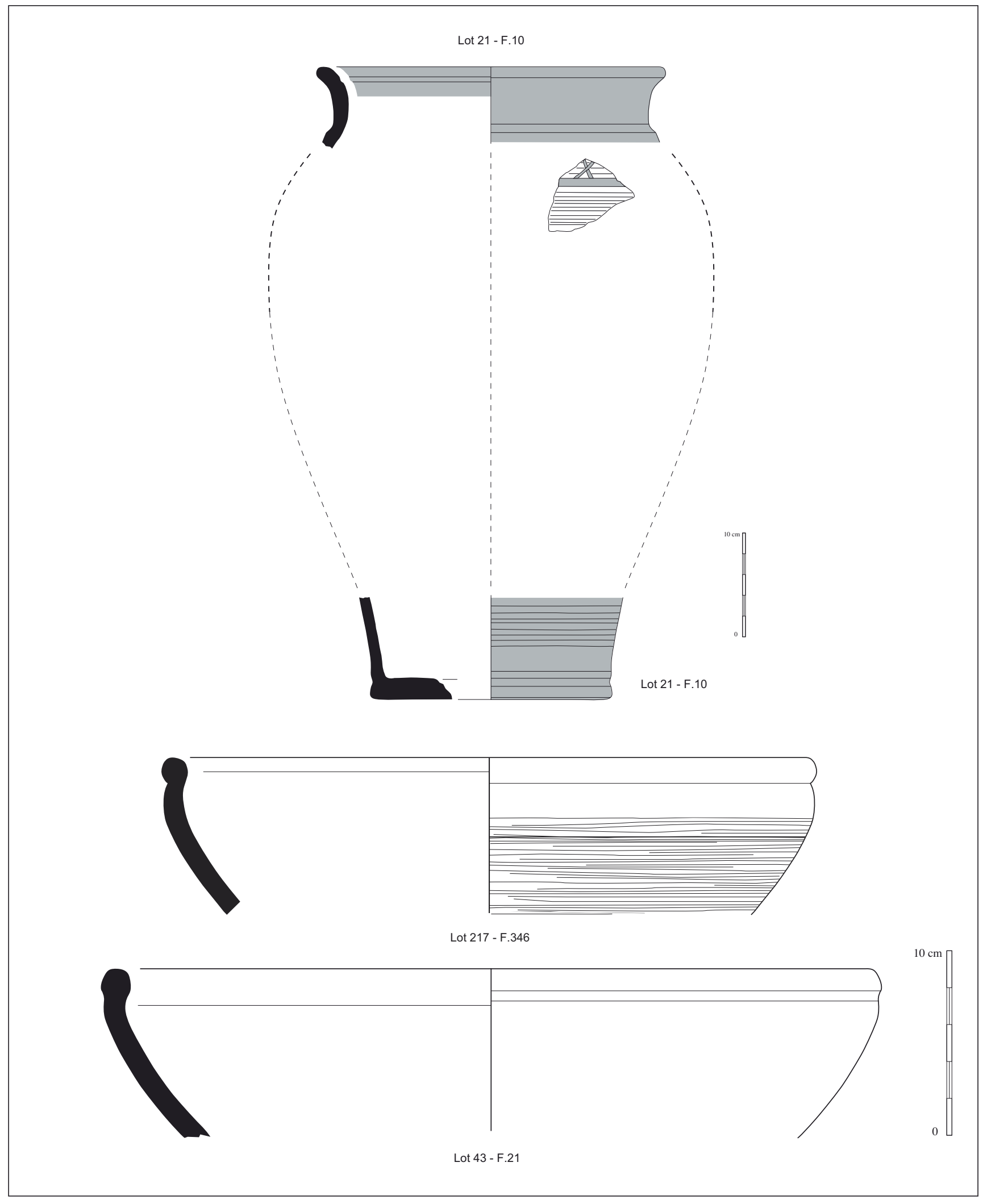

Figure 15: Le mobilier céramique de La Tène moyenne : les pots; le mobilier de La Tène Finale : les coupes. Figure 15: Pottery from the middle of the La Tène period: pots; pottery from the Late La Tène: dishes. 

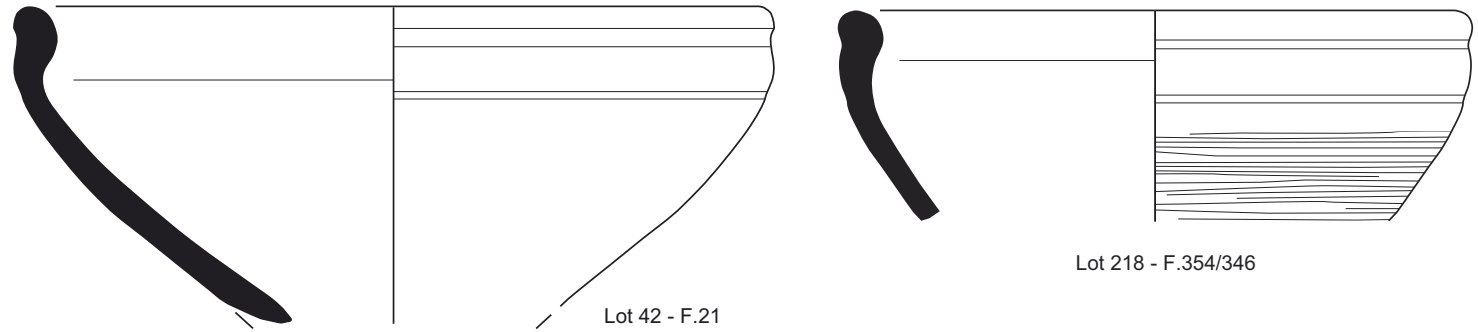

Lot 218 - F.354/346

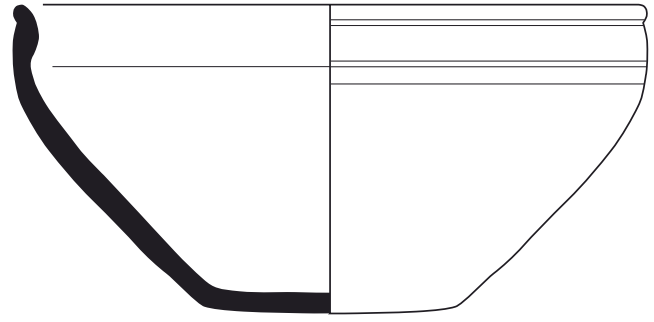

Lot 5 - F.1

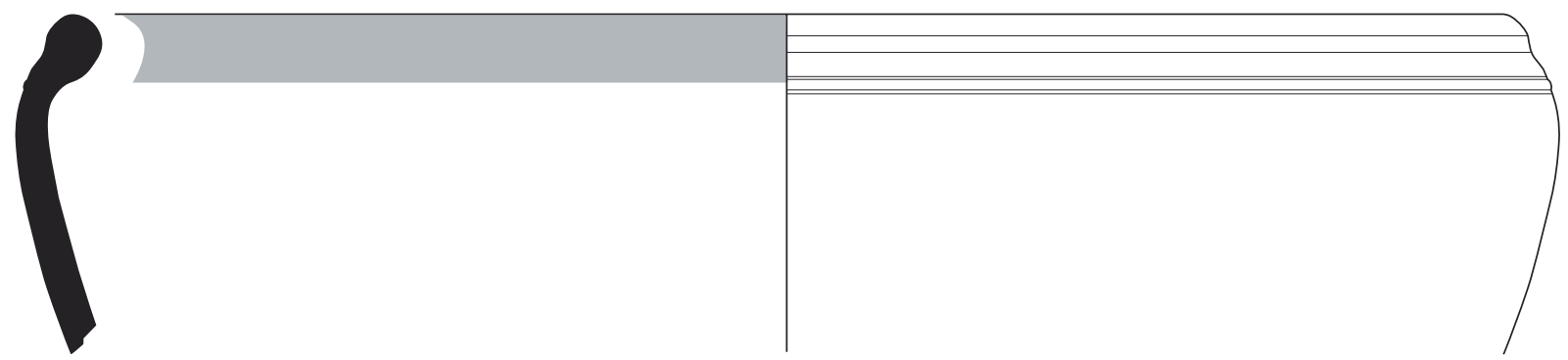

Lot $224-F .358$

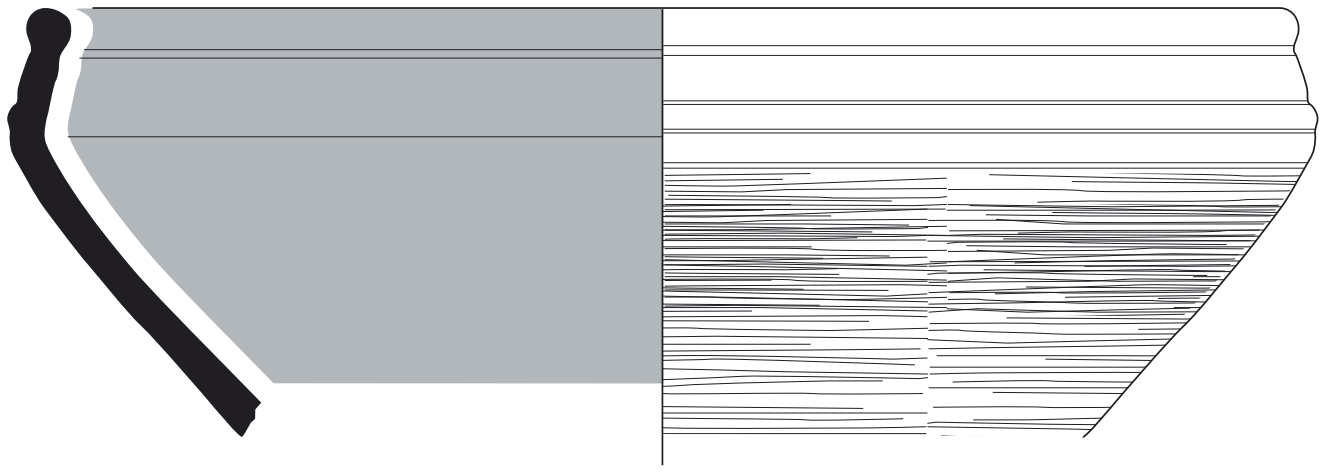

Lot 44 - F.21

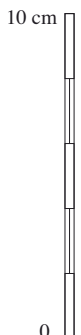

Figure 16 : Le mobilier céramique de La Tène finale : les coupes.

Figure 16: Pottery from the Late La Tène: dishes. 


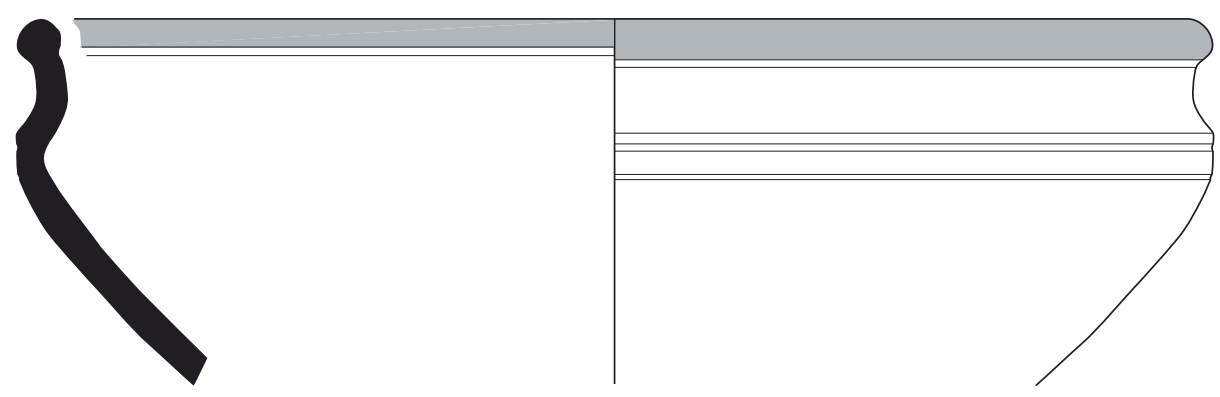

Lot $135-$ F.206

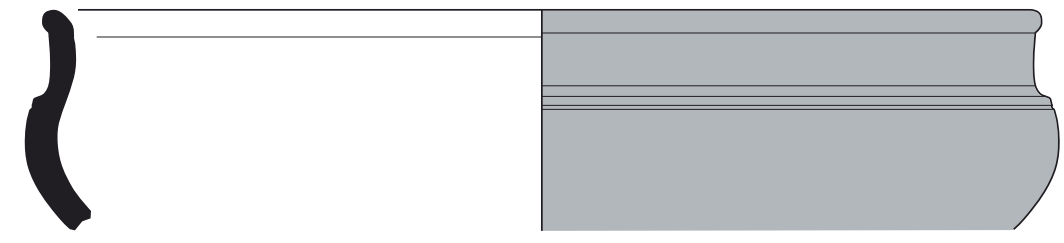

Lot $97-\mathrm{F} .42$

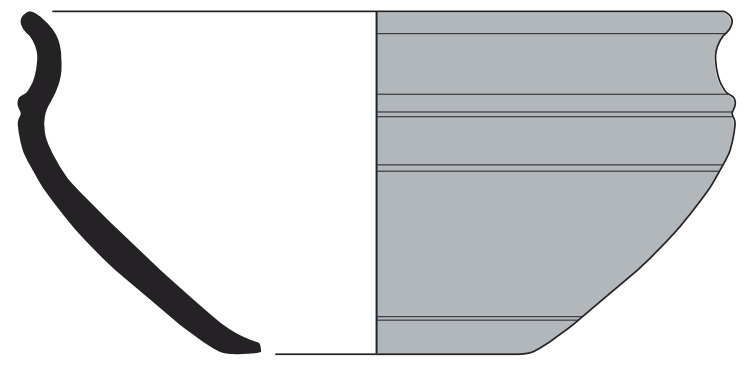

Lot 77 - F.31

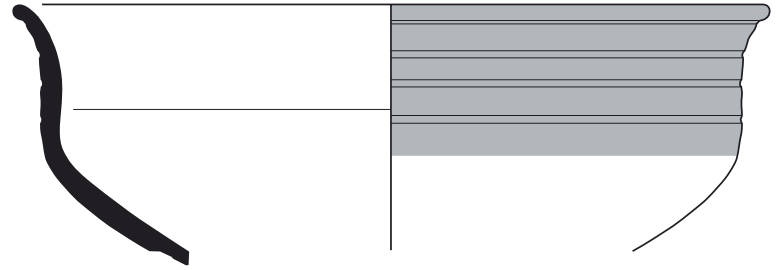

Lot 136 - F.206

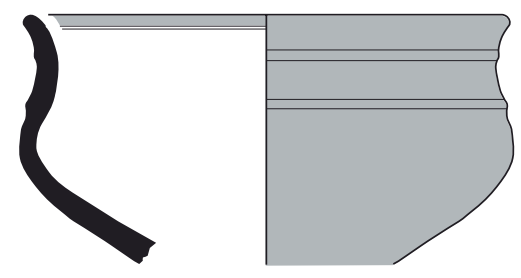

Lot 40 - F.21

Figure 17 : Le mobilier céramique de La Tène finale : les coupes et les bols.

Figure 17: Pottery from the Late La Tène: dishes and bowls. 


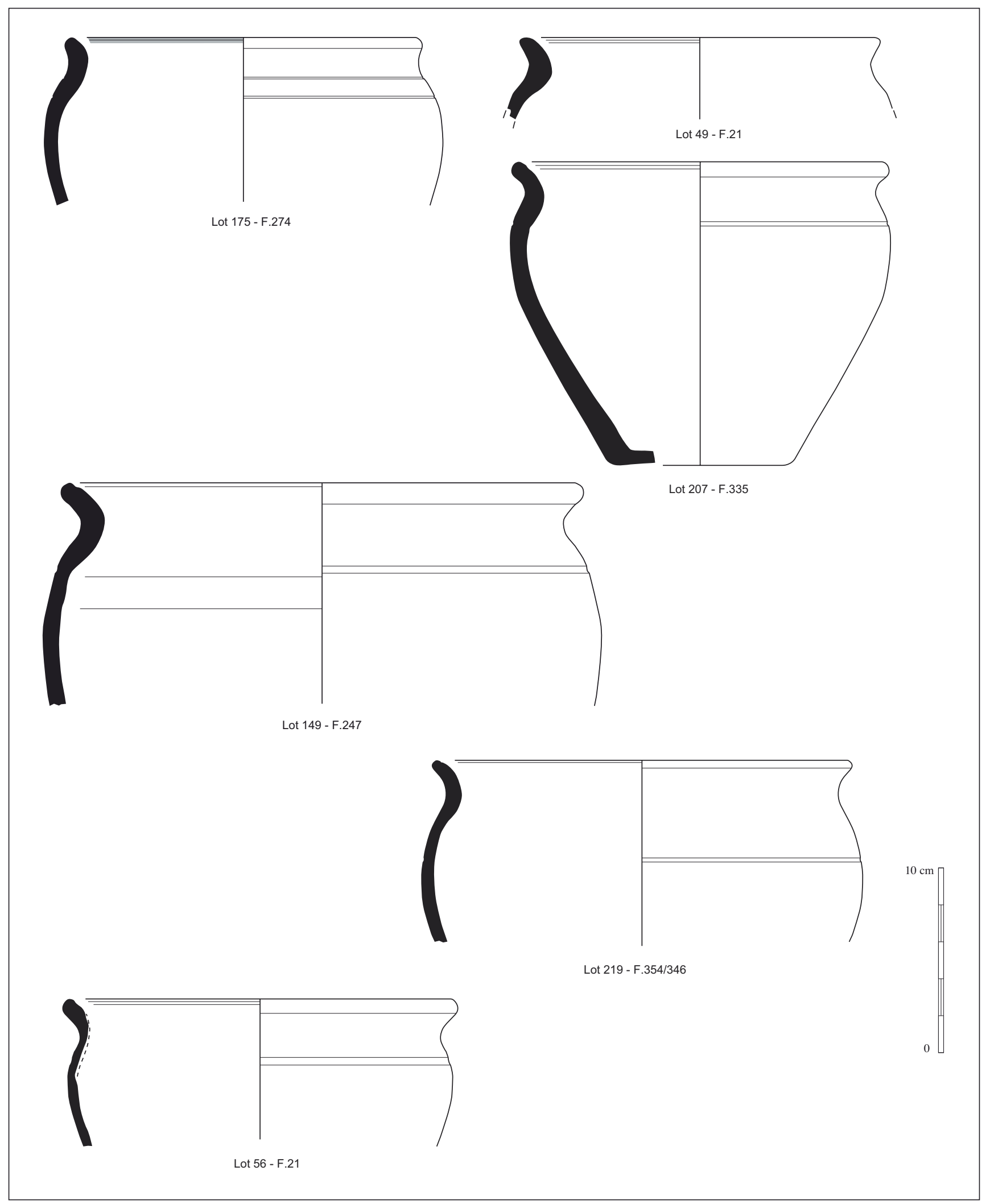

Figure 18 : Le mobilier céramique de La Tène finale : les pots.

Figure 18: Pottery from the Late La Tène: pots. 


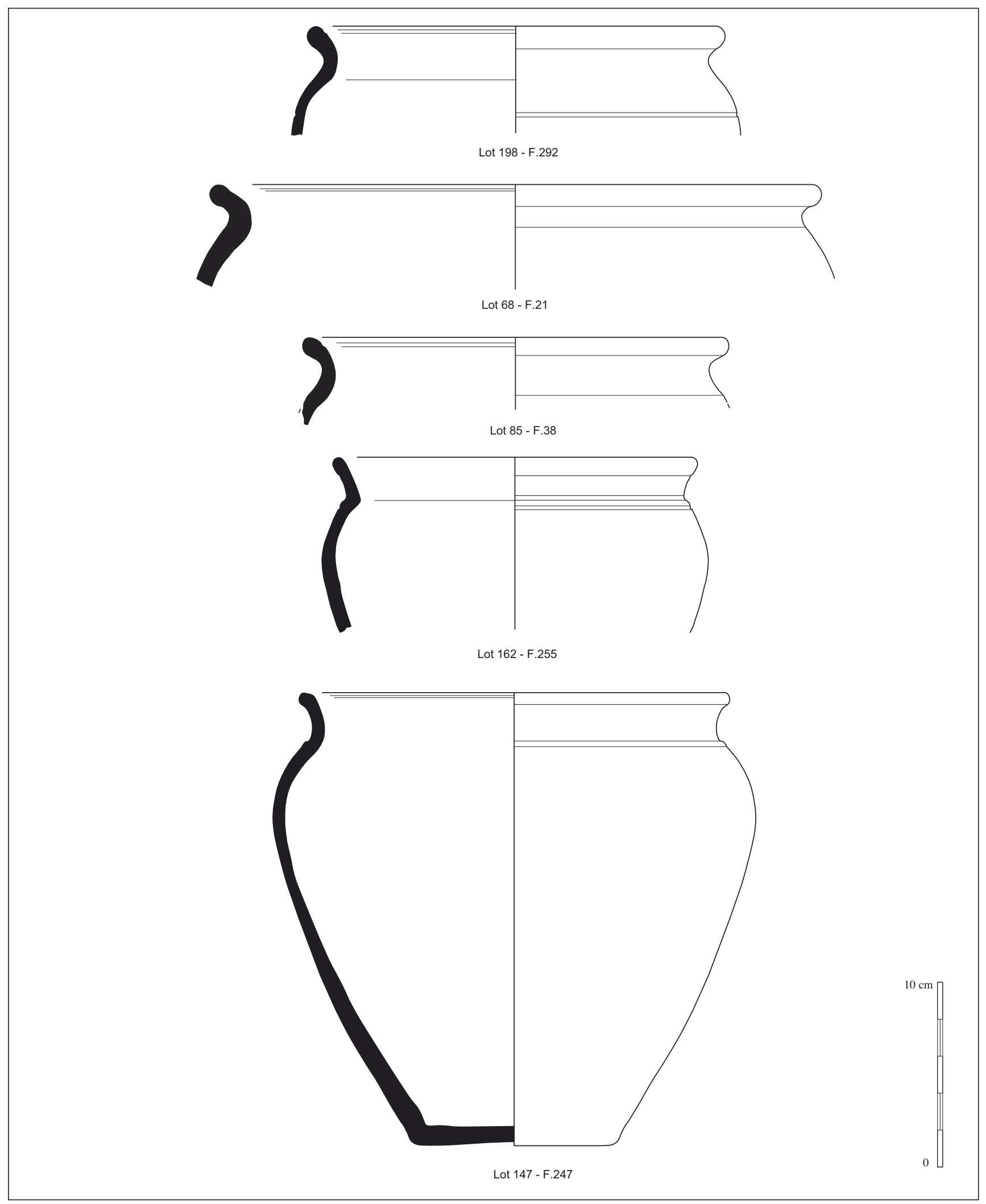

Figure 19 : Le mobilier céramique de La Tène finale : les pots.

Figure 19: Pottery from the Late La Tène: pots. 


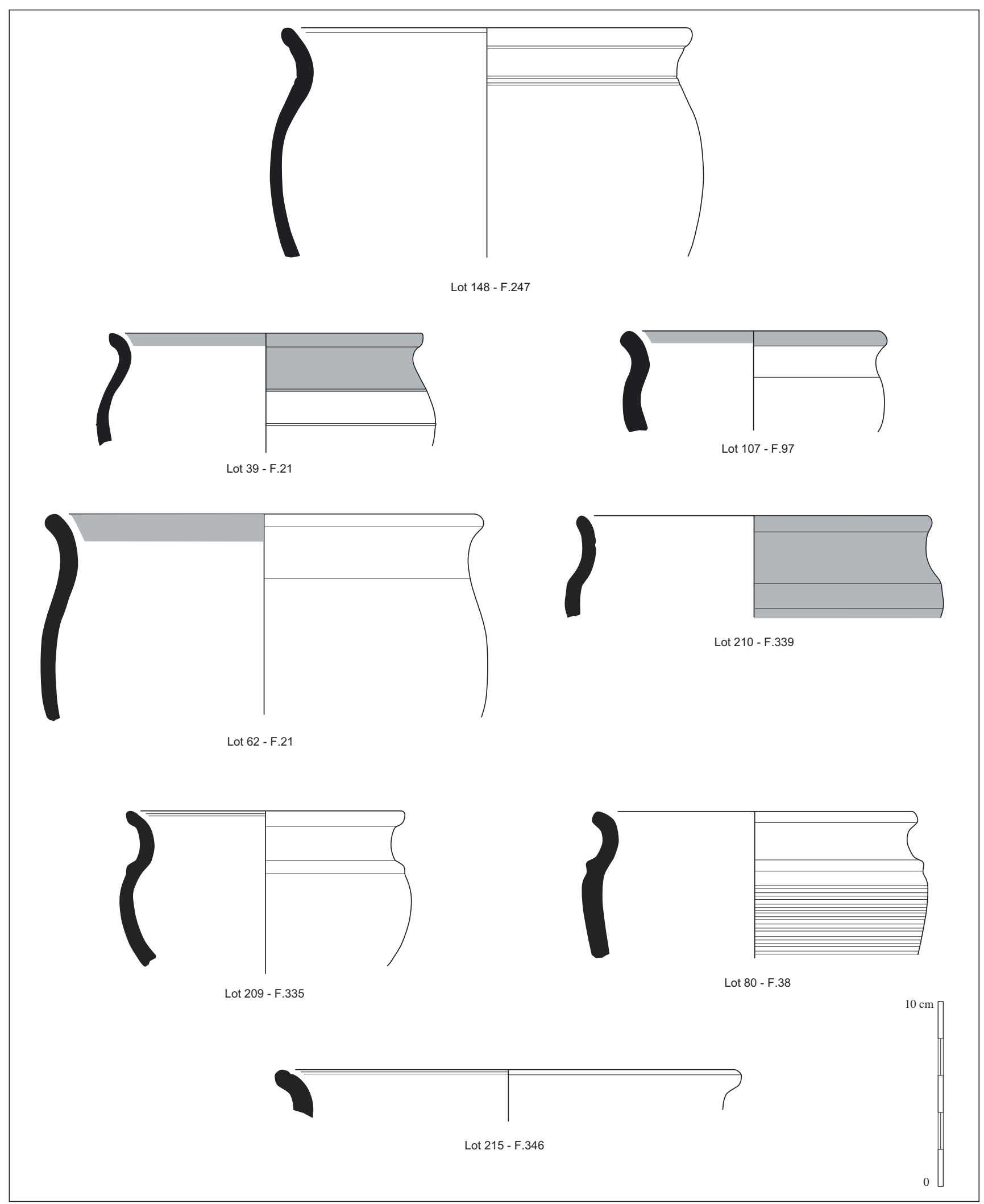

Figure 20 : Le mobilier céramique de La Tène finale : les pots.

Figure 20: Pottery from the Late La Tène: pots. 


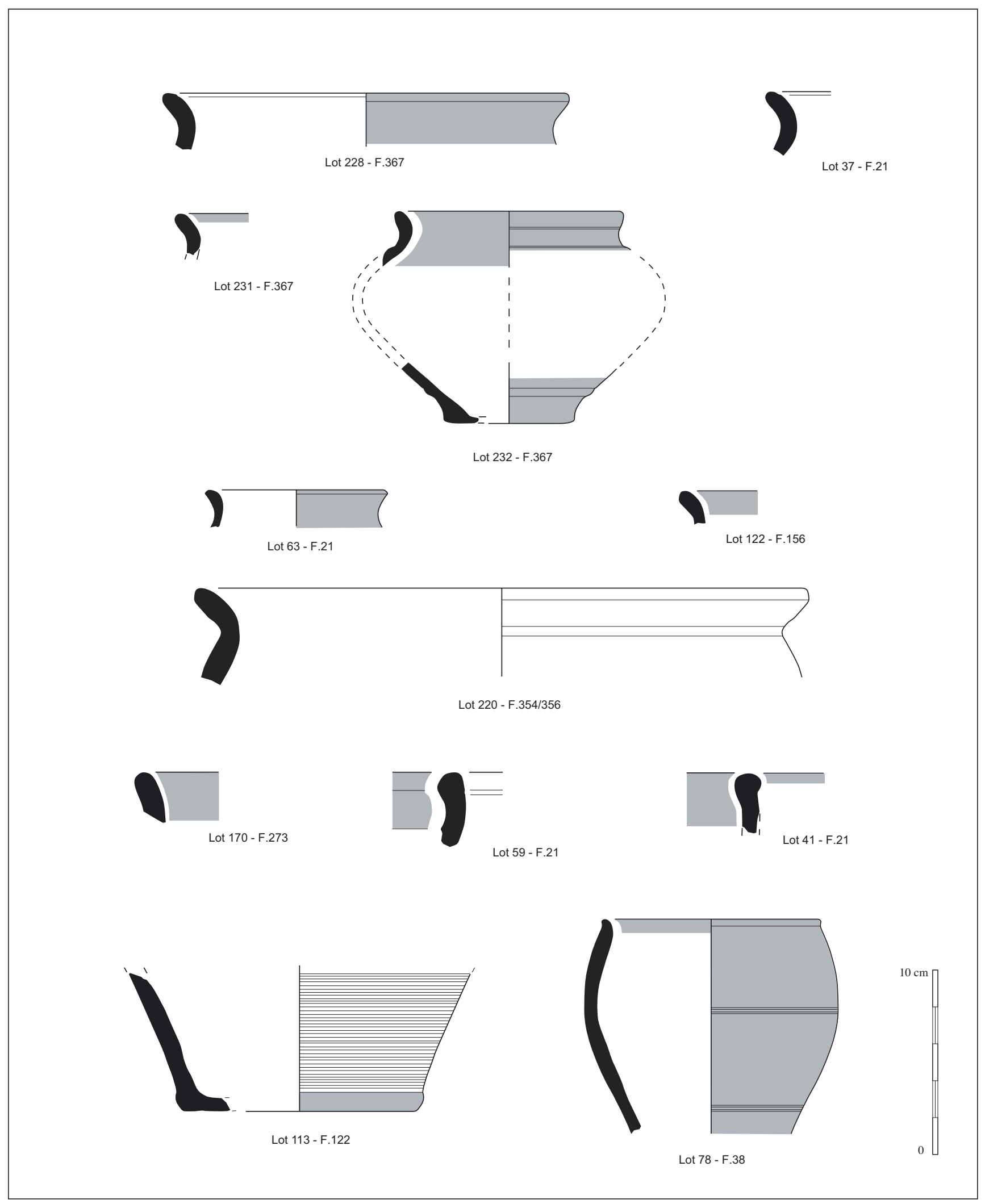

Figure 21 : Le mobilier céramique de La Tène finale : les pots et les gobelets. Figure 21: pottery from the Late La Tène: pots and goblets. 
pourrait le rapprocher des grands vases de stockage connus pour la période précédente (lot 41).

Enfin, on recense une rare forme de vase tonnelet (ou gobelet tonneau) à panse ovoïde (lot 78). Cette forme s'est rencontrée sur le site du Clos-Henry (Valais et al., 2008, fig. $14 \mathrm{n}^{\circ}$ 18). À Yvré-l'Évêque, dans la Sarthe, ce type apparaît dans un contexte de La Tène D1 (Mortreau, 1999).

\section{Considérations sur la répartition des différents types}

Même si on doit garder à l'esprit le caractère partiel du corpus documentaire à notre disposition, insuffisant pour asseoir une étude statistique valable, on peut toutefois émettre quelques remarques générales qui seront à confirmer lors de prochaines études.

Quantitativement, les formes hautes l'emportent légèrement sur les formes basses ou moyennes : sur les 81 individus bords ou formes archéologiquement complètes recensés, on compte pour La Tène moyenne, 8 formes basses ou moyennes ouvertes (assiettes ou bols/coupes/jattes), 15 formes hautes fermées ( 12 pots, un gobelet et 2 vases de stockage) et 7 formes indéterminées (la trop grande fragmentation des vases réduits au seul rebord n'autorise pas de discrimination valable). Pour la période de La Tène finale, on recense 20 formes moyennes ouvertes (bols/coupes/jattes) contre 31 formes hautes fermées (30 pots et un gobelet). En général, les formes basses et moyennes sont un peu moins nombreuses que les formes hautes. Parmi celles attribuées à La Tène finale, on remarque la surreprésentation d'une forme de bol ou de jatte propre au territoire diablinte : le bol mayennais (Bouvet, 1997; Bouvet, Le Goff, 1999).

Une forme exceptionnelle de pot (?) très fragmentée montre une pâte particulièrement fine de couleur rouge à surface noire lissée. Elle se signale également par l'emploi d'un dégraissant à base de coquilles fossiles de type bioclastes. Le type a déjà été rencontré à Entrammes, La Carie II (Coffineau, 2006, Pl. 19, nº 31).

Par rapport au site sarthois d'Oisseau-le-Petit, on constate la rareté des gobelets. Par contre, le pot à cuire est largement prépondérant dans le domaine des formes hautes fermées que ce soit pour La Tène moyenne ou finale.

$\mathrm{Si}$ les formes de stockage de type dolium à bord épais, col court concave, de grand diamètre sont absents de notre contexte d'étude, il apparaît qu'un autre type les remplace à La Tène moyenne. Il s'agit de vases de grand diamètre, à grand col concave et à la panse parfois décorée de motifs lissés. Ces vases existent avec des anses dans les contextes bretons, comme sur la ferme du Boisannne où ils semblent remplir la même fonction que les dolia précités (Menez, 1996).

Si on compare ces données à une étude récente (Mortreau, 2007), on note des résultats divergents. Pour Oisseau-le-
Petit, sur un total de 1193 individus, la moitié des types, voire $57,5 \%$ si on y ajoute les indéterminés, appartient à des formes basses ou moyennes ouvertes (bols, coupes ou jattes). Les $40 \%$ restant, $43,5 \%$ si on y additionne les formes indéterminées, relèvent du domaine des formes hautes (pots et gobelets).

\section{Les décors}

Comme nous l'avons souligné plus haut, la mauvaise conservation des vases a affecté notre reconnaissance des états de surface et des décors. Cependant, cette réserve étant émise, quand la détermination était possible, on s'aperçoit que le décor ou traitement de surface le plus répandu consiste en un lissage complet ou partiel de la surface externe $\mathrm{du}$ vase. Ce lissage peut éventuellement se limiter à des motifs en croisillons (fig. 15, lot 21) ou en chevrons (fig. 13, lot 114) ou obliques en diagonale (fig. 13, lot 138) réalisés à l'aide d'une spatule ordonnés selon un registre horizontal sur le haut de la panse. Il semble que ce décor ait été beaucoup utilisé à La Tène moyenne. On peut aussi citer a contrario un exemple où le décor de croisillons lissés recouvre toute la panse (fig. 12, lot 137). La Tène moyenne est encore proposée pour la datation. Enfin, on constate l'absence de fine ligne ondée lissée simple.

Le décor peigné ou plutôt un traitement de surface consistant en un simple peignage complet ou partiel horizontal (fig. 20, lot 80 ; fig. 16, lot 218, lot 44, lot 21 ; fig. 14, lot 15; fig. 21, lot 113) est appliqué à l'aide d'un outil dentelé sur la face externe de la panse. Elle concerne $22,5 \%$ du nombre total d'individus et $18,7 \%$ du NT. Cette technique peut avoir eu également pour but d'égaliser les surfaces après un premier façonnage du vase à la main. Fréquentes sur la panse des pots, les cannelures s'observent aussi sur la face interne de la lèvre. Plusieurs exemplaires présentent une large cannelure labiale interne. Cet indice d'une chronologie haute se vérifie au regard des contextes de découvertes d'Aron (Vauterin, 1999, p. 64). Plus larges que des baguettes, les moulures sont réalisées par enlèvement de matière à l'aide d'une estèque. Très fréquemment, elles soulignent la liaison entre le col et la panse. Par groupes de deux, elles décorent le col des bols (fig. 17, lot 40). Le seul décor estampé recensé est documenté par des motifs en $S$ estampés à l'aide d'une matrice et disposés en deux registres superposés séparés par des cannelures (fig. 14, lot 200). Ce type de décor est attesté localement à Jublains (Bigot, 1988; Bouvet, 1997) et à Laval, ZAC des Bozées (Thooris, 1991; Bouvet, 1997). Il est généralement attribué à La Tène moyenne. Le décor par enduction graphité est rarissime : seul un vase répond à cette définition (fig. 13, lot 98). Très fragmenté, son profil a été reconstitué à l'aide de plusieurs tessons non jointifs. Aucune impression digitée, incision oblique ni décor peint 
à l'hématite n'a été reconnu sur le site. Les décors rencontrés sur le site d'Aron présentent de nombreuses analogies avec ceux rencontrés sur les sites contemporains de Mayenne (Jublains, Entrammes, Écorcé).

La rareté des décors peints et graphités, apanage du domaine armoricain, pour les ensembles datés de La Tène moyenne s'explique sans doute par la faiblesse des lots. Le décor estampé est également peu fréquent. Pour La Tène finale, la palette des décors ne se différencie pas de celle attestée sur les sites mayennais voisins. L'évolution la plus sensible à la fin de cette période est le développement de la pratique du tour rapide. Cet usage aura une influence sur l'épaisseur des parois des vases qui deviennent plus minces et sur le développement des décors de baguettes et de cannelures multiples (Mortreau, 1999). Les céramiques recueillies à Aron offrent un bon exemple de cette pratique.

\section{Les fonds}

Les fonds des pots de La Tène finale sont en général plats, légèrement soulevés, sans pourtour débordant. Pour les vases rattachés à La Tène moyenne, la base a subi un tournassage pour ménager une cannelure sur le pourtour (fig. 15, lot 21 et fig. 14, lot 28). Ce même décor s'observe à Jublains pour le mobilier issu du comblement d'une fosse de tisserand (Mortreau, à paraitre) et à Oisseau-le-Petit, Les Noirâs en Sarthe (Mortreau, 2007). Trois fonds à anneau porteur datés de la même période ont été obtenus par enlèvement de matière en utilisant la même technique (fig. 12, lots 3 et 221).

La répartition des différents types de fonds indique un faciès laténien final où dominent les fonds plats légèrement soulevés. Les plus rares fonds annulaires ou à pourtour décoré d'une cannelure appartiennent quant à eux à l'horizon de La Tène moyenne. On note cependant l'absence de fonds balustres et de fond en piédestal, association caractéristique de l'horizon de La Tène moyenne, absence due peut-être également à une faiblesse documentaire.

\section{La céramique gallo-romaine}

Cette période est représentée en tout et pour tout par deux tessons. Le premier est issu du fait 39. Il s'agit d'une panse de pot à pâte grossière grise (lot 88). Le second, recueilli dans le fait 199, est constitué d'une section d'anse en pâte grossière sableuse claire (lot 131). Elle devait appartenir à un récipient de stockage ou de service du type pichet ou cruche. L'emploi de pâte sableuse cuite en vrai mode B ne se rencontre que dans les contextes gallo-romains du HautEmpire, notamment à Jublains (Mortreau, à paraître). De même, les cruches ou pichets sont des récipients typiquement méditerranéens dont l'imitation ne se développe qu’à la période romaine (avant il s'agit d'importations à pâte calcaire ou bien de productions engobées de blanc). Dans les deux cas, les fragments ont été trouvés mêlés à des tessons protohistoriques. S'agit-il de mobilier intrusif ou de témoignages d'une occupation plus tardive? La question est posée.

\section{La céramique du haut Moyen Âge}

Un artefact correspondant à un couvercle à bâtière ou d'une coupe à collerette du haut Moyen Âge a été recueilli dans le fait 273 (lot 168). Ce vestige isolé rend compte d'une occupation postérieure du site de fait assez lâche considérant qu'il s'agit du seul témoin. Lors de la phase III de diagnostic, un autre site de même période fut repéré sur le tracé de la future déviation Moulay-Mayenne. Le fait 15 issu du sondage 227 livra ainsi un mobilier daté des $\mathrm{VII}^{\mathrm{e}}-\mathrm{VIII}^{\mathrm{e}}$ siècles apr. J.-C. (Mortreau, 2005, fig 48h, p. 91). Cette datation rejoint celle retenue pour le couvercle à bâtière dont il a été fait mention précédemment.

\section{Conclusion}

Mis à part deux artéfacts appartenant à la période galloromaine et alto-médiévale, l'essentiel de l'occupation peut être attribuée à la période gauloise. La chronologie des lots étudiés pour la période gauloise couvre une large période allant de La Tène moyenne à La Tène finale. Le mobilier d'importation est représenté exclusivement par deux panses de deux amphores de type Dressel 1. Le vaisselier en céramique commune offre de nombreuses similitudes avec les sites géographiquement proches comme l'oppidum du Mesnil (Boissel, Dielh, Naveau, 1972; Valais, 2004, fig. 29, sondages 704 et 718 ) et d'autres plus éloignés comme celui d'Entrammes, La Carie II (Coffineau, 2006) et du fossé de la Carrière d'Écorcé (Naveau, 1977).

Le département voisin de la Sarthe a livré aussi quelques comparaisons significatives (Cherel, 1999; Vauterin, 1999; Mortreau, 2007) ainsi que la Bretagne (Menez, 1996, 2001). À l'influence de la sphère armoricaine, on peut attribuer la présence de céramiques graphitées, des cannelures labiales internes, des stries multiples et des décors estampés. Par contre, on remarque l'absence des lèvres en "Y ", bien représentées sur le site du Clos-Henry, à Château-Gontier, si chères à Jean-Claude Meuret (Meuret 2001; Valais et al., 2008). Plus qu'un problème de chronologie, il faut plutôt y voir la preuve de l'existence de microfaciès locaux ou de la patte d'un artisan potier. Si la majeure partie de la poterie a pu être fabriquée localement, l'étude visuelle des pâtes montre aussi ponctuellement une autre source d'approvisionnement dont l'origine précise doit être recherchée (pâte à bioclastes). Sur le statut du site, l'étude de la céramique peut apporter quelques éléments de réponse, à corréler bien sûr avec les études spécialisées des autres mobiliers recueillis. 
Pour La Tène finale, la rareté des importations (amphores) doit-elle être mise au crédit d'un statut inférieur des habitants de cette ferme ou bien à l'existence d'autres récipients de stockage attestés par ailleurs à cette époque? En parallèle, la rareté de la vaisselle fine dite " de luxe » constituée par des formes de service ou de présentation (bols carénés décorés, jattes décorées de moulure sur le bas de la panse et gobelets à boire) est à noter. La vaisselle culinaire pour la préparation ou la cuisson des aliments est par contre très bien représentée. Les pots à cuire aux formes simples, usuelles et rarement décorés (ornés seulement d'une cannelure) prédominent dans le répertoire des formes hautes fermées.

Parmi les formes basses ouvertes, on soulignera la prédominance d'un type de jatte à panse tronconique ou hémisphérique connu sous le nom de "bol mayennais". Les différents modules rencontrés peuvent peut-être correspondre à des fonctions diverses? Les vases de stockage se signalent par leur relative abondance. Quand on peut la mesurer, cette capacité de stockage est un indicateur de richesse ou de standing social comme sur la résidence aristocratique de Montmartin dans l'Oise (Brunaux, Méniel, 1997). La rareté des vases tonnelets (gobelet à boire), qui va de pair avec celle des amphores, est à souligner. Cette absence tranche avec la relative abondance de ces conteneurs rencontrée sur un autre site comme le fossé de la Carrière d'Écorcé ou à La Carie II, sur la commune d'Entrammes (Naveau, 1977; Guillier, 2006).

Le taux de fragmentation très faible (12 tessons pour 1 vase) pour les vases recueillis sur le site est équivalent à celui observé sur le site des Noirâs à Oisseau-le-Petit, dans la Sarthe (Mortreau, 2007). La présence de nombreuses pièces ayant manifestement subi l'action du feu permet de mettre en évidence un évènement accidentel dans l'histoire du site. Les restes de cet incendie qui a détruit des constructions ont été évacués dans une fosse aux grandes dimensions. Ceci nous permet d'approcher le mode de gestion des ordures dans une communauté rurale gauloise. Les lots céramiques étudiés provenant du site du Panveau, à Aron trouvent ainsi toute leur place dans le cadre de la mise en place d'une chronologie des mobiliers de La Tène en nord-Mayenne, ainsi que dans une perspective régionale plus large.

\section{Le vase en lignite par M. Mortreau (fig. 22)}

La fouille de la dépression F.37 située dans la partie sud-est du site du Panveau, à Aron (Mayenne) a livré trois fragments en lignite d'une coupe ouverte à parois obliques décorée d'une baguette (inv. : F.37-OG.6). La lèvre amincie est soulignée d'une mince cannelure labiale interne. Le décor de baguette a été obtenu par enlèvement de matière lors du tournage de la pièce.

Les fouilles menées localement à Jublains (inédit, fouilles du Taillis des Boissières, Anne Bocquet) et à Moulay (Boissel, Dielh, Naveau, 1972, identification M. Mortreau) ainsi qu'au château d'Angers (Maine-et-Loire, Bouvet et al., 2003, p. 184, fig. 8 et inédit) et à Fleury-sur-Orne (Calvados, SanJuan et al., 1994, fig. 25, $\mathrm{n}^{\circ} 13-14$ ) ont permis de recueillir des fragments de vases similaires. Ils correspondent tous à une forme basse ouverte (ici, diam. 20,1 cm) type coupe à parois concaves ou obliques décorées de baguettes reposant sur un fond plat soulevé décoré de moulures. Cette forme est attestée par ailleurs en céramique en Gaule de l'Ouest sous l'appellation de "vase baquet " (Giot, Briard, Pape, 1979, p. 339 et Daire, 1992).

Les sites de découvertes de vases en lignite sont connus pour leur séquence d'occupation longue, ainsi on ne peut avancer qu'une datation située au plus tard dans le $\mathrm{I}^{\text {er }}$ siècle avant J.-C. Les éléments découverts en contexte romain doivent être considérés comme résiduels ainsi que l'attestent les appariements remarqués (observation personnelle).

Des articles récents issus de travaux de master université de Rennes 2 se sont attachés à étudier les objets de parure en Bretagne et dans ses marges, mais ils ne font curieusement pas mention de vases (Baron, 2012). Cette rareté est peut-

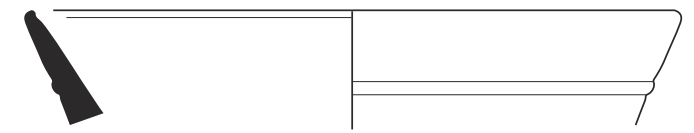

Lot OG 08 - F.37
Figure 22 : Le mobilier organique : le vase baquet.

Figure 22: Conserved wood vessel. 
être due à un défaut d'identification, mais il doit refléter une certaine réalité. Outre les découvertes inédites déjà citées, le dépouillement bibliographique fait mention d'autres formes : un vase ovoïde décoré de baguette provenant de la sépulture à incinération mise au jour à Saint-Gatien-desBois (Calvados) et datée du II siècle avant J.-C. (Pion, 1999, p. $144 \mathrm{n}^{\circ} 282$ ) et d'une coupe ouverte mise au jour sur la ferme du Boisanne, à Plouër-sur-Rance (Côtes-d'Armor, Menez, 1996, p. 226, Pl. 8 no 84.25).

En conclusion, la carte de répartition actuelle permet d'observer une distribution de "vases baquets " en lignite le long d'un axe Basse-Normandie, Mayenne et Maine-etLoire (Angers). Les lieux de découvertes correspondent à des habitats ouverts de type fermes (Fleury-sur-Orne, Aron), de hauteur fortifiés de type oppida (Moulay ou Angers) ou indéterminés (Jublains). Ces objets apparaissent donc comme précieux eu égard à la rareté de leur découverte et conduisent à s'interroger sur le statut même du site d'Aron. Le lieu même de provenance du lignite employé n'est pas connu même si l'analyse du vase en sapropélite de SaintGatien indique une provenance de Bretagne insulaire. Loin de s'interdire l'hypothèse d'un commerce lointain, force est de reconnaître la présence d'un gisement plus proche à Gesnes-Le-Gandelin dans la Sarthe (Naveau, 1999, n 159 p. 90). Les éléments chronologiques dont nous disposons actuellement pour cette production ne vont pas à l'encontre de la datation La Tène moyenne/La Tène finale documentée par la fouille du Panveau.

\section{Les meules par Boris Robin}

\section{Présentation du corpus ${ }^{2}$}

Le site de Panveau à Aron, a fourni dix fragments de meules rotatives, auxquels peuvent être associés une dizaine de fragments de granite, pouvant provenir de meules, mais dont aucune surface ne permet l'identification certaine (fig. 23). Le corpus se compose de deux meta (meules inférieures et fixes) (53 ARO 0003 et 53 ARO 0008), de cinq catillus (meules supérieures et mobiles) (53 ARO 0001, 53 ARO 0002, 53 ARO 0004, $53 \mathrm{ARO} 0006,53 \mathrm{ARO} 0007)$ et de trois fragments indéterminés (53 ARO 0005, 53 ARO 0009, 53 ARO 0010). Le matériau mis en œuvre pour la quasi-totalité du corpus est un granite, seul un fragment est en grès. Ce granite est similaire à celui ayant servi à la fabrication des meules découvertes sur le site voisin du Grand Mesnil à Moulay (53; Robin, 2005). Il s'agit d'un granite à faciès gneissique, avec quartz et feldspaths plagioclases abondants, micas blancs. Ce

2. Les meules ont été numérotées pour l'étude, les correspondances avec les numéros de faits et d'us se trouvent en annexe 1 . type de granite se trouve en affleurement sur la commune de Moulay, sur les bords des deux rivières : la Mayenne et l'Aron et au niveau de leur confluence. Concernant le grès, au premier examen, il semble correspondre à celui utilisé pour la fabrication de l'unique meule en grès retrouvée sur le site du Grand Mesnil. Lidentification plus précise de ce grès et de son lieu de provenance, nécessiterait la fabrication d'une lame mince, dans le cadre d'une étude plus poussée sur les meules de cette région et de cette période.

\section{Approche typologique}

Les différentes observations proposées pour l'étude de ce corpus vont s'appuyer sur les meules issues du site du Grand Mesnil (Robin, 2005). Le diamètre des catillus varie de 33 à $40 \mathrm{~cm}$, et le diamètre des meta varie de 32 à $38 \mathrm{~cm}$. Cette corrélation entre ces valeurs, nous permettant d'envisager une quasi standardisation du diamètre des moulins sur le site de Panveau. Ces valeurs sont celles observées sur le site du Grand Mesnil.

Les catillus (53 ARO 0001, 53 ARO 0002, 53 ARO 0006, 53 ARO 0007) présentent une simple cuvette pour leur surface supérieure sans rebord ou méplat. Ils sont de forme plutôt haute (hauteurs comprises entre 14 et $20 \mathrm{~cm}$ ), avec un diamètre moyen de l'œil central de $6 \mathrm{~cm}$. Ces caractéristiques permettent de les rattacher au type $\mathrm{C} 1$ de la typologie mise en place pour le site du Grand Mesnil. La datation associée à ces éléments (La Tène finale) va aussi dans ce sens, puisque ce type semblait être le plus récent des trois types définis pour le Grand Mesnil.

La meta 53 ARO 0003 possède une surface inférieure plane et un bord curviligne. Elle est de forme relativement basse (hauteur de $14 \mathrm{~cm}$ ), avec une perforation centrale non traversante de $8 \mathrm{~cm}$ de diamètre et $7 \mathrm{~cm}$ de profondeur. Son diamètre est de $38 \mathrm{~cm}$ et la pente de la surface active est de 5 degrés. Ces différents critères permettent de la rattacher au type M 21 b de la typologie du Grand Mesnil. Nous n'avons malheureusement pas de datation associée pour cet élément, la seule observation que l'on peut faire, est que le type M 21 b, qui est un sous-type du type M 2 (type le plus récent de la typologie du Grand Mesnil), reste une forme encore non aboutie de ce type. L'hypothèse que l'on peut alors émettre est que cette meule, si on la rattache à la datation de La Tène finale, serait à lier à une phase moyenne de cette période. L'autre meta (53 ARO 0008) est en grès, de forme basse et à bord droit. Elle ne peut être rattachée à la typologie du Grand Mesnil, établie sur les meules en granite. La datation qui est associée à cet élément (La Tène moyenne) permet cependant d'émettre une hypothèse concernant sa provenance. Cette meule pourrait être un élément importé, avant la mise en place d'un atelier dans les environs utilisant le matériau local. Cette importation pouvant résulter d'une 


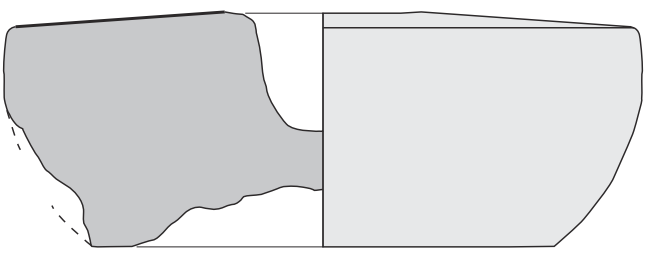

53 ARO 0003

F 37

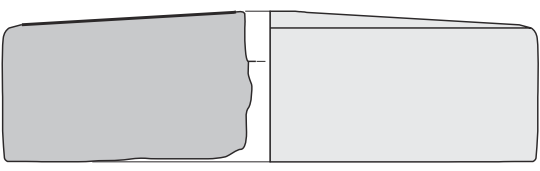

53 ARO 0008

F 42 Sd 1023

Meta

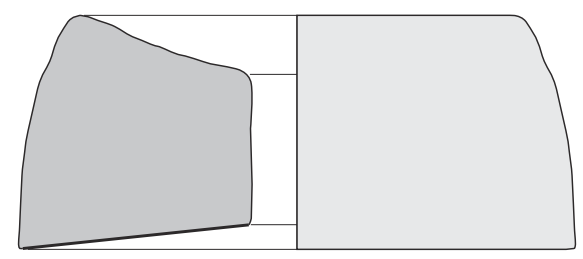

53 ARO 0006

F 37

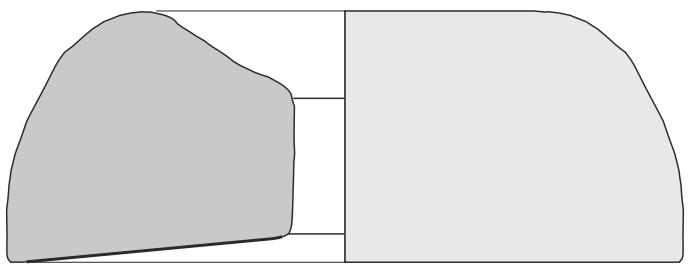

53 ARO 0001

F1 Sd 1097

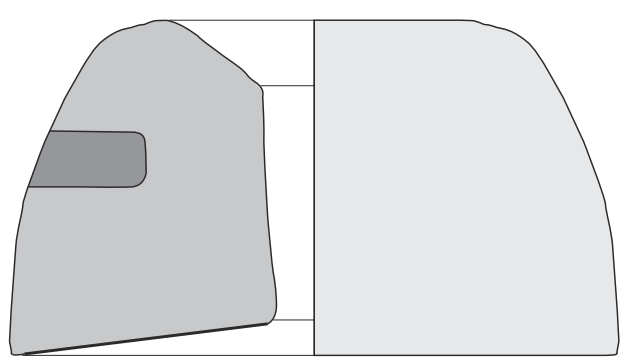

53 ARO 0002

126 ou 127

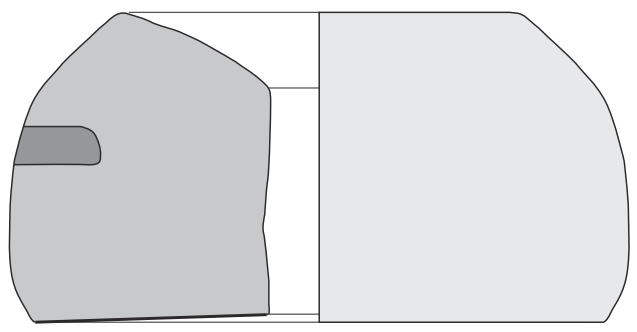

53 ARO 0007

F 21 Sd 1091

\section{Catillus}

Do
罚

Figure 23 : Planche des meules découvertes sur le site du Panveau à Aron.

Figure 23: Querns from the Panveau site at Aron. 


\begin{tabular}{|c|c|c|c|c|c|c|c|c|c|c|}
\hline Position perforation latérale & そ & 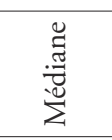 & そ & $\stackrel{\wp}{Z}$ & そ & そ & 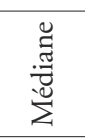 & そ & $\stackrel{\wp}{Z}$ & $\stackrel{\circ}{Z}$ \\
\hline $\begin{array}{c}\text { Profondeur perforation } \\
\text { latérale }\end{array}$ & $\stackrel{\circ}{Z}$ & $\wedge$ & $\stackrel{0}{Z}$ & $\stackrel{\circ}{Z}$ & $\stackrel{\circ}{Z}$ & $\stackrel{\circ}{Z}$ & n & $\stackrel{\imath}{z}$ & $\stackrel{\imath}{z}$ & $\stackrel{\circ}{Z}$ \\
\hline Largeur perforation latérale & $\stackrel{\bigcirc}{Z}$ & $\tilde{m}$ & $\stackrel{O}{z}$ & $\stackrel{0}{Z}$ & $\stackrel{\circ}{Z}$ & $\stackrel{\circ}{Z}$ & $\hat{i}$ & $\stackrel{\circ}{z}$ & $\stackrel{\circ}{Z}$ & $\stackrel{\circ}{Z}$ \\
\hline Longueur perforation latérale & $\stackrel{\wp}{Z}$ & $n$ & $\stackrel{\wp}{Z}$ & $\stackrel{\wp}{Z}$ & 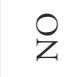 & $\stackrel{一}{Z}$ & $\approx$ & $\stackrel{\bigcirc}{Z}$ & $\stackrel{O}{Z}$ & $\stackrel{\circ}{Z}$ \\
\hline Forme perforation latérale & $\stackrel{0}{Z}$ & $\frac{0}{\tilde{5}}$ & $\stackrel{0}{Z}$ & $\stackrel{0}{Z}$ & $\stackrel{0}{Z}$ & $\stackrel{0}{Z}$ & 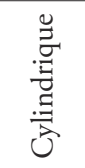 & $\stackrel{\circ}{Z}$ & $\begin{array}{l}0 \\
Z\end{array}$ & $\stackrel{\bigcirc}{Z}$ \\
\hline $\begin{array}{l}\text { Profondeur perforation } \\
\text { centrale }\end{array}$ & $\infty$ & \pm & $\wedge$ & $\stackrel{0}{Z}$ & そ & $a$ & $\Xi$ & n & そ & $\stackrel{\circ}{Z}$ \\
\hline Diamètre perforation centrale & $\bullet$ & 6 & $\infty$ & $\stackrel{\circ}{Z}$ & $\stackrel{0}{Z}$ & $\approx$ & ○ & m & そ & $\stackrel{\bigcirc}{Z}$ \\
\hline Forme perforation centrale & 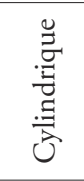 & 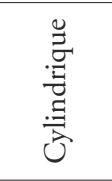 & 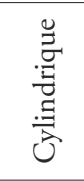 & $\stackrel{\bigcirc}{Z}$ & $\stackrel{0}{Z}$ & 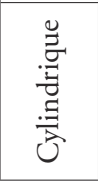 & 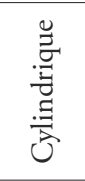 & 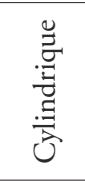 & $\begin{array}{l}0 \\
z\end{array}$ & $\stackrel{\bigcirc}{Z}$ \\
\hline Hauteur mini & $\stackrel{\circ}{Z}$ & $\stackrel{\circ}{Z}$ & $\hat{n}$ & $\stackrel{0}{Z}$ & $\stackrel{\wp}{z}$ & & & $\infty$ & $\stackrel{\circ}{Z}$ & $\stackrel{\circ}{z}$ \\
\hline Hauteur maxi & $\cong$ & ิ & \pm & $\stackrel{0}{Z}$ & $\stackrel{0}{Z}$ & $\Xi$ & $\stackrel{n}{\infty}$ & $a$ & $\begin{array}{l}0 \\
Z\end{array}$ & $\stackrel{\bigcirc}{Z}$ \\
\hline Diamètre mini & o t & $\stackrel{n}{n}$ & $\stackrel{\sim}{\sim}$ & ○ & $\stackrel{\wp}{z}$ & $m$ & $\stackrel{m}{m}$ & $\approx$ & $\stackrel{O}{Z}$ & $\stackrel{O}{Z}$ \\
\hline Diamètre maxi & $\stackrel{\sim}{\sim}$ & $\stackrel{\infty}{-}$ & $\stackrel{\infty}{n}$ & $\stackrel{\circ}{Z}$ & $\stackrel{\circ}{Z}$ & 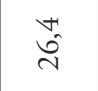 & $\stackrel{\varpi}{\sim}$ & $\approx$ & $\stackrel{\vartheta}{Z}$ & $\stackrel{\bigcirc}{Z}$ \\
\hline $\begin{array}{l}\text { Lieu probable de provenance } \\
\text { du matériau }\end{array}$ & 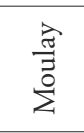 & 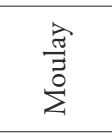 & $\frac{\text { 苛 }}{\vdots}$ & 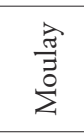 & $\frac{\text { 䆑 }}{\stackrel{5}{\vdots}}$ & $\frac{\vec{\pi}}{\overrightarrow{0}}$ & $\begin{array}{l}\frac{\hat{\sigma}}{\vec{z}} \\
\sum^{0}\end{array}$ & n. & 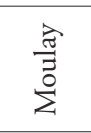 & $\begin{array}{l}\frac{\overrightarrow{0}}{\vec{J}} \\
\frac{\bar{z}}{\Sigma}\end{array}$ \\
\hline Matériau & 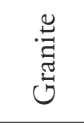 & 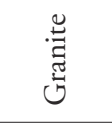 & 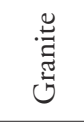 & 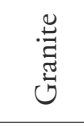 & 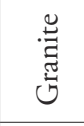 & 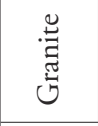 & 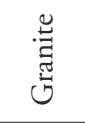 & Uू. & 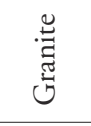 & 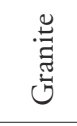 \\
\hline Partie du moulin & 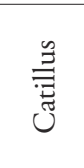 & 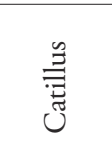 & $\sum_{\Sigma}^{\pi}$ & 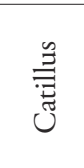 & 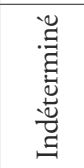 & 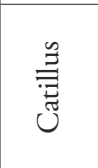 & 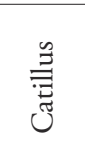 & $\stackrel{\pi}{\mathbb{E}^{2}}$ & 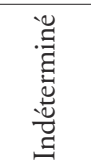 & 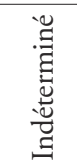 \\
\hline Fragmentation & $\stackrel{\Delta}{\leftrightarrows}$ & $\stackrel{=}{N}$ & $\stackrel{\sim}{I}$ & 嘉 & 点 & $\stackrel{N}{=}$ & $\stackrel{\uplus}{=}$ & $\stackrel{\wp}{=}$ & 望 & 点 \\
\hline $\mathrm{N}^{\circ}$ Structure & 在昘 & 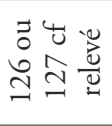 & $\hat{m}$ & $\hat{\omega}$ & $\hat{\omega}$ & $\hat{n}$ & $\begin{array}{l}\vec{\sim} \\
\vec{\omega} \\
\vec{\omega}\end{array}$ & 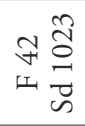 & $\underset{\mathrm{A}}{\stackrel{\leftrightarrow}{ \pm}}$ & $\underset{\substack{\infty \\
亡}}{\sim}$ \\
\hline $\mathrm{N}^{\circ}$ Meule & 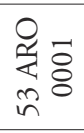 & 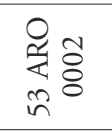 & $\begin{array}{l}0 \\
\text { 幽各 } \\
\text { nn }\end{array}$ & 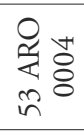 & 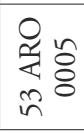 & 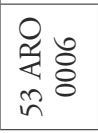 & 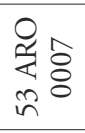 & 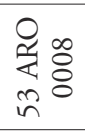 & 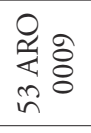 & $\underset{n}{\stackrel{0}{4}}$ \\
\hline
\end{tabular}


nécessité, du fait de l'absence d'un atelier dans les environs pour cette période, ou encore provenir d'un mouvement de populations ayant emporté leur mobilier avec eux.

\section{ConClusion}

Les meules du site de Panveau, viennent compléter l'étude des meules rotatives de l'âge du Fer de cette région, et elles permettent de confirmer les hypothèses émises concernant la typologie mise en place pour le site du Grand Mesnil. La poursuite du travail consistera en l'étude de la totalité des meules gauloises en granite découvertes sur les sites mayennais et dans un rayon assez large, dans le but de réaliser une synthèse, visant à comprendre l'ensemble du processus de production (atelier de taille, typologie) et de diffusion de ces meules.

\section{SYNTHÈSES DES DONNÉES}

Cette partie s'appuie sur une analyse spatiale des structures, sur les quelques relations stratigraphiques reconnues et le tout est confronté aux résultats de l'étude céramique. Les trois phases distinguées au niveau des enclos ont été reprises et étayées de cette façon. Nous avons également tenté de leur associer des bâtiments.

\section{La phase I (fig. 24)}

Dès la phase 1 que l'étude céramique nous permet de faire remonter à La Tène moyenne, un enclos aux fossés peu marqués est établi. Nous n'en connaissons que l'angle sud-est. Semblent être associés à cette enceinte les fossés F.175 et F.23 au sud. Le côté nord de l'enclos, si l'on se fie aux dimensions modestes relevées au sud, pourrait avoir été totalement oblitéré lors de la mise en place du fossé F.365 au nord. L'enclos pourrait ainsi occuper un peu moins de 60 mètres de largeur du nord au sud pour au moins 47 mètres d'est en ouest. Les fossés ne mesurent jamais plus d'1 mètre de largeur au niveau du décapage et une cinquantaine de centimètres de profondeur. Dès cette période, les autres aménagements (trous de poteau et fosses) se cantonnent à l'intérieur de l'enclos. Une zone non remaniée apparait dans le grand axe (est-ouest) du site. Ce secteur qui semble constituer dès cette phase une zone de cour ou de passage, est bordé par le fossé F.368 et peutêtre par le fossé F.42. Quelques fossés de partition nordsud existe comme F.3 que prolonge sans doute F.22. Deux bâtiments pourraient remonter à cette phase : le $\mathrm{n}^{\circ} 5$ en raison de son implantation dans l'angle sud-ouest de l'en- clos à égale distance des deux côtés et le bâtiment 13. Ce dernier pourrait s'articuler avec le fossé F.23 qui en longe le pignon sud. D'autre part, il est possible que l'hypothèse de bâtiment formé par les tranchées F.43, F.133 et F.10 qui on livré du mobilier de La Tène moyenne associées au moins au poteau F.140 aient pu exister durant cette phase.

\section{Phase II}

Un nouvel enclos est établi. Le mobilier recueilli indique déjà La Tène finale. Il reprend globalement l'emprise de l'enceinte antérieure tout en repoussant quelquefois les limites. Du côté nord, seul un tronçon (F.365) semble subsister. Au sud, la limite ancienne est remplacée par le fosse F.31. À l'est également, les limites de l'enclos sont repoussées, partie orientale de l'enclos où les ensembles de La Tène moyenne sont absents. Dès lors, l'enclos mesure au moins la largeur de l'emprise de la rocade, soit plus de 50 mètres d'est en ouest. Le fosse F.154 semble se connecter à ce nouveau complexe plus vaste et perpétuer un dispositif de partition interne. Vers le nord, il est impossible de connaître son développement. La zone, dépourvue de structures, est maintenue dans l'axe est-ouest du site bordée au sud par le fosse F.42. Cette zone centrale constitue, semble-t-il, toujours l'axe principal de circulation de l'enclos et il est possible que l'anomalie topographique remblayée appartienne également à cet aménagement. Toujours à l'intérieur de ce nouvel enclos, les aménagements doivent se multiplier, malheureusement, les éléments décisifs nous permettant de les associer manquent. Nous ne pouvons donc que proposer des hypothèses. Le bâtiment 8 pourrait appartenir à cette phase en admettant qu'il est postérieur à l'un des fossés d'enclos de la phase antérieure. Une convergence d'orientation pourrait indiquer que le bâtiment 7 remonte également à cette même période tout comme le bâtiment 6 tout proche. Bien que ne présentant pas la même orientation, ce dernier, pourrait appartenir à un même ensemble. Il en est de même pour les autres structures du décapage, mais nul ne sait lesquelles exactement, le mobilier n'étant pas suffisant pour percevoir l'évolution de l'occupation du site au cours de La Tène finale. Il est également possible que les fossés F.36, F.35, 363 et 366 qui constituent autant de limites parcellaires remontent à cette seconde phase. Signalons toutefois le gabarit bien supérieur du fossé F.363 qui pourrait confirmer que ce côté oriental de l'enclos était bien celui de l'entrée du site.

\section{Phase III}

La principale modification pour cette phase est constituée par la mise en place des fossés les plus larges et profonds du site que sont $\mathrm{F} .1$ au nord qui reprend pratiquement l'intégra- 


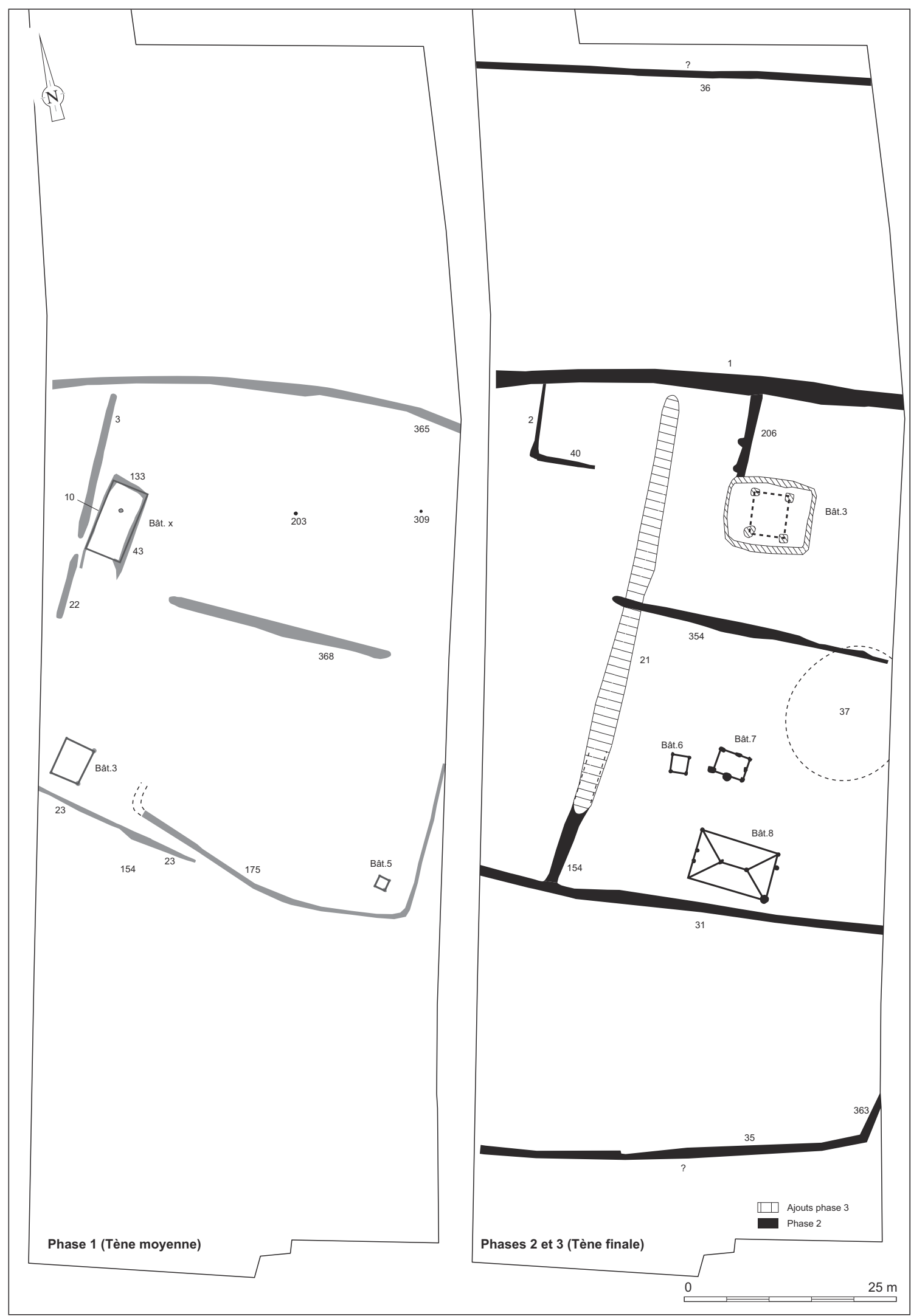

Figure 24 : Planche de synthèse par phase.

Figure 24: Chronological phase. 
lité du fossé F.365 et la limite F.21 qui en fait de même avec le fossé F.154. Celle-ci marque une partition interne remarquable qui remplit au moins un rôle de drain en reprenant l'orientation générale du versant. On ne sait quelles sont les structures de la seconde phase qui se maintiennent alors. Qu'en est-il par exemple des bâtiments 6, 7 et 8 déjà cités? Avec ce phénomène qui tend à un développement du gabarit de certains des fossés de l'enclos depuis La Tène moyenne (phase I) et tout au long de La Tène finale, nous considérons qu'à mesure du temps, le site a tendance à se développer. Ce constat permet ainsi d'attribuer le principal bâtiment du site à cette dernière phase. Du fait de son importance et sans doute de son élévation et même s'il faut se garder de toute conclusion hâtive, le site étant en partie hors emprise, ce bâtiment, qui évoque une habitation, constitue assurément le pôle de cet établissement. La découverte de fragments d'amphore, exclusivement issus du fossé de partition interne (F.21) et de la tranchée de fondation de ce bâtiment principal (F.255) semble également confirmer ce statut d'un habitat qui parait alors atteindre son " apogée ". La présence de ce type d'architecture à parois porteuses durant cette phase pourrait aller dans le sens de ce qui a été proposé pour ce mode architectural en Basse-Normandie (Jahier et al., 2009, p. 353). Dans cette région, il remonte également plutôt à une date tardive de La Tène.

\section{Conclusions générales}

Le site du Panveau qui domine le méandre d'une modeste vallée d'un affluent de l'Aron constitue un exemple de ferme indigène établie dès La Tène moyenne et abandonnée avant la Conquête romaine. Dès le début de l'occupation, l'établissement est cerné par des fossés d'enclos. Son emprise, en partie hors de l'aménagement, occupe un rectangle estouest d'au moins 60 mètres de côté. Au cours de La Tène finale, la plupart des fossés sont repris et élargis tandis que d'autres limites - notamment au sud et à l'est - sont repoussées, donnant à l'enclos une emprise supérieure. Ses caractéristiques principales sont maintenues, notamment la zone axiale assimilée à un secteur de cour ou de passage est-ouest ainsi que le fossé de partition nord-sud qui est repris et augmenté. Les lots de mobilier de La Tène finale sont mieux répartis sur l'ensemble de l'enclos, tandis que les bâtiments qui existent alors semblent plus nombreux avec des surfaces qui permettent souvent d'en proposer la fonction. Il semble ainsi que les principales constructions, sans doute les habitations, appartiennent plutôt à la partie orientale de l'enclos et elles sont accompagnées de plusieurs petits bâtiments de type grenier. Les deux ensembles ainsi constitués pourraient former autant d'unités agricoles qui ont toutefois pu se succéder dans le temps. En raison de sa taille, le bâtiment 3, le plus imposant du site, pourrait être le plus récent. Il semble associé à la phase où les fossés sont les plus larges. Plus à l'ouest, les bâtiments proposés semblent de taille plus modeste et ne constituent que des annexes agricoles. La rareté de la céramique d'importation comme les amphores et la vaisselle fine indique qu'il s'agit probablement d'un site de statut social relativement modeste, même si l'on ne doit pas oublier que nous n'avons recueilli qu'une part infime des rejets d'un habitat occupé pendant plusieurs siècles. Contrairement à des sites enclos organisés autour d'un bâtiment principal, une habitation comme les exemples de La Corbinière à Beaucouzé (49; Maguer et Lusson, 2009, p. 449) ou le Clos-Henry à Château-Gontier (53; Valais et al., 2008), le site du Panveau malgré la diachronie de ses différents bâtiments et le fait que nous n'ayons qu'une partie de l'enclos pourrait plutôt évoquer un établissement où les bâtiments sont disposés autour d'une cour ou d'une zone de passage. Ce type d'implantation a été signalé à La Bleure et aux Natteries, deux sites enclos de la région de Cholet. Sur ce dernier site, on distingue une habitation plus grande, associée à d'autres plus modestes, modèle qui pourrait peutêtre exister, certes en plus modeste, au Panveau (Maguer et Lusson, 2009, p. 450).

En attendant les résultats des fouilles de l'oppidum du Mesnil et des enclos de La Garde et de La Hucherie à Moulay, la ferme du Panveau constitue un premier jalon sur l'organisation des campagnes, notamment durant La Tène finale, dans une région densément occupée. Il sera intéressant de comparer les durées d'occupation de tous ces sites, leur mode de consommation, leurs interactions et leur abandon qui semble survenir dès la Conquête.

Avec la fin de l'occupation du Panveau autour de la Conquête, peut-être en même temps que l'oppidum qui semble se réduire à une douzaine d'hectares, il sera également pertinent d'évaluer les mutations qui vont s'opérer au début de la période romaine avec la mise en place de nouveaux habitats dont celui de La Davière à quelques centaines de mètres au nord du Panveau et surtout les conséquences de la création de la cité de Jublains également toute proche $(7 \mathrm{~km})$ sur l'organisation générale des campagnes des environs de la ville de Mayenne. 


\section{Bibliographie}

Angot A., I900-I910 - Dictionnaire topographique et biographique de la Mayenne, 4 tomes.

Audouze F. et Buchsenschutz O., I 989 - Villes, villages et campagnes de l'Europe celtique, Bibliothèque d'archéologie, Hachette.

BARON A., 2012 - Provenance et circulation des objets en roches noires ("lignite ") à l'âge du Fer en Europe celtique (VIIt-I" s. av. J.-C.), Oxford : BAR International Series 2453, Archaeopress, 289 p.

Besombes P.-A., 2005 - "Le dépôt de 22438 monnaies du gué de Saint-Léonard (Mayenne) ", Trésors monétaires - Tome XXI, Bibliothèque nationale de France.

Вigot B., I988 - «Quelques céramiques protohistoriques trouvées au temple de Jublains (Mayenne) ", La Mayenne : Archéologie, Histoire, 11, p. 3-9.

Boissel R., Diehl R. et Naveau J., I 972 - «L'oppidum de Moulay (fouilles de l'année 1972) ", Bulletin de la Commission historique et archéologique de la Mayenne, 29, p. 3-36.

Boissel R. et Naveau J., I980 - " Les fouilles du terrain de sport de Jublains (Mayenne) 1972-1979 ", La Mayenne : Archéologie, Histoire, 2, p. 3-34.

Bouvet J.-P., I 997 - " 2- Les céramiques de l'âge du fer ", in Naveau J. (dir.), Recherches sur Jublains (Mayenne) et sur la cité des Diablintes, Documents archéologiques de l'Ouest, p. 222240.

Bouvet J.-P. et Le Goff E., I999 - «La céramique », in Santrot J., Santrot M.-H. et Meuret J.-C. (dir.), Nos ancêtres les Gaulois aux marges de l'Armorique, Nantes : musée Dobrée, p. $42-43$.

Bouvet J.-P. et Mortreau M., I 998 - Château d'Angers, Fouilles des jardins du Quadrilatère et de la terrasse du Logis Royal, Étude des élévations de la Grande Salle. Rapport de fouille préventive 1993-1996, vol. 5, Étude céramologique, Étude du mobilier de l'âge du Fer, Le Mans, Afan.

Bouvet J.-P., Brodeur J., Chevet P., Mortreau M. et Siraudeau J., 2003 - "Un oppidum au château d'Angers (Maine-et-Loire) ", Revue archéologique de l'Ouest, suppl. 10, 2003, p. 173-187.

Boissel R., Dieh R. et Naveau J., I 972 - «L'oppidum de Moulay (fouille de l'été 1972) ", Bulletin de la Commission historique et archéologique de la Mayenne, 29, p. 3-35.

Brunaux J.-L. et Meniel P., I 997 - La résidence aristocratique de Montmartin (Oise) du III au II s. av. J.-C, Paris : Documents d'archéologie française, 64, $272 \mathrm{p}$.

Buchez N., 2005 - "Architecture de l'habitat de l'âge du Bronze à La Tène ancienne dans la Somme ", Architectures protohistoriques en Europe occidentale du Néolithique final à l'âge du Fer, éditions du CTHS, p. 203-208.

Casadeï D., Lecomte L. et al., 2009 - «Analyse spatiale d'un établissement rural de La Tène D1 : Louvres/Le Vieux Moulin
(Val d'Oise) ", in Marion S. et Blancquaert G. (dir.), Les installations agricoles de l'âge du Fer en France septentrionale, Étude d'histoire et d'archéologie, 6, p. 37-73.

Cherel A.-F., I 999 - "La céramique de l'âge du Fer ", in Guillier G. (dir.), Commune de Vivoin Lieu-dit : "La Gaudine ", Rapport de fouilles, Le Mans, Afan, p. 34-50.

Coffineau E., 2006 - "La céramique laténienne ", in Guillier G. (dir.), Commune d'Entrammes (Mayenne), "La Carie II ", Rapport de fouilles, Cesson-Sévigné, Inrap Grand Ouest, p. 27-32.

DAIRE M.-Y., I992 - "Les céramiques armoricaines de la fin de l'âge du Fer ", Travaux du Laboratoire d'Anthropologie de Rennes, 39, $313 \mathrm{p}$.

EARly R., 200 I - "Les origines du château de Mayenne, Apports archéologiques ", in Renoux A. (dir.), Aux marches du palais. Qu'est-ce qu'un palais médiéval, Le Mans, université du Maine, p. 273-287.

Forre P. et VAlais A. 2006 - «Un indice d'occupation méso-néolithique à La Hucherie, Moulay (Mayenne) ", Feuillets mensuels de la Société nantaise de préhistoire, 50 année, $\mathrm{n}^{\circ}$ 435, p. 18-21.

Giot P.-R., Briard J. et Pape L., I 979 - Protohistoire de la Bretagne, Rennes, Ouest-France Université, 1979, 443 p.

GuÉRIN F. I 999 - Le site de la Boirie 1, DFS de sauvetage urgent, A87 (Angers/Cholet), Le Mans, Afan, 94 p.

Guiller G., 2006 - Entrammes (Mayenne), La Carie II, Rapport d'opération de fouille d'archéologie préventive, CessonSévigné : Inrap Grand Ouest, vol 1 : 168 p.; vol 2 : 150 p.

Guillier G., 20 io - "Entrammes « Le Clos des Primevères ", Bilan scientifique 2008, Service régional de l'Archéologie des Pays de la Loire, p. 73-74.

Jahier I., Besnard-Vauterin C., Lepaumier H., Paris P., Renault V., San Juan G., Dron J.-L., Hincker V. et Forfait N., 2009 - "Les bâtiments des habitats de l'âge du Fer en Basse-Normandie : panorama des découvertes ", in MARION S. et BlanCQuAert G. (dir.), Les installations agricoles de l'âge du Fer en France septentrionale, Études d'histoire et d'archéologie, 6, p. 339-357.

LAMbert F., I 865 - "Recherches de voies romaines autour de Jublains ", Bulletin de la Société d'archéologie, sciences, arts et belles-lettres de la Mayenne, Mayenne, Derenne A., 1865, p. 117-130.

LAmbert C. et Rioufreyt J., I 975-I 976 - « Des enceintes protohistoriques aux sanctuaires gallo-romains, I - la triple enceinte quadrangulaire de La Tène finale d'Azé près de ChâteauGontier - 53 ", Bulletin de la Commission historique et archéologique de la Mayenne, 41-43, p. 3-38.

Maguer P., 2000 - Cholet "Les Natteries », A87 (tronçon 1) Angers/ Mortagne-sur-Sèvre, Rapport de sauvetage urgent, Le Mans : Afan, 338 p. 
Maguer P., Arthuis R. et Hienard J., 2005 - « L'établissement de la Chapellière à La Chaize-le-Vicomte (Vendée) ", Aquitania, XXI, p. 21-72.

Maguer P., Cherel A.-F. et Auxiette G., 2003 - « Nouvelles données sur les habitats de l'âge du Fer dans le nord de la Sarthe (commune de Vivoin, A28)", in Mandy B. et De Saulce A. (dir.), Les marges de l'Armorique à l'âge du Fer, Archéologie et Histoire : culture matérielle et sources écrites, (RAO suppl. 10), actes du XXIII ${ }^{\mathrm{e}}$ colloque de l'AFEAF tenu à Nantes, 13-17 mai 1999, p. 213-234.

Maguer P., 2005 - « L'architecture des bâtiments de La Tène dans le sud du Maine-et-Loire : études de cas ", in Buchsenschutz O. et Mordant C. (dir.), Architectures protohistoriques en Europe occidentale du néolithique final à l'âge du Fer, éditions du CTHS, p. 331-345.

Maguer P. et Lusson D., 2009 - "Fermes, hameaux et résidences aristocratiques entre Loire et Dordogne ", Les Gaulois entre Loire et Dordogne, Actes du XXXI ${ }^{\mathrm{e}}$ colloque de l'Association française pour l'étude de l'âge du Fer, tome I - (Mémoire XXXIV), p. 423-457.

Malrain F., Matterne V. et Meniel P. 2002 - Les paysans gaulois (III siècle-52 av. J.-C.), Errance, coll. " des Hespérides".

Menez Y., 1996 - Une ferme de l'Armorique gauloise. Le Boisanne à Plouër-sur-Rance (Côtes-d'Armor), Documents d'archéologie française, 58, Paris, $272 \mathrm{p}$.

Menez Y., 2001 - « Trois ensembles mobiliers issus des fouilles du Camp de Saint-Symphorien à Paule (Côtes-d'Armor) ", Les mobiliers des II et $I^{e r}$ siècles avant notre ère dans l'ouest de la Gaule, UMR 6566 CNRS-Culture-Université C2A, Thème : âges du fer, document de travail, réunion du 22 mars 2001, np.

Meuret J.-C., 2001 - "Athée (Mayenne) - La Glannerie. Fouilles : J.-C. Meuret, 1996, 1997 et 1998 », in Les mobiliers des II et $I^{e r}$ siècles avant notre ère dans l'ouest de la Gaule, UMR 6566 CNRS-Culture-Université C2A, Thème : âges du fer, document de travail, réunion du 22 mars 2001, np.

Mortreau M., 1999 - "Annexe 3, 1 : étude céramique : la céramique gauloise du site du Grand Aunay ", in VAcher S., Autoroute A28 Commune de Yvré-L'Évêque (72) "Le Grand Aunay ", Rapport de fouille, Le Mans, Afan, 28 p. et inventaire $41 \mathrm{p}$.

Mortreau M., 2005 - "Le mobilier céramique ", in Valais A., Déviation RN 162 Moulay (53162) - Mayenne (53147), phase III, Rapport de diagnostic archéologique, CessonSévigné : Inrap Grand Ouest, p. 81-91.

Mortreau M., 2007 - «Étude du mobilier céramique protohistorique ", in Petorin N., Commune de Oisseau-le-Petit (Sarthe), "Les Noirâs ", Rapport de fouille préventive, Cesson-Sévigné : Inrap Grand Ouest, p. 29-42.

Mortreau M., à paraître - "L'Horizon La Tène moyenne ", in Bocquet A. (dir.), Les fouilles du Taillis des Boissières, Jublains (53), Documents d'archéologie de l'ouest, à paraître.
Mortreau M., à paraître - "L'Horizon fin $\mathrm{I}^{\mathrm{er}} /$ début $\mathrm{II}^{\mathrm{e}}$ siècle ", in Bocquet A. (dir.), Les fouilles du Taillis des Boissières, Jublains (53), Documents d'archéologie de l'ouest, à paraître.

Naveau J., 1973 - "L'oppidum de Moulay (fouilles de l'année 1973) ", Bulletin de la Commission historique et archéologique de la Mayenne, 33, p. 5-17, pl. I.

Naveau J., 1974 - "L'oppidum de Moulay (travaux de l'année 1974) ", Bulletin de la Commission historique et archéologique de la Mayenne, 37, p. 3-35.

Naveau J., 1976 - "L'oppidum de Moulay (travaux de l'année 1975) ", Bulletin de la Commission historique et archéologique de la Mayenne, 41-42, p. 61-98.

Naveau J., 1977 - «Fouille d'un fossé de l'âge du fer dans la carrière d'Écorcé à Entrammes ", Bulletin de la Commission historique et archéologique de la Mayenne, 46, p. 3-23.

Naveau J., 1982 - "Le temple celto-romain et le camp protohistorique de Port-du-Salut à Entrammes ", La Mayenne : Archéologie, Histoire, 4, p. 17-47, 30 pl.

Naveau J., 1983 - «Un site rural à Montflours, de l'âge du fer au Moyen Âge ", La Mayenne : Archéologie, Histoire, 5, p. 3-18.

Naveau J., 1999 - " Grand vase coriosolite du type balustre à baguettes ", in Santrot J., Santrot M.-H. et Meuret J.-C. (dir.), Nos ancêtres les Gaulois aux marges de l'Armorique, Nantes : musée Dobrée, Nantes, p. 99.

Naveau J. et Boufflet J.-H., 1999 - La Mayenne au fil du temps, Siloé.

Nillesse O., 2003 - «Les établissements ruraux gaulois de la plaine de Luçon (Vendée) ", Habitats, mobiliers et groupes régionaux à l'âge du Fer, Actes du XX $\mathrm{XX}^{\mathrm{e}}$ colloque de l'AFEAF, Colmar-Mittelwhir, 16-19 mai 1996, Revue archéologique de l'Est, $20^{\text {e }}$ suppl., p. 275-287.

PicOn M., 1973 - Introduction à l'étude des céramiques sigillées de Lezoux, Dijon, centre de recherche sur les techniques galloromaines, 2, $135 \mathrm{p}$.

Pion P., 1999 - « Notice n 282 : mobilier d'une sépulture à incinération de Saint-Gatien-des-Bois ", in Santrot J., Santrot M.-H. et Meuret J.-C. (dir.), Nos ancêtres les gaulois aux marges de l'Armorique, Nantes, musée Dobrée, 1999, p. 144.

Robin B., 2005 - Étude de meules rotatives de l'âge du Fer : le site du Grand Mesnil à Moulay, mémoire de master 1, DAIre M.-Y. (dir.), université de Rennes 2.

SAndoz G., 1999 - Cholet «La Bleure », A 87, rapport de fouilles, Le Mans, Afan, 95 p.

San-Juan G., Meniel P., Alduc-Lebagousse A. et Pilet-Lemiere J., 1994 - «Un établissement rural du I ${ }^{\text {er }}$ siècle av. J.-C. à Fleury-sur-Orne (Calvados), Revue archéologique de l'Ouest, 11, 1994, p. 131-164.

Tanguy D., 2000 - « Le site d'habitat de l'âge du Fer de Kerven Teignouse à Inguiniel (Morbihan) ", Revue Archéologique de l'Ouest, 17, p. 143-173. 
Thooris C., 1991 - Laval (Mayenne), Les Bozées, Enclos gaulois, Rapport de sauvetage urgent, Direction des Antiquités des Pays-de-La-Loire.

Valais A., 2004 - RN 162, déviation Moulay-Mayenne (53), phase 1, Rapport intermédiaire de diagnostic, Cesson-Sévigné : Inrap Grand Ouest, 77 p.

Valais A., Arthuis R., Mortreau M., Edin F. et Ezanno O., 2005 - Déviation RN 162 Moulay-Mayenne, Phase III, Rapport de diagnostic, Cesson-Sévigné, Inrap Grand Ouest, 98 p.

VAlais A., 2008 - « Premier bilan des découvertes sur le tracé de la rocade de Mayenne ", La Mayenne: Archéologie Histoire, 30, p. 200-217.
Valais A., Meuret J.-C. et Nauleau J.-F. avec la collaboration de Edin F., Hamon G. et Mutarelli V., 2008 - « Le ClosHenry : une ferme de La Tène finale à Château-Gontier ", Revue archéologique de l'Ouest, 25, p. 139-161.

Vauterin C., 1999 - « La céramique de La Tène », in Maguer P., Commune de Vivoin (72) "La Pièce de Bildoux ", Rapport de fouille, Le Mans, Afan, p. 50-65.

Zusammenfassung: Le Panveau: ein latènezeitliches Gehöft in der Nähe des oppidums von Mesnil bei Moulay (Mayenne) - Das latènezeitliche Gehöft von Panveau bei Aron (Mayenne) liegt rund 2 km nördlich des Befestigungswalles des oppidums von Mesnil bei Moulay. Es wurde bei einer Baggerprospektion entdeckt, die anlässlich des beabsichtigten Baues einer Ortsumgehung von Mayenne durchgeführt wurde. Dieses eingehegte Gehöft der Mittel- und Spätlatènezeit zeigt eine Entwicklung bezüglich der Ausmaße der Grabenanlagen, die es umgeben. Mehrere Gebäude, darunter eines mit Fundamentgräbchen und einer Grundfläche von beinahe $80 \mathrm{~m}^{2}$, wurden freigelegt.

Resumen: Panveau: una granja de La Tène cerca del oppidum de Mesnil en el pueblo de Moulay (Mayenne) - La granja de Panveau en Aron fue descubierta durante un diagnostico arqueológico que se hizo para desviar la ciudad de Mayenne, en un poco más de 2 kilómetros al norte de la pared del oppidum de Mesnil en el pueblo de Moulay encontrado dentro del marco de la misma operación. Este hábitat cerrado ocupado durante la mitad y el final de La Tène muestra una evolución de los tamaños de las zanjas que lo rodean. Muchos edificios, incluyendo uno constituido de zanjas de cimentación que alcanzan hasta 80 mètres carrés, se han destacado.

Schlüsselworte: Mittellatènezeit, Spätlatènezeit, eingehegtes Gehöft, Gebäude, Keramik, Mühlsteine

Palabras clave: mitad y final de La Tène, hábitat cerrado, edificios, cerámica, muelas 